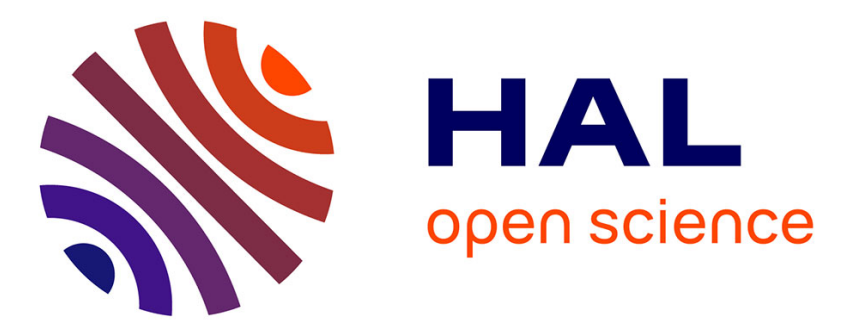

\title{
Recherches archéologiques en Gaule en 1952 (suite)
}

Raymond Lantier

\section{To cite this version:}

Raymond Lantier. Recherches archéologiques en Gaule en 1952 (suite). Gallia - Fouilles et monuments archéologiques en France métropolitaine, 1954, 12 (2), pp.527-577. 10.3406/galia.1954.1417 . hal01921126

\section{HAL Id: hal-01921126 \\ https://hal.science/hal-01921126}

Submitted on 4 Feb 2020

HAL is a multi-disciplinary open access archive for the deposit and dissemination of scientific research documents, whether they are published or not. The documents may come from teaching and research institutions in France or abroad, or from public or private research centers.
L'archive ouverte pluridisciplinaire HAL, est destinée au dépôt et à la diffusion de documents scientifiques de niveau recherche, publiés ou non, émanant des établissements d'enseignement et de recherche français ou étrangers, des laboratoires publics ou privés.

\section{(이)(\$)}

Distributed under a Creative Commons Attribution - NonCommercial - NoDerivatives| 4.0 


\title{
CHRONIQUE DES PUBLICATIONS
}

\author{
Reciencies archéologiques en Gaule kn 19:32 (suite) \\ (Période historique)
}

V

\section{Epoque Gali.o-Romaine}

I. La conquêtc. Travaux militaircs. - Il faut désespérer d'en terminer avec les longues et fastidieuses controverses Alaise-Alésia, même après le sage petit livre d'A. Colombet 2, tentative de mise au point des problèmes relatifs à l'identification du site d'Alésia. Si les aperçus philologiques sont un peu sommaires, les références sont précises et on lira avec profit les pages traitant de l'évolution historique de la lutte opposant les deux cités rivales. $\Lambda$ noter cncorc un relevé des souvenirs du siège d'Alésia recucillis dans les documents médiévaux. Bien que des recherches sérieuses aient eu pour théatre le site de Chataillon 3 , on veut toujours le doter d'une ligne de fortifications, de resles imposants d'une ville celtique, alors qu'on y a seulement trouvé des fonds de cabanes qui ne sont pas tous antiques.

L'interprétation des textes césariens exerce toujours la sagacité des chercheurs. Dans une brève étude sur la marche de César avant le blocus d'Alésia, N. Noché 4 , relevant l'emploi constant (B. G., VII, 66,2$)$ de la préposition per, suppose

(1) Voir Gallia, XII, 1954, I, p. 233-284.

(2) À la recherche d'Alésia, Alaise ou Alise. Dijon, 1952.

(3) Annales Bourgogne, XXIV, 1952, p. 281- que le pays traversé, la Lingonie, est différent des contrées d'où partit Cćsar, la Sćnonnie, et propose de localiser le combat de cavalerie an N.-O. d'Alise-SainteReine. Le camp d'où Labienus se mit en marche pour combattre les Trévires (B.G., $\mathrm{V}, 58$ ) ne pout être recherché au Mont-deBrun, mais doit être situé au Mont Jules, près de Neuville-les-This ( $\Lambda$ rdennes), au voisinage d'un affluent de la Meuse, la Sormonne, où l'on reconnait l'emplacement d'un camp romain qui mériterait d'être fouilles. La situation topographique du Mont-de-Brun ne permet pas le déroulement d'un combat de cavalerie et la longue poursuite jusqu'au gué. Le bimillénaire du combat naval de Tauroentum a été commémoré par un article de mise au point 6 replaçant l'événement à sa juste place dans l'histoire navale de la Méditerranée et signalant au passage que l'on est toujours aussi mal renseigné sur la topographie de Tauroentum, l'un des points d'appui les plus importants des Marseillais.

Le débat vient de se rouvrir à propos de la prétendue venue d'Auguste à Dax, lors du voyage pyrénéen des années 26-25 av. J.-C. 7. Au vrai, Auguste ne serait alle

(4) Les IIumanites, 1952, n० 4, p. 94-98.

(5) R. Tarllardet, La Grive, no 72, janvier 1952, p. 23-30.

(6) E. Davin, Bull. assoc. Guillaume Budé, mars 1952 , p. $70-83$. 
ni à Dax, ni à Bagnères-de-Bigorre, pas plus qu'à Luchon. La distance et la difficulté des communications s'opposent à faire de Dax la base d'opérations contre les Cantabres. On sait aussi qu'au $1^{\text {er }}$ janvier 26, Auguste assume son premier consulat à Terragone et se rend ensuite à Segisama. Tombé malade, c'est à Terragone qu'il vient se reposer et ce n'est pas à Dax qu'il fera une cure, mais en Espagne, peut-être à Caldas de Monbuy. Enfin. on nous propose de dater les trophées de Saint-Bertrand-de-Comminges, non plus de la pacification finale des Cantabres en 25, mais du passage d'Auguste descendant en Espagne.

Si, malgré les nouvelles des journaux ${ }^{8}$, il n'y a rien à retenir de prétendues fortifications révélćes à Alise-Sainte-Reine par les inégalités de croissance de la végétation, il n'en est pas de même près de la Meinau, à $3 \mathrm{~km} .500$ de Strasbourg où ces mêmes différences ont fait connaître l'cxistence d'un camp romain de la période flavienne ou du règne de Nerva, dessinant le tracé d'une porte, d'une route fortifiée en direction du Rhin et du prétoire 9. En Limousin, sur lc Pcu-Buy, près de Château-Ponsac (Haute-Vienne). on signale l'existence d'une enceinte circulaire 10. Dans un article sur l'architecture militaire en Bretagne jusqu'au temps de Vauban ${ }^{11}$, on trouvera des indications sur les fortifications de la période galloromaine.

2. Les villes gallo-romaines. - La topographie de Glanum (Saint-Remy-de-

(7) R. ÉtienNe, Annales Midi, 64, 1952, p. 5-14.

(8) Le Monde, 2 août 1952.

(9) J.-J. HATT, Bull. soc. nat. antiq. Fr., 1950-51, p. 190.

(10) Bull. soc. hist. et archéol. Limousin, LXXXIV, 1952, p. 297.

(11) Bull. mon., CX, 1951, p. 237-271.
Provence, Bouches-du-Rhóne) s'enrichit d'une très importante découverte. Dans le vallon, au Sud de la cité, se dressait une cité divine, dont le fanum Herculis a été dégagé avec ses gradins et ses autels encore en place, portant des dédicaces de soldats. Les fouilles ont aussi apporté un ensemble cohérent de documents à l'étude de la diffusion de la mosaïque dans les pays occidentaux au cours des deux premiers siècles de la romanisation. Au $\mathrm{II}^{\mathbf{e}}$ s. avant l'ère, dans les constructions les plus anciennes, on relìve l'emploi de l'opus barbaricum, de l'opus signinum à la fin du ${ }^{\text {er }}$ s., de l'opus tessellatum à l'ípoque impériale ${ }^{1}$.

De nouvelles recherches ont été conduites à Fréjus (Var) ${ }^{2}$, sur la citadelle de la butte Saint-Nicolas, où l'on mit au jour une tête d'enfant en marbre du $\mathrm{I}^{\text {er }} \mathrm{s}$. de notre ère; au Nord de l'Hopital, sur un emplacement occupé aux deux premiers siècles de l'Empire, on recueillit des tessons de céramiques. L'abandon dès le III $^{e} \mathrm{~s}$. de ce quartier placé au centre de la ville antique, témoigne de ia rapidité de la décadence de Forum Julii. Faut-il rapporter à la part prise par l'armće dans l'édification de l'aqueduc, la présence d'un buste de légionnaire encastré dans les ares de la Bouteillère? Le porphyre utilisé dans la construction provient du vallon descendant de l'Aubisque, où une des carrières a été signalée à Caous, près de Boulouris.

De nouvelles mosaïques ont été retrouvées à Nîmes, dans un quartier antique, sur l'emplacement des rues de Halles, des Lombards, de la Maison Carrée, du Général Perrier et de Corconne, toutes à décor

(1) H. Rolland, Bull. soc. nat. antiq. Fr., 1950, p. 24-26; - Archivo españ. arqueol., XXV, 1952, p. 1-14.

(2) P.-A. FÉvRJER, lrovence historique, 1952, p. 71-74. 
géométrique ${ }^{3}$. Place de la Calade, des éléments architecturaux, pilastre, corniche, frise, dallage de marbre blanc. marquent l'emplacement d'un important éditice, et au Pal Vacher, dans le prolongement de la rue de Baucaire, sur le tracé de la voie Domitienne, des sépultures antiques précisent, de ce còté, une limite de la cité.

Ises pilotis retrouvés sur les bords de l'Ouvèze, à Vaison (Vaucluse) ${ }^{4}$, n'appartiennent pas à un système de quais. Ils étaient destinćs à consolider les assises de maisons, bordant plus étroitement qu'aujourd'hui le lit de la rivière. A La Villasse, dans la maison du Dauphin, des latrines avec sioges limitent la demeure à l'Ouest, et sur ce môme còté un péristyle encadre un bassin orné de trois exèdres. Des bains avaient ritó installés dans la partic Nord.

Une monographie de Valence (Drôme), à l'spoque romaine 5, pose nettement les problèmes à résoudre par les fouilles à venir, identifie la centuriation du territoire et restitue le quadrillage urbain. Ia naissance et l'histoire de la cité sont liées ì la route.

A Castel-Roussillon (I'yrénćes-Orientales) ", le chantier atteint les niveaux romains sur l'emplacement supposé du forum où, sur les ruines d'une maison d'époque républicaine, aux murs revêtus de bandes de coulcur, avait été élevé, au début de l'Empire, un temple dont le soubassement rectangulaire forme un grand rectangle de $100 \mathrm{~m}^{2}$. Quatre piliers dans la partie Nord du forum paraissent appartenir à un portique d'entrée. Deux salles,

(3) Le Vieux Nîmes, n' 26, 1952; - BEAUQUIER, Annales Midi, 64, 1952, p. 277.

(4) J. Sautri, Provence hist., 1952, p. 51-52.

(5) A. Buavc, Valence romaine. Bordighera, Inst. d'Et. ligures, 1953.

(6) G. Chausthes, Soc. agricole, scienlif. el litt. Pyrénées-Orientales, 67, 1952, 71-85. accolées à droite et un peu plus bas sur la gauche, complètent l'ensemble du monument, dont l'existence fut assez courte, puisque sur ses ruines on a reconnu l'existence de maisons, orientées N.-S.-S.-F. appartenant aux II $^{\circ}$ et ${ }^{\prime \prime} I^{\circ}$ s. de notre ère. Les fouilles de 1951 ont permis de rectifier les conclusions de Thiers qui, des 1910 , avait conduit des recherches sur ces mêmes emplacements, ayant fait partie de l'agglomération préromaine et occupés par des habitations depuis le $\mathrm{vI}^{\mathrm{e}} \mathrm{S}$. av. J.-C. Une construction à chaînages de briques, une lampe du $\mathrm{III}^{\mathrm{e}} \mathrm{s}$., des rejets de cuisine ont été signalés dans la butte d'Elne (Pyrénées-Orientales) ${ }^{7}$.

La reprise des fouilles de Saint-Bertrand-de-Comminges (Haute-Garonne) 8 , dans la partie méridionale du grand édifice dit «bâtiment. Bordère », fait connaître la présence d'un premier édilice à plan basilical, comprenant plusieurs nefs, dont les bases magonnées supportant colonnes ou pilastres, peut-ctre en bois, étaient implantées dans un couche d'incendie renfermant des tessons de l'époque d'Auguste et de Caligula. Sous les Flaviens, le monument fut translormé en marché par l'installation de boutiques entre les piliers. A cette période appartiennent une grande mosaïque à cuhes hlanes et noirs et les restes de la charpente soutenue par quatre piliers posés dans l'axe de la construction.

Des travaux d'édilité, place du Capitole, à Toulouse 9 , ont amené la découverte d'un nouveau tronçon de l'enceinte: la muraille en blocage, avec parement de moellons et chaînages de briques, repose, en retrait de $0^{\mathrm{m}}, 10$, sur un fondation de galets et de béton, épaisse de $2^{\mathrm{m}}, 70$ a $2^{\mathrm{m}}, 80$. A

(i) B. Poxsich, Études rousillonnaises, II, 1952, p. 286-288.

(8) M. Lamhousst:, Gallia, $\mathrm{X}, 1951, \mathrm{p}, 134$.

(9) Ibid., p. 176-177. 
l'Institut Catholique, le blocage était consolidé par des fragments de sculptures et de monuments funéraires. La présence d'un sul antique, cours Arsenal, marque l'emplacement d'un édifice romain, immédiatement à l'extćrieur de cette enceinte du Bas Empire, crevé par les tombes barbares du cimetiòre entourant l'église de Saint-Pierre-des-Cuisines.

Le principal résultat des fouilles de Fourvière à Lyon 10 avait été de préciser que l'amphithéâtre, oì furent exécutés les martyrs de 177, ne se trouvait pas sur ce site et qu'il était à rechercher dans la région de l'ancien confluent du Rhône et de la Saòne, et de restituer à cette partie de la ville antique la physionomie d'un vaste quartier, avec ses deux artères principales, cardo et decumanus, ses rues, un temple, un théâtre et, deuxième monument de ce genre, après celui de Vienne (Isc̀re), un odéon. Pour la construction de ces deux ćdifices, relevant, le premier, de l'époque d'Hadrien, le second pouvant être daté de l'année 160, on avait utilisć pour le gros muvre des pierres einpruntées au sol de Lyon ou de ses environs, Bugey, Tarascon; les matćriaux de la décoration sont tous originaires de carrières lointaines, marbre d'Italie et de Grèce, calcaire rouge de klarey, près de vâcon. Au cours de l'histoire urbaine de Lyon, Fourvière subit des transformations : deux trongons de rues, aux extrómités d'une voie nouvelle contournant le sommet du théâtre, représentent les restes d'une ancienne artire. Ces remaniements sont liés à des aménagements nouveaux relevant de deux moments différents, affectant les constructions situées à l'Ouest du quartier, boutiques à enduits peints et un temple, peut-ître de Cybèle.

(10) P. Wuilleumien, Fouilles de Fourvière à Lyon. Préface du Président E. Henrot. (Fouilles et monuments archéol. en France métropolitaine, IV). Suppl. à Gallia, 1951.
Dans l'agglomération lyonnaise, composée de trois quartiers isolés par des cours d'eau, Fourvière représente la cité administrative; sur la rive droite et dans l'île d'Ainay, s'étend la ville commerçante; au pied de la Croix-Rousse, c'est la ville fédérale des cités gauloises. I.es documents épigraphiques apportent d'utiles indications à la démographie de la cité galln-romaine. I.es quartiers commercants abritent une colonie grecque, dont l'importance se manifeste à la fin du $\mathrm{I}^{\text {er }} \mathrm{s}$. de notre ère. On relève peu de noms gaulois sur les ćpitaphes et les Germains apparaissent dans res listes à partir de 550, au cimeticre Saint-Laurent. I'histoire des cimetières et celle de la cité, s'inscrivent dans huit étapes : au cours de la seconde moitic du $\mathrm{I}^{\mathrm{er}}$ s., la formule hic adquicscit, gravée sur la stèle ou sur le monument à portique surmontant la tombe à incinération maçonnée, disparait et, au début du II s. le cippe en forme d'autel remplace le monument, cependant qu'apparaissent l'ascia, le sarcophage et la mention memoriac aeternac. Le $\mathrm{III}^{\circ} \mathrm{s}$. est caractérisć par des épitaphes laudatives et sentimentales et, à la fin de la période, les influences chrétiennes se manifestent dans des appellations religieuses. $A u \mathrm{IV}^{\mathrm{e}}$ et au $\mathrm{V}^{\mathrm{re}} \mathrm{s}$. les sarcophages sont Hbrités par des monuments, des plaques de marbres sont substituées aux cippes et, à la fin du $v^{*}$ s., la tombe est située près de l'église.

Poursuivant ses recherches dans le sous-sol de Strasbourg, J.-J. Hatt 12 apporte des détails nouveaux à l'histoire

(11) Amable Aubry, Sur la géographie de Lyon romain. La population, les voies et les quartiers d'après les documents épigraphiques, in Revue de gégraphie de Lyon, XXVII, 1952 , p. $133-140$.

(12) C.R.A.I., 1952, p. 97-100; - Cahiers d'archeol. et d'hist. Alsace, 132, 1952, p. 6382; - Rev. des arts, II, 1952, p. 120-121. 
urbaine de la ville romaine: sous l'église Saint-Nicolas, carrefour de voies romaines, tête de pont installée au delà d'un bras de l'Ill ; sous Trajan, construction d'une route oblique à la route principale, desservant de nouveaux quartiers suburbains, d'un poste de douane, incendié à quatre reprises et remplacé, sous le règne de Maximin, par un castellum appartenant à la ligne de défense de la cité; - sous la rue du Sanglier, rue extérieure au camp augustéen, bordée par les bâtiments d'un atelier légionnaire destiné à la fabrication d'objets d'équipement, auquel succèdent, après l'incendie de 70, des logements pour officiers, abandonnés, ainsi que le camp, en 120, puis occupés par des constructions en bois à l'usage de la population. Un nouvel incendie, sous Marc-Aurèle, amène la destruction de l'agglomération civile située en dehors du camp et, au début du III $^{\mathrm{e}}$ s., sur l'emplacement, en partie désaffecté, du prétoire, s'installent les civils. Le tabularium est alors restauré et décoré de reliefs auxquels appartient une très jolie tête juvénile, portrait de Caracalla, dans sa quatorzième année. Camp et maisons sont anéantis par le feu en 235 et ce n'est que sous le rìgne de Maximien ou de ses successeurs, que les militaires reprennent possession du camp. La défense de l'agglomération civile est assurée par le fortin retrouvé sous l'église Saint-Nicolas et des travaux d'aménagement sont entrepris : comblement des fossés de drainage; construction de deux rangées d'arcades le long des voies prétorienne et principale, d'un grand grenier en bois pour les provisions en blé de la légion, incendié à trois reprises, en 335,378 et au début du v $\mathrm{v}^{\mathrm{s}} \mathrm{s}$. Après l'invasion des Alamans, la vie de la cité est précaire et, dans les niveaux de destruction, s'inscrivent les témoins d'une ultime restauration, rues dallées de fragments de tuileaux, bases de charpentes en matériaux de remploi, dont la durée ne dépasse pas la première moitié $d u v^{\bullet} \mathrm{s}$.

On sait maintenant que l'enceinte d'Autun (Saône-et-Loire), dont un nouveau tronçon a été relevé entre l'Evêché et la Maîtrise d'une part, le Palais de Justice et la place Saint-Louis d'autre part 13, avait été construite d'un seul jet et non pour englober, après coup, le théâtre et l'amphithéâtre ${ }^{14}$.

I.e long du parcours, nouvellement reconnu, à Dijon (Cóte d'Or), de la route Vergy-Autun, des sépultures ont été relevées. La ville était délimitée par une ceinture de cimetières 15.

A l'époque augustéenne, et vraisemblablement dès la seconde moitié du $\mathrm{I}^{\mathrm{er}} \mathrm{s}$. avant l'ère, la partie Ouest du rebord méridional du plateau de Gergovie (Puy-deDòme) était occupée par une petite agglomération de caractère artisanal, dont les maisons à plan carré, en bois ou en torchis sur un soubassement de pierres sèches, se superposent à un habitat posthallstattien 16.

Les recherches faites à Clermont-Ferrand (Puy-de-Dòme), sur l'emplacement de l'asile Sainte-Marie, ont révélé l'existence d'un quartier assez pauvre, installé sur un banc d'alluvions entre les deux bras de la Tiretaine 17. Dans les maisons à demi-enterrées, on recueillit une abondante vaisselle domestique, où dominent les formes creuses. ce qui laisse entrevoir la prépondérance dans l'alimentation des bouillies et des potages. La fouille, conduite avec soin et judicieusement in-

(13) L'Éduen, n० 18, 15 nov. 1952.

(14) P.-M. Duval, Bull. soc. nat. antiq. Fr., 1950, p. 26-27.

(15) Mém. comm. antiq. Cote-d'Or, XXII, III, 1952, p. 471, 510, 525.

(16) M. Labnousse, Gallia, VIII, 1950, p. 1453.

(17) P.-F. Fournitr, ibid., IX, 1951, p. 112113 ; - Bull. histor. et scientif. Auvergne, IJXXII, 1952, p. 138-152. 
terprétée, apporte un nouveau témoigniage. de la persistance des modes gauloises de cuisine et de construction sous l'Empire, les maisons ayant étó occupées depuis le début du $\mathrm{I}^{\text {er }} \mathrm{s}$. juscju'au IV

Le dépotoir de la rue Wilson, à Cahors (Lot) ${ }^{18}$, est daté de la fin du $\mathrm{I}^{\mathrm{er}} \mathrm{s}$. avant et $d u{ }^{I^{e r}}$ s. après J.-C. Il est difficile de préciser la destination des gros murs, trouvés à Poitiers (Vienne) en bordure du boulevard du Grand Cerf 19. Est-ce le péristyle d'un temple qui a été relevé sous le presbytere de Saint-Porchaire? Au quartier des $\Lambda$ rènes, un des vomitoires de l'amphithéchtre a été mis au jour. $\Lambda$ Limoges (Haute-Vienne), une partie du réseau des égouts romains a pu ctre précisée ${ }^{20}$, et à Saintes (Charente-Maritime) l'emplacement d'un cirque, au Nord de l'agglomération 21. A l'exception d'un tronçon de voie antique, à l'angle des rues Cordier et de Bourgogne, les découvertes faites dans le sous-sol d'Orléans (Loiret) 22 apportent peu de précisions à la topographie antique: fragments de murs, dépotoir des $\mathrm{I}^{\text {er }}$ et $\mathrm{II}^{\mathrm{e}}$ s., sépulture à inluumalion vers la place du Martroi ; tessons dans les jardins de la Préfecture et rue du Sanglier. Ce qui restait des ruines du théatre antique d'Orléans a disparu dans les bombardements et les travaux de reconstruction. Plus curieuse est la découverte à Tours (Indre-et-Loire) ${ }^{23}$, dans le quadrilatère déterminé par les rues Nationale, de la Sellerie, Emile Zola et

(18) M. Labrousse, Gallia, IX, 1951, p. 139.

(19) E. EYGUN, ibid., p. 101-105.

(20) J. Perrier, Bull. soc. hist. et archeol. Limousin. LXXXIV, 1952, p. 132-134.

(21) F. Eygun, Gallia, IX, 1951, p. 107.

(22) Bull. soc. archéol. et hist. Orléanais, XXV, 1945, p. 9-15, 34, 37, 38; - Bull. liaison provisoire, soc. archécl. el hist. Orléanais, no 20, nov.-déc. 1952, p. 7-8.

(23) Lenoux, Bull. trim. soc. archéol. Touraine, XXXI, 1952 , p. 59-60; - P. CondoNNIEn-DF́TuIE, Gallia, IX, 1951, p. 94-97. de Tuçé, d'un grand édifice circulaire de $29^{\mathrm{m}}, 10$ de diamètre, flanqué à l'Est d'une construction rectangulaire, peut-être les ruines d'un temple semblable à ceux de la "Tour de Vésone » à Périgueux et du 《Moulin du Fầ à Talmont (CharenteMaritime).

On signale à Nantes (Loire-Inférieure), la présence de vestiges sous la rue de la Marne, constructions des III" et $\mathrm{IV}^{\mathrm{c}} \mathrm{s}$., dont, l'une a pu servir de cellier, place de l'Éluse. entre la rive de l'Erdre et l'enceinte du Bas Empire, d'une maison et, sous l'église Sainte-Croix, des restes d'un hypocauste 24 . Ce sont surtout des sépultures qui ont élé trouvées au Mans (Sarthe), oì fut reconnu aussi le tracé de l'un des aqueducs. On a pu constater que l'enceinte ne possédait pas de fondations et avait été construite directement sur le sol 25. Des observations importantes ont été faites sur le tracé des remparts de basse époque à Beauvais (Oise) 20 et à Senlis (Oise) 27 , où la muraille, flantrıée de vingt-huit tours, était précédée d'un large fossé. Construite sur plan polygonal, un soubassement de blocs remployés, elle était couronnée d'un chemin de ronde et comportait deux portes principales et plusieurs poternes. A Sens (Yonne), on a relevé le tracé de rues et d'égouts, des restes d'édifices et une boutique de potier 28.

$\Lambda$ Amiens (Somme) ${ }^{20}$, les thermes de la rue de Beauvais, qui ne sont pas an-

(24) L. Bouchaud, Bull. soc. archéol. et hist. Nantes et Loire-Inf., 90, 1951, p. 36-42.

(25) P. CondonnIER-DÉTrIE, Gallia, IX, 1951, p. $97-100$.

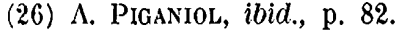

(27) R. JaRRY, Soc. d'hist. et d'archéol. Senlis, 1952 , p. 2-3.

(28) Annales Bourgogne, XXIV, 1952, p. 183.

(29) J. Heurgon, Bull. soc. nat. antiq. Fr., 1949, p. 2'J2-203; - Gallia, IX, 1951, p. 72-73; - P. Vasselde, Bull. trim. antiq. Picardie, 1952, p. 147-193. 
térieurs à l'époque d'Hadrien, reposent sur les substructions d'un édifice d'époque néronienne, qui avait rȩ̧u une riche décoration sculpturale, dont les restes ont été recueillis dans les caves du voisinage : blocs de calcaire, ayant pu appartenir à un monument du type du Pilier des Nautes parisiens, décoré de rinceaux avec un oiseau et d'une divinité fluviale. Le problème de l'enceinte du Bas Empire touche à sa solution à la suite de la découverte de plusieurs éléments en place. La muraille, qui épouse la configuration du terrain, a pu être suivie sur une grande partie de son tracé du coté occidental, orientée N.-S., puis se dirigeant N.-0. - S.-E. et prononçant un angle, irrégularité qui peut s'expliquer par la présence d'un marécage. De là, elle rejoint l'amphithéâtre pour s'y appuyer. Une porte était peut-être ouverte près de l'Hôtel de Ville et, à partir de cet endroit, le mur reprend la direction du Nord pour gagner la Somme. La cathédrale reste en dehors du rempart qui enserre tous les édifices du centre de la ville. Sa construction offre cette particularité de n'utiliser aucun matériau de remploi. lipaisse de 3 mètres, elle présente à la base plusicurs talons superposés.

Des monographics ont été consacrées aux villes romaines de Périgueux (Dordogne ${ }^{30}$, de Libourne ${ }^{31}$, aux origines de Compiègne (0ise) et aux fouilles de sa forêt sous le Second Empire ${ }^{32}$.

3. Les monuments. - Des précisions sont apportées à la disposition générale du texte de l'inscription du Trophée de

(30) Bounichon, Vesunna. Périgueux à l'époque gallo-romaine. Périgueux, 1952.

(31) B. DuCasse, Rev. hist. et archéol. Libournais, 1952, p. 45 sqq.

(32) M. HÉMERY, Bull. soc. hist. Compiègne, 24, 1952, p. 49-83.
La Turbie (Alpes-Maritimes)1 ${ }^{1}$ : la découverte d'un $B$ à la dimension des grandes lettres des trois premieres lignes, suivi d'un point, indique que le mot tribunicia était abrégé en TRIB., confirmant l'hypothèse de J. Formigé sur la longueur de la seconde ligne.

L'histoire monumentale d'Arles (Bou('hes-du-Rhône) est liée à celle des événements contemporains de la fondation de la colonie 2 . Implantés au centre de la ville, comme à Narbonne et à Aoste, les «cryptoportiques» sont solidaires du plan initial; antérieurs aux autres édifices, ils précisent la fonction stratégique, militaire et commerciale de la colonie fondée par César et Octavien dans le delta du Rhòne, pour remplacer le port de Marseille, dont la décadence est associée à celle du parti républicain. Les cryptoportiques encadrent d'une double galerie, voûtée en berceau, les trois côtés d'une arca et ouvrent de plain-pied, à l'Est, sur une voie. Établies sur la déclivité du terrain qui s'incline vers le Nord-Ouest, les galeries, utilisćes comme grenier, sont souterraines au Sud, en surélévalion par rapport au niveau du sol antique au Nord. Le monument, qui a subi des transformations aux III $^{\circ}$ et rve s., était accessible alı Nord par deux portes ouvrant sur le decumanus. Sur l'area, où l'on pénètre par la face orientale, s'élevaient des édifices religieux d'époques différentes: époque augustéenne pour les cryptoportiques, période quelque peu plus tardive pour le temple tétrastyle. Restauré sous le règne de Constantin, on peut se demander si le temple correspond au capitole d'Arles, l'inscription de la place du Forum célé-

(1) J. FonmGé, Bull. soc. nat. antiq. Fr., 1948, p. 119.

(2) F. BeNoit, ibid, 1951, p. 227-240; 一 Rev. archéol., 1952, 2, p. 31-67. 
brant à la fois la famille de l'empereur et les monuments dus à sa munificence. Mais ces constructions sont difficiles à identifier : une promenade avec des aulnes, une meunerie (Barbegal). Un dépôt de marbres, découvert dans les cryptoportiques, a donné, parmi d'autres pièces, une copie du clipeus Virtutis et un buste en marbre de Luna, Octavien portant la barbe, plus grand que nature.

Les nouvelles frises dionysiaques d'Orange (Vaucluse) sont à rapprocher de découvertes plus anciennes et montrent que ces pièces doivent être exclues du décor du théâtre. Il existait donc, dans la cité à l'époque augustcenne, qui est celle du théâtre, un édifice orné de frises dionysiaques, temple ou autre, où se déroulaient les épisodes continus de l'histoire légendaire du dieu : engagement du thiase contre Persée, retour d'Héphaistos à l'Olympe, processions sacrées. De style un peu froid, comme le remarque $\mathrm{Ch}$. $\mathrm{Pi}$ card 3 , ces fragments, retrouvés les uns au theâtre, les autres dans le dépotoir de la rue de la République, pourraient bien dériver des grandes compositions alexandrincs cn bronze, où Dionysos avait la place d'honneur, comme au Sérapeion de Memphis, où les textes littéraires ont mentionné le combat d'Argos, seul sujet qui peut associer Dionysos et Persée. Un autre monument a été aussi révélé à Nîmes (Gard), sur la site de La Tour Magne qui, antérieurement à cet édifice, avait été occupé par un ouvrage considérable, dont le pied des murs extérieurs était en talus. On ignore encore sa destination, son âge et sa forme. Quant à la construction de la Tour Magne, certaincs dispositions architecturales, escalier prenant naissance sur le chemin de ronde, logement des dalles de ce chemin de ronde

(3) Ch. PICARD, Rev. archéol., 1952, I, p. 115-118. dans le parement de la tour, prouvent sa contemporanéité avec l'édification du rempart. Les caractères de la bàtisse, l'analngie de son décor aveos celui du gymnase d'Orange datant du règne d'Auguste, apportent une autre preuve à cette conclusion de J. Formigé 4 . Il en est de même à Autun où portes et enceinte appartiennent à une même campagne de construction : cependant les galeries de la Porte Saint-André relèvent d'une reconstruction $d u \mathrm{IV}^{\mathrm{e}}$ s., restauration faite d'après son état premier ou sur le modèle de la porte d'Arroux ${ }^{5}$.

Jes fouilles qui se poursuivent à Draguignan (Var), dans la villa de SaintHermentaire $\mathbf{6}$, ont fait connaitre des remaniements du plan initial : adjonction d'une salle au Sud-Est et annexe comprenant un four pour le traitement du minerai, au voisinage d'un canal.

Aux Fontaines-Salées, à Saint-Pèresous-Vézelay (Yonne) 7 , les dégagements se poursuivent dans l'aile droite du temple de la première époque. Des monnaies ont été recueillies, ainsi que des fragments d'une pierre aux quatre dieux : divinité assise; dieu au Serpent; Hercule.

Vandalisme conscient ou non, il n'en reste pas moins qu'il ne subsiste plus guère que le souvenir de monuments importants, tel le «Palais du Miroir» à Colombes-les-Vienne (Isère)8, ou les curieux aménagements de la chaufferie, avec ses trois batteries de fours et ses réservoirs, alimentant le caldarium des thermes retrouvés dans le cimetière de Briançon-Ville (Hautes-Alpes), détruits

(4) J. Formate, Bull. soc. nat. antiq. Fr., 195\%, p. 67-74.

(5) P.-M. Duval, ibid., 1950, p. 81-87.

(6) Abbé R. Boyer, Bull. soc. d'et. scientif. et lill. Draguignan, XLVIII, 1950, I, p. 14-15.

(i) Annales Bourgogne, XXIV, 1952, p. 193; - Rev. archeol. kst, III, 1952, p. 51.

(8) J. CotTAz, Rhodania, 24, 1951, p. 8-22. 
en 1951 par la pelle mécanique 9. Les quelques indications fournies sur ces édifices n'en sont que plus nécessaires. l'iconographie ancienne d'un monument est aussi des plus instructives, et les anciennes estampes consacrées au Palais des Thermes de Gluny sont riches en enseignements pour la restitution de dispositions disparues 10. Au bilan des fouilles de ce monument s'inscrit le dégagement complet de la face Nord, la découverte de salles nouvelles dans le Musée. Non moins curieuses que les images des navires décorant les chapiteaux des pilastres dans la grande salle de Cluny sont. les quatre panneaux sculptés sur les façades, au-dessus de petites baies, à l'arc d'Orange, représentant des dépouilles de navires gréco-romains, souvenirs de la victoirc d'Actium. Sauf la coque, les voiles et les bans de rameurs, toutes les autres parties sont représentées 11.

A Bavai (Nord), de nouvelles parties ont été dóblayées à l'angle N.-O. et à l'angle s.-O. du double portique, ainsi qu'une partie du dallage de l'esplanade centrale et deux grandes bases de statues. Les monnaies constantiniennes et les tessons décorés à la molette datent ces niveaux du $I^{\circ}$ s. 12. Le doublement du mur du grand portique est un mode aberrant de construction qui pourrait s'expliquer par un dispositif permettant l'aération et l'assćchement constant de murs destinćs à protéger des provisions stoquées dans un grand dépòt et craignant l'humidité. On semble donc hésiter encore sur la destination du monument, thermes ou

(9) F.H. Gardihian, Bull. soc. d'ét. hist. et scientif. Ilautes-Alpes, 7e sér., 1952, p. 41-45.

(10) P.-M. DuvaL, Bull. soc. nat. antiq. Fr., 1948 , p. 187 ; 1949 , p. $190-191$; - A. PIGANIOL, Gallia, IX, 1951, p. 81-82.

(11) P.-M. Duval, Bull. soc. nat. antiq. Fr., 1948, p. 68-69.

(12) J. Heurgon, Gallia, IX, 1951, p. 80-81. magasin 13. Un rapprochement 14 a été tenté entre le grand complexe architectural, basilique et marchés de Ladenburg, et le grand monument de Bavai, dont le sous-sol aurait été occupé, lui aussi, par des magasins.

On avait depuis longtemps déjà reconnu que les diver's blocs sculptés, découverts à Paris sous Notre-Dame et sur l'emplacement de l'ancien Hôtel-Dieu, souvent improprement appelés autels, avaient appartenu à un seul monument, sorte de haut pilier sur plan carré, décoré sur ses quatre faces. Dans l'essai de restitution 15 qui nous est proposé, le monument, haut de $6 \mathrm{~m}$. environ, comportail quatre étages: bloc de Jupiter au sommet, celui des huit divinités à la base; au-dessus de celui-ci la Procession des Nautes, l'inscription, Castor et Pollux. La colonne aurait été couronnée par une figure de Jupiter assis. Avec le Pilier des Nautes, dressé à Lutèce entre 15 et 25 ap. J.-C., commencerait en Gaule lv: règne de la grande sculpture monumentale. On pourrait y reconnaître le prototype de la Colonne de Mayence et des monuments contemporains des règnes de 'Tibère et de Claude : piliers de Mavilly, de Dijon, etc. Une même inspiration puise sa source dans le culte de Jupiter et de l'Empereur qui, parti de la Gaule du Centre, gagne progressivement la Rhénanie par les vallées do la Saónc et do la Moselle. Cette sculpture gallo-romaine du Bassin Parisien et de la Bourgogne aurait exercé aussi son action sur l'art funéraire militaire de la vallée du Rhin et ses origines sont liées à la présence dans le sous-sol parisien d'un matériau, la

(13) H. BIÉVELET, Annales XXXe Congrès fédér. archéol. et hist. Belgique, II, p. 32-34.

(14) J. Feyder-Fetirans, L'Antiq. classq., 1952, p. 417; cf. Germania, 1952, p. 56-69.

(15) J.-J. IlATT, Rev. des arts, 1951, p. 205 sqq.; - Rev. urcheol., 1952, I, p. 68-83. 
pierre de Saint-Leu qu'utiliseront les sculpteurs rhénans de la stèle de Flavoleius et de la Colonne de Mayence, adoptant la techniquc parisienne du basrelief en champlevé, appliquant à la pierre tendre les procédés artisanaux des praticiens narbonnais.

In relevé des thétres el des indications sur leur état de conservation a été publié pour les départements du Cher 16 et du Joiret ${ }^{17}$. In cirque a peut-être śté reconnu à Sceaux-du-Gâtinais.

Une étude d'ensemble sur les aqueducs de la Gaule romaine 18 fait ressortir la grande diversité des types de ponts, la varieté des canalisations souterraines, la rareté des réparations, la préférence marquée pour l'aqueduc aux dépens de la machine élévatoire. Lourds, à larges arcades au $\mathrm{r}^{\text {er }} \mathrm{s}$. de notre dre, les aqueducs, à partir du règne d'Hadrien, s'allègent et les vides occupent $50 \%$ de la construction. On constate aussi que le site d'une ville n'a pas été choisi en raison de ses ressources en eau, de là l'importance et la longueur des aqueducs.

4. Occupation territoriale et voies romaines. -- La multiplicité des cadastres trouvés à Orange s'explique par des révisions périodiques de l'état de la propriété 1 . 'Trois fragments nouveaux se recommandent par leur exceptionnellc exactitude. Sur cette carte au $1 / 5.000^{\circ}$, le paysage géographique figure une île au milieu d'une rivière que deux canaux débordent à droite et à gauche. Il semble que ce relevé représente un passage très

(16) Cilavayat, Bull. liaison provisoire soc. archéol. et hist. Orléanais, n० 19, déc. 1952, p. 5-6; -- abbé Moufflet, ibid., p. 16.

(18) P.-M. Duval, Bull. soc. nat. antiq. Fr., 1949, p. 228-229.

(1) $\Lambda$. Piganior, Bull. soc. nat. nat. antiq. Fr., 1950-1951, p. 66-67; - J. SAUter el A. Piganiol, C.R.A.I., 1952, p. 486-487. ancicn de l'Eigues, à une dizaine de kilomètres d'Orange, au Nord de Travaillon.

En Vaucluse, si l'on n'a encore que peu de précisions sur les découvertes failes à Cavaillon 2, dans des fosses et des puits qui ont donné un matériel de la fin de l'époque républicaine et de la période augustéenne, les recherches sur la colline de Perréal, à $2 \mathrm{~km}$. au N.-O. d'Apt, ont révélé l'existence d'une agglomération qui semble contemporaine 3 . Sont-ce les ruines de la station Ad Fines, qui furent retrouvécs à Villeneuve, au S.-E. de Gordes, bain et hypocauste avec monnaies des $\mathrm{III}^{\mathrm{e}}$ et $\mathrm{IV}^{\circ}$ s. 4 ? On signale la découverte aux Borys, à Mérindol, d'une salle, d'une galerie et de deux textes en l'honneur de Marc-Aurèle et de Gallien 5 .

F. Benoît 6 donne l'inventaire des découvertes sous-marines faites sur le littoral provençal: murs antiques à $F_{0}$ (Bouches-du-Rhône) au large du rocher Saint-Gervais et dans les alluvions anciennes de la cote; tessons campaniens, arrétins, de La Graufesenque, skyphos avec pampres ( ${ }^{\text {er }} \mathrm{s}$.) et fragments archilecturaux, balustres paléochrétiens; sarcophages hellénistiques avec candélabre accosté de deux panthères (Port-de-Bouc, Bouches-du-Rhône); épaves de navires et collier de plomb d'un gréement à Sanary (Var); traces d'un môle à Hyères (Var); épave ensablée de l'époque grecque au large de la citadelle de Bréganson; autre épave au rocher de La Four-

(2) A. Dumoulin, Acti congr. internaz. di prehist. $e$ prolohist. Mediter., Firenze-Roma, 1950, p. 535-536.

(3) J. SAUTEL, Provence hist., 1952, p. 49.

(4) Ibid., p. 49-50.

(5) Ibid., p. 40.

(6) Op. cit., p. CLIX-CLXII ; - F. BRaLMen, Bull. Centre etudes sous-marines, I, 1952, p. 48 ; - R. LANTIER, Archiv. de prehistoria lerantina, III, 1952, p. 199-207; - Ph. Diolt, promenades d'archéologic sous-marine, $\mathrm{Pi}$ ris, 1952. 
mique au Lavandou (Var); épave chargée d'amphores du ier s. de notre ère à AgayAnthéor (Var); jas d'aneres en plomb à l'île Sainte-Marguerite et à l'Est du cap d'Antibes (Var) avec masque de Méduse.

Des ruines romaines ont été relevécs près de la plage du Canet, à Rivesaltes, entre Arles-sur-Tech et la route d'Espagne (Pyrénées-Orientales) 7 ; aux environs d'Aigne (Hérault), près de la ferme de Comberant, aux tènements des Oules et de l'Estrade, territoire colonisé à partir du $\mathrm{I}^{\text {er }}$ S. av. J.-C. 8; tronçon de voie romaine à Plaisance-de-Touch (Haute-Garonne), entre le carrefour de la route de Fonsorbes à La Salvetat, avec le chemin de Fontenelles et le ruisseau de l'Aussonnette ${ }^{9}$; villas au Purgatoire, près d'Hauterive ${ }^{10}$, sur le territoire d'Aux à Nuret 11. Au pied de l'oppidum de SaintMartory, à la sortie Ouest de l'agglomération, entre l'escarpement rocheux et la Garonne, un dépotoir utilisé pendant toute la période gallo-romaine, un four de potier, des monnaies du $\mathrm{IV}^{\mathrm{c}}$ ou du début $\mathrm{du}^{\circ} \mathrm{v}^{\circ}$ s., prouvent que la station de Calagurris était descendue de l'oppidum sur les bords de la Garonne, près de la voie de Toulouse à Dax 12.

A la suite des fouilles entreprises depuis 1948 dans la grande villa de Montmaurin (Haute-Garonne) ${ }^{13}$, le plan général se caractérise par son unité, sa symétrie et son ampleur, plus de 150 pièces. L'aile Nord, entièrement dégagée, abritait les thermes, dont les piscines, les vasques et les escaliers étaient revêtus de

(7) G. Claustres, itudes roussillonnaises, II, 1952 , p. 205.

(8) 0. TAFFanel et M. Louls, Rev. ét. ligures, XIX, 1952, p. 98-106.

(9) M. Labnousse, Gallia, IX, 1951, p. 128.

(10) Ibid., p. 128.

(11) Ibid., p. 128

(12) Ibid., p. 129-130.

(13) Ibid., p. 131-133. marbres de Saint-Béat. Les hypocaustes présentent cette particularité de ne pas comporter de piliers, mais des canalisations. La partie la mieux conscrvée de ce remarquable ensemble est un nymphée de basse ćpoque, réduction du nymphée de la villa d'Hadrien à Tivoli, avec sa pièce absidiale ouverte sur un portique de deux colonnes et son péristyle encadrant un jardinet et un bassin. Sur un emplacement déjà occupé par des constructions, une grande villa avait été bâtie au milieu du $\mathrm{II}^{\mathrm{e}}$ s. Sa destruction au $\mathrm{IV}^{\mathrm{e}}$ ou au $\mathrm{v}^{\mathrm{e}} \mathrm{s}$. fut suivie d'une occupation sporadique au temps des Grandes Invasions (sépulturc ct foyer). A la lumière de ces découvertes, il apparait que le milieu du $\mathrm{II}^{\mathrm{e}} \mathrm{s}$. fut pour la Gaule du S.-O. une époque de prospérité qui se traduit par la construction de belles et importantes villas. Bien que, par la richesse du décor et par l'ampleur de bâtiments, la villa de Montmaurin apparaisse comme l'un des plus beaux ensembles de ce type dans ces rógions, la villa contemporaine en cours d'exploration au territoire d'Arnesp, sur la rive droite du canal d'alimentation de l'usine hydro-d́lectrique de Valentine (Haute-Garonne) 14, avec ses dix-sept pic̀ces dégagées, souvent spacieuses, témoigne d'un certain luxe: sols dallés de marbres, murs lambrissés ou recouverts de stucs peints, pièce à $a b-$ side sur hypocauste. Les murs sont le plus souvent bâtis en cailloux de la Garonne, renforcés aux angles par des moellons de grès. Il semble que la villa qui, avec ses dépendances, peut couvrir une superficie de deux hectares, ait connu deux états : l'un de la seconde moitié du III s., l'autre du début du Iv; vraisemblablement, après l'invasion, comme à Montmaurin, des tombes barbares ont été installées sur les ruines. S'il est encore

(14) Ibid., p. 133-134. 
difficile de juger de l'importance de la villa, dont une pièce pavée d'une mosaïque à décor géométrique (probablement un triclinium) a été trouvée au Sas de Mary, près de l'église Saint-Roman, à Fauroux (Tarn-et-Garonne) 15, il semble dès maintenant qu'on se trouve en présence des ruines d'un édifice important relevant aussi des restaurations de la fin du $\mathrm{III}^{\mathrm{e}}$ s. ou du début du IV $\mathrm{v}^{\circ}$. Primitivement le triclinium comportait un décor stuqué de coquilles et de grappes de raisins. A la même époque appartient la mosaïque de Pompogne (Lot-et-Garonne), décorant la salle d'une grande villa, qui a aussi donné des sépultures, sans doute barbares. On se trouve en présence d'un site important pour l'histoire de la région au $\mathrm{IV}^{\mathrm{e}} \mathrm{s}$., en un temps où l'on relìve les ruines de la première invasion 10.

La villa agricole de moyenne importance de La Tasque, à Cadeilhan-SaintClar (Gers) 17, bâtie au voisinage d'une source et à proximite de la voie romaine Toulousc-Lectoure, est contemporaine de l'un des premiers essais de mise en valeur de ces territoires au $\mathrm{I}^{\text {er }} \mathrm{s}$. de notre ère. La partie essentielle est représentéc par un bâtiment, rectangulaire allongé, flanqué au Nord d'une cour, au Sud d'une sorte de couloir divisé en un certain nombre de salles étagées suivant la pente du terrain. A l'extrémité orientale s'amorce une aile en retour; à l'opposé, la grande salle précédemment découverte se prolonge au sud par une abside semi-circulaire surólevée et pavée d'une mosaïque décorée de stylisations d'acanthes. La villa a été construite au cours de plusieurs campagnes, comme en témoignent les trois couches d'incendie, la première correspondant à un défrichement par le feu, la seconde contemporaine de la fin du $\mathrm{i}^{\text {or }} \mathrm{s}$., la troisième de la destruction finale.

L'intérêt de la découverte de ruines antiques faites à l'extrémité septentrionale du Camp de Caylus, à la limite des départements du Lot et du Tarn-et-Garonne, au-dessus de la fontaine Saint-Albi et sur le territoire de la commune de SaintTrogit, est de fixer un habitat romain et peut-être préromain -- deux tumulus à incinération ont été reconnus au voisinage - en un point du causse, déjà désert au Moyen âge, mais desservi par les deux voies romaines de Rodez à Cahors et de Rodez à Cos 18.

Si à l'Impernal de Luzceh (Lot) les recherches entreprises pour retrouver le murus gallicus sur ses faces occidentale et méridionale n'ont donné aucun résultat ${ }^{19}$, des restes d'édifices ont été mis au jour dans les parcelles 572 et 608 : murs en petit appareil construits sur le rocher avec contrefort circulaire, fonderie de fer, tour ou château d'eau. L'oppidum, dont la superficie ne devait pas dépasser 10 hectares, apparait comme un sanctuaire, dont le centre était un temple carré de tradition celtique. Comme il arrive fréquemment, artisans et marchands avaient installé leurs ateliers et leurs boutiques à l'abri du lieu du culte, et l'occupation du site se poursuit jusqu'au début du II $^{\circ}$ s. de notre ère. T'aqueduc dont un tronçon a été reconnu sur le territoire de Tavie (Gers), parallèlement à la rive droite $d u$ Gers ${ }^{20}$, devait alimenter la partie de l'agglomération gallo-romaine d'Auch, correspondant au faubourg actuel de Garros.

Dans un mémoire traitant de la romanisation de la province d'Aquitaine, Emi-
(15) Ibid., p. 137-138.

(16) Ibid., p. 126.

(17) Ibid., p. 135-136.
(18) lbid., p. 138-139.

(19) Ibid., p. 139-140.

(20) Ibid., p. 136. 
le Gailhard 21 tente de mesurer et de localiser l'importance de la romanisation entre la Loire et la Garonne, d'après la répartition géographique des ruines, des monuments sculptés et des textes épigraphiques. Le Ct Marié 22 apporte des précisions sur les voies impériales du Nord de l'Aquitaine et sur l'importance de Poitiers comme nœud routier. Élie I Jambert $\mathbf{2 3}$ fait le point des recherches sur les routes des pyrénées atlantiques et leur emploi au cours des âges, et les rapports routiers entre la Gaule et l'Espagne dans l'Antiquité. Deux voies principales longeaient la chaîne du Noord au Sud, l'une sur le versant français de Dax à Toulouse, par Lescar, Bagnères-de-Bigorre, Saint-Bertrand-de-Comminges, l'autre en Espagne par Calahorra, Saragosse et Lćrida, de Briviesca à Barcelone et de là passait la chaîne à l'Est, soit par Emporion et la côte, soit surtout par Gérone et le col du Perthus. A l'Ouest, où le passage fut de tous temps difficile, l'Itinéraire Antonin décrit les deux routes d'Oloron à Saragosse et de Saint-Jean-Piedde-Port à Pampelune. Mais on ne sait pas exactement quels sont les deux cols désignés sous le même nom de Summus Pyrenaeus. Il apparait qu'à l'époque romaine la route principale passait par le Somport, pour descendre directement vers Jaca par la vallée de Canfranc. De part et d'autre de la voie, il ne serait pas impossible que deux autres routes aient doublé celle-ci en direction de Saragosse, et cette coexistence de trois voies parallèles voisines, mais distinctes, permettrait peut-être d'expliquer un passage énigma-

(21) Diplôme d'êt. sup. histoire, Faculté Leltres Toulouse, 1952.

(22) Bull. soc. antiq. Picardie, $4^{\circ}$ sér., II, 1952, p. 79-82.

(23) Primer congresso internaz. del Pyreneo del Instiluto d'estudios pyrenaicos, Saragosse, 1951, extrt. tique d'Al Idrisi, signalant, au $\times \mathrm{xI}^{\bullet} \mathrm{s}$. les trois routes du Port de Cize, du Port de Jaca et du Port d'Aspe. Enfin, plus à l'Est, un autre chemin dirigé N.-S. passait par Saint-Bertrand-de-Comminges pour suivre la vallée d'Aure et le val de Rioumajou. On peut se demander si les Romains ont suivi une voie venant de Bayonne et franchissant la chaîne par le col de Velate, car, aux premier's siècles, l'occupation romaine est assez lâche le long du littoral du Pays Basque, et, quant à la montagne, il semble que la romanisation ne l'ait guère entamée.

Les ruines fouillées à Taleyson (cne de Bernos, Gironde) appartiennent à une petite ferme dont l'occupation s'est poursuivie aux temps mérovingiens ${ }^{24}$. La station de Saint-Germain-du-Puich était reliće par un ancien chemin à un ctablissement contemporain de la Croix de l'Espelette, entre Nérigean et Génissac (Gironde) 25. Des poteries gauloises, des tuiles romaines, des fragments de placages de marbre et des cubes de mosaïques, recueillis à Tourseiller-Médis (CharenteMaritime), où l'on avait trouvé la bague ornée de la représentation de JupiterSarapis, témoignent d'une occupation du site aux $\mathrm{III}^{\circ}$ et $\mathrm{IV}^{0} \mathrm{~S} .26$.

A Champagnac-la-Noaille (Gorrèze) 27, la cachette des Fontenelles, qui a donné des monnaies et des céramiques, signale l'emplacement d'un hahitat dans la région des plateaux séparant les bassins de la Montane et du Doustre, alors occupée par des domaines ruraux. La densité du peuplement y est comparable à celles d'autres parties du Bas-Limousin. Dans le

(24) P. Grinal, Gallia, IX, 1951, p. 124.

(25) Fripuet, Rev. hist. et archéol. Libournais, 1952, p. 42-72.

(26) Rev. Saintonge et Aunis, nouv. sér., I. 6e livi., 1952, p. 35-38.

(27) M. Labrousse, Bull. soc. scientif. et archeol. Correze, 74, 1952, p. 57-68. 
même département, où l'on constate l'association sur un même emplacement, à La Mouthe (cne de Sćrandon) 28 et à RiéGrand (cue de Chavanac) ${ }^{20}$, de tessons posthallstattiens, de La Tène III et galloromains, deux établissements agricoles ont été relevés à Aumont (cne de La $\mathrm{Pa}$ lisse) 30 et au Cros-des-Serves (cne de Margerides) ${ }^{31}$, celui-ci occupé au III $^{\circ} \mathrm{s}$. Les grottes ouvertes dans les monts calcaires de la Basse-Corrèze 32 ont été habitées alors. Dans l'une d'elles, aux « Contrebandiers » à Puy-Gérald, près de Lissac-sur-Couze, des tessons gallo-romains et peut-être plus anciens ont été ramassés.

On doit au regretté Frank Delage 33 une vue d'ensemble sur la Haute-Vienne gallo-romaine, de laquelle on peut conclure à une répartition à peu près égale des vestiges dans les régions de Limoges, de Bellac, de Rochechouart et de SaintYriex. L'un des établissements les plus importants de ce territoire est la villa d'Antone ${ }^{34}$, à Pierrebuffière, au sommet d'un promontoire dominant les confluent de la Brinace et du Blanzou, détruite par un incendie, puis reconstruite. Les constructions, qui se raccordent, sont étagées sur le plateau et sur trois paliers. Au niveau inférieur se développent de grands thermes alimentés par une source captée et comportant un nymphée circulaire. A Saint-Prix-sous-Aixe, sur la rive gauche de la Vienne, la boucle dominée par les villages de Vaud et de Chez-Roger 35 a été un centre de peuplement agricole aux $\mathrm{II}^{\circ}$ et $\mathrm{III}^{\ominus} \mathrm{S}$. Parmi les objets recueillis, on

(28) P.-F. Founnikr, Gallia, IX, 1951, p. 111.

(29) Ibid., p. 111.

(30) Ibid., p. 109.

(31) Ibid., p. 110.

(32) Bull. soc. scientif., histor. et archeol. Corrize, 6i, 1952, p. 139.

(33) Bull. archéol. Comité, 1950, p. 167-176.

(34) F. Delage, Gallia, X, 1952, p. 1-30.

(35) J. Perritk, Bull. soce hist. de artheol. Limousin, LXXXIV, 1952, p. 35-42. retiendra une assez jolie tête féminine, la chevelure ceinte d'une couronne de feuillages, et une petite tête d'enfant. Une réelle indécision plane sur l'âge des silos et des fosses trouvés à Razès, en contrebas du château 36. Dans la Creuse, d'autres établissements agricoles ont été reconnus à La Métairie (cne de Gartempe) ${ }^{37}$, à La Brède 38 et à La Chassaigne (cne de Peyrat-]a-Nonière) 39 ; dans la Haute-Loire, à Fix-Saint-Geneys 40 et dans la Loire à Chaissieux, près de Moindt 41 . Une occupation gallo-romaine a succédé à des habitats du Néolithique et de l'âge du Bronze à Rieutort-de-Randon (Lozère), sur les pics jumelés de Fortunio et de Randon $\mathbf{4 2}$.

Dans le Rouergue, ce sont encore les fouilles de La Graufesenque (Aveyron) ${ }^{43}$ qui retiennent l'attention : au Sud des tranchées précédemment ouvertes, des murs, des dallages, deux mosaïques à décors géométriques appartiennent à la maison du potier, et des fragments d'amphores proviennent du cimetière à incinération. Des sondages au Nord de la ferme ont fait connaître un petit dépôt d'amphores et un foyer gaulois. Dominant cette plaine de La Graufesenque, un éperon avancé du Larzac présente, à La Garenède (cne de Millau, Aveyron), les traces d'occupations successives depuis le Hallstattien jusqu'au cours du $\mathrm{I}^{\text {er }} \mathrm{s}$. de notre dre ${ }^{44}$. Sur les pentes occidentales de ce

(36) F. Dllage, ibid., p. 29-33.

(37) P.-F. Fournier, Gallia, IX, 1951, p. 111.

(38) Dr G. Janicaud, Mem. soc. des sc. nat. et archéol. Creuse, 31, 1952, p. xvir.

(39) Ibid., p. xxi.

(40) P.-F. Fournier, Gallia, IX, 1951, p. 112.

(41) Bull. archéol. Comité, 1950, p. 135.

(42) DE Lescure, B.S.P.F., XLIV, 1952, p. 501 ; - Bull. trim. soc. litt., sc. et arts Lozère, 1952, p. 195.

(43) L. BaLSAN, Rer. Rouergue, VI, 1952, p. $384-385$.

(44) P.-F. Fournier, Gallia, IX, 1951, p. 109. 
même causse, au Combalou ${ }^{45}$, les ruines d'un fanum ont donné les éléments d'un mobilier cultuel, tessons indigènes et de La Graufesenque, statuettes de terre-cuite représentant des personnages et des animaux, bracelets, bagues et fibules de métal. En Dordogne, des substructions ont été relevées sur l'oppidum de La Boissière à Périgueux ${ }^{46}$ et aux Lèches, lieu dit Combe de Cosse ${ }^{47}$. Dans les DeuxSèvres, la région d'Airvault est riche en vestiges de l'occupation agricole, aux limites de la plaine et du bocage 48 .

Le terroir gallo-romain de la Touraine a été partiellement prospecté par voie aérienne. Les premiers résultats sont assez encourageants 49 et ont permis de constater (domaine de Rouvray, à SaintJean-Saint-Germain, près de Loches, Indre-et-Loire) que la villa s'étend parallèlement au tracé de la voie romaine sur une superficie de 100 hectares. A Cheile, près d'Azay-le-Rideau (Indre-et-Loire), une exploitation rurale du $\mathrm{II}^{\mathrm{e}} \mathrm{s}$. était dotée d'un pressoir du type «casse-cou », encore observable dans la région ${ }^{50}$. L'abbé A. Nouel a entrepris le relevé des traces de l'occupation romaine en forêt d'Orléans (inspection de Lerris) ${ }^{51}$. Des murs, un dépotoir contenant des poteries et des verreries ont été reconnus à Sceaux-du-Gâtinais (Loiret) 52. La construction en bois, faite d'une ligne transversale d'énormes

(45) L. Balsan, Rev. Rouergue, VI, 1952, p. 419-424.

(46) G. Barrière, Bull. soc. hist. et archéol. Perigord, LXXIX, 1952, p. 23-27.

(47) Ibid., p. 122.

(48) D.-M. MARIÉ, Bull. soc. antiq. Ouest, $4^{e}$ sér., II, 1952, p. 82-108.

(49) Boussard, Bull. soc. nat. antiq. Fr., 1948, p. 136.

(50) Ibid., p. 46.

(51) lbid., 1952, p. 340.

(52) Abbé MoUrfeter, Bull. liaison provis. soc. hist. et archéol. Orléanais, no 19, juill.oct. 1952, p. 4. troncs d'arbres couchés, découverte au bois d'Yères, près de Vierzon (Cher). n'appartient pas à un rempart $\mathbf{3 3}$.

On discute toujours sur les limites de la cité des Osismes, au Sud-Est, et P. Merlat ${ }^{54}$ se rallie à la frontière de l'Ellé. Une même incertitude s'attache aux indentifications proposées pour la localisation, entre Guérande et Vannes, de la station Blabia, mentionnée dans la Notitia dignitatum 55. Les travaux d'urbanisme ont apporté quelques précisions nouvelles à la topographie antique de Nantes 56: tronçon de l'enceinte de basse époque, rue de la Marne; habitation, rue de l'Écluse; construction en schiste, rue Dugommier, dans l'établissement des Jésuites.

Dans une position dominante au bord du golfe du Morbihan, le site de Castel Bénance, à Sarzeau (Morbihan), parait correspondre à l'un de ces mouillages anciens dont on suppose l'existence sur le littoral 57. Malgré le caractère fragmentaire des fouilles de la ferme de Kergoléden en Meilars (Finistère), on peut reconnaître, dans les masses organiques de cailloux, les vestiges des substructions d'un édifice à plusieurs salles, en rapport avec une levée correspondant à une cloture 58. On se trouverait en présence des ruines d'un établissement agricole assez pauvre, entouré d'une enceinte, qui aurait directement succédé à un établissement gaulois du genre des acdificia circumdata silva (César, B. G. VI, 30). Une autre

(53) R. Louis, Bull. soc. nat. antiq. Fr., 1950, p. 31.

(54) P. Merlat, Ann. Bretagne, 1952, p. 99-105.

(55) H.-F. BuFFeT, ibid., p. 313-336; Bull. soc. polym. Morbihan, 1951-52, p. 70-72. $77,78,87$.

(56) L. Bouchaud, Bull. soc. archeol. et hist. Nantes, $\mathrm{XC}, 1951$, p. 36-43.

(57) P. MerLat, Gallia, IX, 1951, p. 86-87.

(58) Du MÈME, ibid., p. 90-92; — Ann. BrCtagne, LIX, 1952, p. 228-255. 
ferme a laissé des traces à Lanneunoc en Plounévez Lochrist (Finistère). L'une des amphores (jui y fut recueillie avec les restes d'un outillage, portait sur la panse l'estampille : Apoll(onii) ou Appoll(inaris) Aer(ii) 59.

L'abbé Nouel 60 a dressé la carte archéologique gallo-romaine pour les territoires compris entre Blois et Chartres, Sens et Auxerre, Etampes, Romorantin et Aubigny-sur-Mere. Une copie partielle de la carte du diocèse de Iisieux, dressée par d'Anville en 1727, permet de préciser le tracé de l'acienne voie d'Angleterre, entre Exmes et Dives, passant au pont de Jort, sur la rive gauche de la Dives pour se diriger vers Magny-la-Campagne et Canon, repassant la rivière au bac d'Annaray et gagnant, par Hautot, Beuvron, Putot, Rouville, le port de la Dives. C'est le chemin suivi par Guillaume le Conquérant pour son expédition d'Angleterre. Mais il y avait d'autres routes : celle du Cotentin, le point le plus rapproché de la Grande-Bretagne, situé en face de l'île de Wight, terminus des routes desservant les îles et l'Irlande; celle de l'estuaire de la Seine 01.

La reprise des fouilles à Saint-Aubinsur-Mer (Calvados), sur la falaise du Catel ${ }^{62}$, a porté sur le dégagement des dépendances orientales du temple, à l'Ouest duquel un complexe de bâtiments a cité repéré au bord de la falaise, sans doute une habitation rustique qui a donné des vaisselles domestiques et un curieux fragment de trépied, portant le croquis à la pointe sèche d'un navire. Des tessons gallo-romains ont été recueillis dans les

(59) DL MÊMe, Gallia, IX, 1951, p. 92-93.

(60) Bull. liaison prov. Orléanais, $\mathrm{n}^{\circ} 18$, maijuin, 1952, p. 1.

(61) Dr. Doranlo, Bull. soc. hist. et archél. Orne, LXX, 1952, p. 34-35.

(62) II. VAN EFFeNTERRl, Gallia, IX, 1951, p. $83-84$, falaises au Sud de Barfleur (Seine-Inférieure 63

D'intêressantes découvertes se poursuivent dans le département de l'Oise : à Buffosse, près de Verneuil ${ }^{64}$, sur la rive gauche de l'Oise, non loin de la ferme de Maubuisson, une villa rustique $d u I^{\circ} \mathrm{s}$. dans laquelle la maison du villicus, séparée par un mur des bâtiments d'exploitation (ćtable, remises, tour carrée ayant servi de pigeonnier), se compose d'une salle commune autour de laquelle se groupent des chambres, et un bain; à Thiverny, près de la route de Saint-Leu, au pied de la falaise, une grande salle est dotée d'une niche pratiquée dans la muraille en pierres de taille, avec un encadrement de colonnes et une corniche d'ordre toscan 65 . Plutôt qu'une villa, ces ruines appartiennent à celles d'un sarictuaire qui devait être en lien étroit avec un ancien culte de la falaise. Les dispositions de la salle souterraine sont surprenantes; - à Creil, les pilotis, trouvés dans le lit de l'Oise 66 appartiennent peutôtre aux restes du port fluvial gallo-romain; à la sortic de la ville, des constructions antiques ont été relevées sur la route de Chantilly. $\Lambda$ Senlis ${ }^{67}$, dans les fouilles du château, un péristyle orienté à l'Est, encadrant une grande porte revêtue de plaques de bronze, donne accès à une cour ouverte. On serait désireux de connaitre l'emplacement exact de la fosse et des excavations ouvertes en forêt de Compidgne ${ }^{68}$.

Ia prospection méthodique des terri-

(63) Bull. soc. antiq. Fr., 1948-1951, p. 466.

(64) Durvin, Soc. d'hist. et d'archeol. Senlis, C. R., 1952, p. 4; - A. PIGaniol, Gallia, IX, 1951 , p. 82 .

(65) Durvin, op. cit., p. 7-8; - 4 . Piganior, op. cit., p. 82.

(66) Dunvis, op. cit., p. 8.

(6i) Soe. Senlis, 1952, p. 8-9; - 4 . Piganiot, op. cil., p. 83.

(68) Ibid., p. 40. 
toires de Noyers-sur-Serein et de Jouxla-Ville (Yonne) a révélé l'existence de villas dispersées et amenć la découverte d'une statuette de Dieu Lare, portant le cucullus et tenant une corne d'abondance ${ }^{69}$.

Dans la Côte d'Or, les établissements agricoles de Montfaucon, au confluent de l'Ougne et de l'Ignon 70, étaient protégés par une ligne de défenses établie sur les hauteurs du Châtel, de Montfaucon, de Chaumont et de Millevoix. Des constructions, des rigoles, des habitats rappelant ccux d'Alésia, ont été reconnus au Nord de Frenes 71. Faut-il voir dans le nom du village de Foigny la forme gallo-romaine Fuscinacus et, en conséquence, la trace d'une occupation antique de la contrée $\mathbf{7 2}$ ? A $3 \mathrm{~km}$. des sources de la Seine, près d'un important croisement de routes, s'étendent, sur près d'un kilomètre, les ruines d'une agglomération qui pourrait représenter un camp de rassemblement pour les pèlerins $\mathbf{7 3}$.

A Chalon-sur-Saône (Saône-et-Ioire), lors de la reconstruction du pont SaintLaurent 74 , on mit au jour les sabots de fer de pilotis de type romain à quatre languettes percées pour le passage des clous. Il existait donc, dès les premiers siècles de notre ìre, un passage de la Saône dans le prolongement de la voie romaine de Besancon passant par la levée de Saint-Marcel, sur l'emplacement même de la découverte. Comme à Mayence, le tablicr de bois du pont reposait sur

(69) Annales Bourgogne, XXIV; 1952, p. 193. (70) G. GrÉmaud, Rev. archéol., 1952, 2, p. $41-51$.

(i1) Courtois, Mem. comm. antiq. Cote d'Or, XXII, 3, 1952, p. 491.

(72) P. LEBEL, ibid., p. 467.

(73) E. GuYoT, Bull. archéol. Comité, 1950, p. 96 .

(74) L. Armand-Calliat, Mém. soc. d'hist. et d'archéol. Chalon-sur-Sa6̂ne, XXXIII, I, 1952, p. 15, 53-63. des piles en gros appareil soutenues par des pilotis. Des vestiges de constructions ont été signalés à Montceau-les-Mines et dans la région de Béran-sous-Sansvignes et à Saint-Vallier 75 . Dans le Clunisois, Chissey-les-Mâcon est presque entièrement bâti sur des fondations gallo-romaines et des ruines ont été relevées à Ia Villa d'Allary (cne de La Chapelle-duMont-de-France) $\mathbf{7 6}$.

E. Dubois $\mathbf{7 7}$ donne l'inventaire des découvertes faites sur les territoires de ILagnieu et de Saint-Sorlin (Ain), et P. Gréal traite de l'Ardèche romaine ${ }^{78}$.

A Valence (Dròme), des travaux d'édilité, sur le côté Nord de l'avenue VictorHugo, au droit du $n^{\circ} 29$, ont révélé l'existence d'un tronçon de voie romaine $\mathbf{7 4}$.

Autour d'une construction à-demi enfoncée dans le flanc de la colline, au lieu dit: La Sarrazinière, à Saint-QuentinFallavier (Isère), se groupent les restes d'une agglomération gallo-romaine ${ }^{80}$. En Savoie, les traces du passage de la route romaine de Saint-Genis à Genève ont été retrouvées à Saint-Maurice-de-Rotherens et, près de Chalmez, un établissement fortifié assurait la défense du passage du Rhône ${ }^{61}$.

L'examen de la répartition des restes gallo-romains dans le département de la Moselle 82 fait connaître une occupation assez différente de la répartition actuelle

(75) J. Bernardin, ibid., p. 29.

(76) Annales Bourgogne, XXIV, 1952, p. 192.

(ii) Bull. soc. naluralisles et archéologues Ain, n* 66, 1952, p. 89-101.

(78) Mém. ét. sup. histoire, Faculté des Lettres, Lyon, 1952.

(79) Bull. soc. d'archéol. et de statisq. Dró$m e, \mathrm{LXXI}, 1952$, p. 60.

(80) R. Ghamillon, Évocations, 6, 1951, p. $707-710$.

(81) Abbé Suret, Mém. et doc. publiés par la soc. savoisienne d'hist. et d'archéol., LXXVI, 1947-1952, p. 21, 28.

(82) A. Golombet, Rev, archéol. Est, III. 1952, p. 52. 
de la population, de nombreux établissements agricoles ayant été trouvés là où règne aujourd'hui la forêt. La région marécageuse de Delle (Territoire de Belfort) a été habitée tardivement. Elle était desservie par la voie de Mandeure à I,argitzen, dont le tracé a été suivi près de Fesches-l'Ecluse et entre Faverois et Florimont 83.

L'occupation au $\mathrm{III}^{\mathrm{C}} \mathrm{s}$. de la région de Sarrebourg (Moselle) fait connaître un régime assez particulier 84 : sur un espace relativement restreint on a reconnu l'existence d'une centaine d'ćtablissements, distants d'un kilomètre les uns des autres. A cet ensemble appartient le grand domaine de Saint-Ulrich-Dolving, dont une fouille partielle a déjà dégagé 117 salles. Il ne peut s'agir d'un domaine purement agricole : l'accumulation des bâtiments ne correspond pas, en effet, à l'exiguïté du terrain occupé. Il faut alors admettre que certaines de ces constructions avaient une destination de caractère industriel. Ie domaine devait se suffire à lui même, et on peut établir une comparaison avec la grande villa d'Anthée (Belgique).

Des précisions ont été apportées sur la stratigraphie du site sur lequel avait cté découverte la cachette d'outils de Tarquimpol (Moselle), située au voisinage de galeries voûtées, aqueduc ou égout 85 , et à la description du pont romain de Kembs (Haut-Rhin) 86. A La Montagne-Verte ${ }^{87}$, une rangée de pilotis de chêne à sabots de fer marque l'emplacement, sur la Bruche, de chantiers de déchargement et de répa-

(83) J. JOACIIM, Bull. soc. belfortaine émul., 1950-51, p. 15-33.

(84) M. LuTz, Les cahiers lorrains, 4, 1952, p. $46-48$.

(85) DU MÊre, ibid., p. 56-60; voir : Gallia, XI, 1953, p. 349.

(86) J.-J. HATT, Cah. d'archeol. et d'hist. Alsace, $\mathrm{n}^{\circ} 133,1952,83-86$; voir : Gallia, XI, 1953 , p. 341 . ration de navires, relevant du port desservant l'agglomération suburbaine de Kơnigshoffen, utilisé jusqu'à la disparition, environ 180, de la route fluviale de la Bruche.

Le tracé de la voie romaine de strasbourg à Lyon, l'une des grandes routes du sel de la Franche-Comté, au passage de la Joue à Cramans (Jura), offre un exemple significatif des changements apportés au cours des âges par des raisons naturelles, économiques ou politiques 88 . Ia nature du terrain a joué aussi un rôle important dans la délimitation de la frontière de la cité des Nerviens, cernée au Sud par la forêt, au Nord par les terres infécondes et inhospitalières de la Toxandrie, à l'Ouest par les marais de l'Tscaut. Ainsi s'explique, malgré la proximité des cités riches et importantes des Rèmes, l'isolement des Nerviens jusqu'aux temps de la conquête des Gaules et les curieuses persistances des survivances celtiques sur ces territoires jusqu'au III $^{\circ}$ s., en fait aussi longtemps que Bavai restera le chef-lieu de la cité $\mathbf{8 9}$.

Reprises au N.-E. de la région précédemment explorée, les fouilles de Raudimont (Pas-de-Calais) ont précisé plusieurs occupations successives sur cet emplacement entre le $\mathrm{I}^{\mathrm{er}}$ et le $\mathrm{III}^{\mathrm{e}} \mathrm{s} .{ }^{20}$.

5. Les sépultures. - Une sépulture à inhumation du $\mathrm{I}^{\mathrm{er}} \mathrm{s}$., dans une urne à panse renflée fermée par un couvercle à bouton, trouvée au quartier de Cavalière (Var), était accompagnée de boucles d'oreilles, de bracelets et de chainettes en or ${ }^{1}$. Au domaine de Gasqué, sur le terri-

(87) P. $\Lambda$ NUET, ibid., p. 89-98.

(88) M. DAYET et P. LEBEL, Rev, archéol. Est, III, 1952, p. 255-260.

(89) F. Falder-Feytuans, L'Antiq. class., XXI, 1952, p. 338-358.

(90) J. Heungon, Gallia, IX, 1951, p. 78-79.

(1) Bull. soc. d'ét. scientif. et litt. Draguignan, XLVIII, 1950, I, p. 13 (p. v.). 
toire de Gonfaron (Var), un manche de couteau, des fioles de verre bleu à long col, une statuette de femme et des monnaies proviennent des tombes du cimetière d'un petit centre rural des $\mathrm{I}^{\mathrm{er}}-\mathrm{IV}^{\mathrm{e}} \mathrm{s} .2$. $\mathrm{Au} \mathrm{\textrm {I } ^ { \mathrm { er } }}$ s. appartiennent les sépultures du quartier des Clots, à Sannes (Vaucluse) ${ }^{3}$. Autour de Saint-Marcel et d'Aulon (Haute-Garonne), de nouvelles recherches ont arnené la découverte, à Sepx, d'une auge funéraire avec les bustes des deux défunts, et d'un buste funéraire de femme à Cap d'Ardets ${ }^{4}$. Ies puits funéraires de Rizières et de Jou Planas, à Saint-Paulien et Bellevue (Haute-Loire), sont vraisemblablement contemporains de la fin du $\mathrm{I}^{\text {er }}$ s. de notre ère 5 . Un peu plus récente est l'incinération trouvée dans un coffre de granit aux Éteules, à Viam (Corrèze)' de même que les sépultures du Jasson à Moustiers-Ventadour ${ }^{7}$. Le cimetière de Lacam à Malemort (Gorrèze) a été utilisé de la fin du $\mathrm{JI}^{\circ}$ au début du $\mathrm{IV}^{\mathrm{e}} \mathrm{s} .8$. Des coffres funéraires en granit ou en gneiss ont été signalés à La Cabane (cne de SaintAugustin, Corrèze) 9 , à Cisternes (cne de Davignac) 10 et à Lachan (cne de Meilhard) 11, et dans la Creuse, aux Buis (cne de Seauve), à Gouzat (cne de Champagnat), aux Châtaigneries (cne de SaintEtienne-de-Fursac) et sur les territoires des communes de Saint-Priest-la-Plaine et de Saint-Sulpice-le-Dunois 12. Dans les dix-huit tombes à inhumation nouvellement fouillées à Voingt (Puy-de-Tồme),

(2) Ibid., p. 18-19.

(3) J. Sautel, Provence hist., 1952, p. 50.

(4) M. Labrousse, Gallio, IX, 1951, p. $13 \mathrm{C}$.

(5) A. Blanchet, Bull. soc. nat. antiq. Fr., 1948, p. 98-99.

(6) P.-F. Foursila, Gallia, IX, 1951, p. 110.

(7) Ibid., p. 110

(8) Ibid., p. 110.

(9) Ibid., p. 109.

(10) lbid., p. 110.

(11) Ibid., p. 110-111.

(12) lbid., p. 111-112. les vases de La Graufesenque sont nombreux ${ }^{13}$. Dans le Lot, au cimetière situé entre la Gironde et Saint-Michel-deGour's, occupé aux III et $I V^{\mathbf{e}}$ s., une sépulture renfermait un crâne, sur lequel une l'ondelle a été prélevée post mortem ${ }^{14}$, et un sarcophage a íté mis au jour à Saint-Iaurent-de-Beauregard 15. En Poitou, la tombe à inhumation du GrandChamp de Lavau à Montmorillon (Vienne), enfermée dans une urne de verre bleu déposće dans un cylindre de grès, est contemporaine des Antonins et précise l'emplacement d'un habitat galloromain 16. Ia tombe d'enfant d'Anché (Vienne), creusée dans une demi-colonne, est assez peu postérieure à l'invasion de 275 et semble appartenir à un cimetiere voisin s'étendant sur le champ du Caieux 17. Dans la Haute-Vienne des sépultures ont été reconnues à Sauviat, à Génébrias et au Mas de Lors, sur la commune de Saint-Junien-les-Combes 18 ; à Chigot (cne de Saint-I_éonard-de-Noblet), deux modes distincts ont étó constatés pour les incinérations, déposées dans les urnes de verre cnfermées dans les coffres en pierre, ou directement mises en terre à môme le sol. Parmi les mobiliers fuméraires figurent un petit buste de femme en terre-cuite, coiffée à la mode de l'époque flavienne, un tesson portant l'estampille de Croescus, et des monnaics de Trajan et d'Hadrien ${ }^{19}$. Le cimetière du Buisson, à Étrechy (Cher)20, a

(13) Ibid., p. 114.

(14) Bull. soc. d'et. litt., scientif. et archéol. Lot, XXVIII, 1952, p. 82-84.

(15) Ibid., p. 87.

(16) F. EYGUN, Gallia, IX, 1951, p. 106-107.

(Ii) lbid., p. 105; - Bull. soc. antiq. Ouest, 1952, p. 63.

(18) Bull. soce. archéol. et hist. Limousin, I.XXXIV, 1952, p. 281, 286, 287.

(19) J. Plimbilisi, ibicl., p. 157-162.

(20) R. Louts, Bull. soc. antiq. Fr., 1950, p. 30-31 el Gallia, VIII-1950, p. 173, ng. 7. 
donné vingt-huit inhumations, quelquesunes superposćes, dans des cercueils de bois et orientées S.S.O.-N.N.E. Les mobiliers funéraires sont pauvres, quelques vases à la tête ou aux pieds, des offrandes alimentaires (os d'oiseaux), quelques verreries. Un grand vase à goulot étroit et à deux anses entre lesquelles est dessinc, à l'ocre brune, un arbre stylisé accosté de deux traits ondés, porte les dédicaces d'Etiona, fille de Carantona, à la déesse Isosa, et de Gnato, fils de Hidua, à Mercure M...ortiumnis. L.e cimetière ćtait utilisé au $\mathrm{IV}^{\mathrm{e}} \mathrm{s}$. par une population campagnarde restée lidele à l'onomastique indigène et à ses anciennes divinités. A Ardillat (Charente-Maritime), au 《Martrais »21, des sarcophages faits de pierres plates juxtaposées ont été exhumés en bordure de la voie antique venant de Châtelaillon. Le cimetière de Gréac'h en Ergué-Armel (Finistère) peut être mis en relation avec le site d'Aquilona (Locmaria) et le poste fortifié du Mont-Frugy 22. Un ustrinum a peut-être été reconnu. Les cendres, dont un certain nombre appartiennent à des enfants n'ayant pas acheve leur ossification, étaient díposées dans des urnes de type biconique ou ovoïde. Le mobilier funćraire était assez pauvre. Les corps avaient été brûlés dans des cercueils de bois, dont le couvercle était peut-ĉtre monté sur des charnières en os. Dans la SeineInférieure, des sépultures ont été relevées à Saint-Martin-le-Gaillard, à Hénouville et à Saint-Jouen-Bruneval 23. On peut se demander si les puits funéraires de la sablière située au sud de Rosnysur-Seine (Seine-et-Oise) sont en partie contemporains de l'époque gallo-romai-

(21) F. EYguv, Gallia, IX, 1951, p. 107.

(22) P. MERLAT, ibid., p. 87-88.

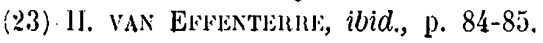

ne 24. Un cimetière à inhumation du $\mathrm{IV}^{\circ} \mathrm{s}$. a été détruit par les bulldozers, lors du nivellement du champ d'aviation de Villaroche, près de Melun (Seine-etMarne) 25. La découverte fortuite d'une sépulture, peut-ĉtre sous caisson de tuiles, constituće par une urne cinćraire en marbre à cannelures concaves et couvercle à bouton, précise l'emplacement d'un cimetière à la périphérie Nord de Sens (Yonne), entre la rivière et la route de Paris 26. Une sablic̀re à Cheny (Yonne) abritait un cimetière utilisé au cours des derniers temps de la civilisation des champs d'urnes, pendant le second âge du F'er et la période gallo-romaine ${ }^{26}$. En Saỏne-et-Loire, une stèle funéraire représentant une fillette assise et tenant sur ses genoux un petit quadrupède, peut-être un chat, a été recueillie à Montceau-les-Mines, le long du tracé supposé de la voie romaine d'Autun à Velleville ${ }^{28}$. Le caractère des stèles et des mobiliers funéraires, en particulier la céramique, des tombes appartenant au dernier s. av. J.-C. et au $\mathrm{I}^{\text {er }}$ s. après, témoignent d'un attachement aux traditions gauloises des populations des pays de Phalsbourg, de Dabo et de Saverne, en contraste avec la rapide romanisation du Pays Messin et de la vallée de la Moselle 29 .

Des inventaires ont été dressés pour les sarcophages découverts dans l'Orléanais et le Loiret ${ }^{30}$. A. Colombet donne

(24) Congrès préhist. Fr., XIII sess., Paris 1950, p. 241-252.

(24) R. LantilR, Bull. soc. nat. antiq. Fr., 1948 , p. 133.

(26) P. Paknuzot, Rer, archél. Est, III, 1952, p. 201-202.

(2i) J. Coudray, ibid., p. 284.

(28) Rerue périod. physsiophile, 1952, p. 50-51.

(29) E. Brldarl), Bull. archéol. Comité, 1950, p. 92 .

(30) Bull. liaison provis. soc. hisl. al archiol. O) léunais, n*19, 1952, p. 8-9. 
la liste des sarcophages en plomb de la Gaule romaine 31.

Après les études d'H. Wuilleumier et de J.-J. Hatt, de nouveau le problème de l'ascin est examiné, en tant qu'instrument et symbole de l'inhumation ${ }^{32}$. Malgré leur ingéniosité, les auteurs ne sont pas encore parvenus à une solution définitive. L'ascia, qui figure sur les tombes, serait l'outil du terrassier et du fossoyeur, la binette. Elle se rencontre d'abord sur une tombe militaire de Dalmatie dans la première moitié du $\mathrm{I}^{\mathrm{er}} \mathrm{s}$., puis en Narbonnaise et en Lyonnaise au temps des Antonins, lorsque l'inhumation revient en faveur. Cette modc dc l'ascia correspondrait alor's à un changement dans les coutumes funéraires. Outil du légionnaire servant au creusement des retranchements, elle serait devenue l'instrument du fossoyeur et le symbole de l'inhumation. Sa présence sur la sépulture désignerait le rite. Je ne suis pas convaincu. Que l'on accepte l'origine orientale pour cette coutume, qu'elle ait une valeur prophylactique, ce sont choses que l'on peut supposer. Mais que l'ascia soit l'instrument caractéristique du légionnaire, puis du fossoyeur, cela ne me semble pas prouvé. On conęoit difficilement l'utilisation de l'ascia travaillant comme une pelle-bêche. Ce n'est pas un outil pour creuser, mais pour le travail du charpentier ou du tailleur de pierre. Une autre difficulté est l'impossibilité d'appliquer la preuve que l'ascia figure exclusivement sur les tombes à inhumation, civiles ou militaires.

6. Arts et métiers. Commerce et industric. - G'est avec regret qu'il faut se

(31) R. LantiEn, Bull. soc. nal. antiq. Fr., 1950, p. 89-90.

(32) P.-L. Couchoud et A. Audin, Rev, hist. relig., 1952, p. 36-66. r'ésigner à ne pouvoir que mentionner, dans cette chronique, l'ouvrage de P.-M. Duval 1 traitant des métiers et des professions, des paysans et des marchands, des loisirs, des croyances et des «pieux devoirs » de ces Gallo-Romains, qui nous ont apporté la première «expression de ce que nous entendons aujourd'hui par la civilisation occidentale ».

Un catalogue récent 2 , bien illustré, s'il ne permet pas de se représenter dans toute son ampleur le décor sculptural d'une ville gallo-romaine, aide cependant à micux comprendre les raisons d'un choix, plutôt reçu que spontané. l'absence, dans les collections lapidaircs du Musée de Vienne (Isère), de monuments se rattachant à la plastique gauloise témoigne d'une romanisation, sinon profonde, au moins générale, et de l'opulence d'une cité assez riche pour, aux beaux jours de l'Empire, acquérir des sculptures grecques et hellénistiques, peut-être aussi faire appel à des artistes étrangers pour le décor de ses édifices. Mais de là aussi la banalité de ces productions qui ne different pas de ce qu'on rencontre alors à Rome et en Italie, monuments triomphaux, grands autels monumentaux.

Les collections du Musée de Chalonsur-Saóne ${ }^{3}$ se sont enrichies de quelques sculptures trouvées en Pays Éduen : pilier en grès gris terminé par une tête humaine d'un modèle celtique répandu en Gaule Orientale; tête d'homme colossale, image d'un dieu sans corps, à ajouter à celles déjà connues de Chorey (Gôte-d'Or) et de Corbridge (Angleterre); l'une et l'autre de ces pièces pourraient

(1) P.-M. Duval, La vie quotidienne en Gaule pendant la paix romaine, Paris, 1952.

(2) E. WILL, La sculpture romaine au Musée lapidaire de Vienne. Vienne, 1952.

(3) L. Armand-Calliat, Gallia, IX, 1951, p. 60-63. 
provenir du Mont Saint-Vincent, oppidum voisin de Montceau-les-Mines; stèle funéraire ornée du buste d'un personnage tenant une coupe et une mappa. Le Musće de Mariemont (Belgique) ${ }^{4}$ conserve des statues ou statuettes trouvées dans les départements de la Côte-d'Or, du Doubs et de la Nievre: Priape de Beaune; Néron en Mercure de Santenay; Mars casqué des environs de Mandeure, postérieur au règne de Commode; déesse de source de Saint-Honoré-les-Bains, la chevelure surmontée d'un diadème, accompagnée de monnaies du Bas Empire. Dans le parc du château de MagnacLaval (Haute-Vienne) 5 est conservée la stèle funcraire d'un marchand ou d'un riche propriétaire; elle porte une tête de Mercure sur la face postérieure. Une description est donnée de quelques-unes des statues de Vichy gallo-romain ${ }^{6}$ : dieu chasseur assis sur un rocher, un chien à sa droite (disparue); dieu au maillet de la rue Callou; hermès double avec deux têtes coupées de la rue Debrest; bas-relief de femme assise; antéfixe du pont sur le Sichon figurant une tête de lion.

De nouvelles interprétations sont proposées pour plusieurs monuments. Une sculpture récemment reconstituée au Musée d'Arles doit être interprétée comme une copie de l'Athéna Héphaistia d'Alcamène 7 , déesse guerrière associée à un Héphaistos, forgeron de la foudre. L'anthémon soutenant le bouclier d'Athéna est en rapport direct avec l'arme de Zeus. Son aspect de fleuron végétal a valu à l'Héphaistia le nom traditionnel,

(4) G. Faider-Feyturans, Rev. archéol. Est, III, 1952, p. 21-24.

(5) F. DelaGe, Gallia, IX, 1952, p. 63-66.

(6) Dr. Monlet, Tourisme, plages et villes d'eaux, Vichy-Cannes, $\mathrm{n}^{\circ} 29$, janv. 1952.

(7) Ch. PICARd. Fontes Ambrosiani, $X X V$, Miscellanea G. Galbiati, I, 1951, n. 19. mais équivoque, d'Athéna à l'acanthe. Ce n'est cependant pas une Ergané, une filandière.

On ne peut plus parler de sculpture archaïque ou pré-classique à propos de la Minerve de Poitiers 8 , cachée lors de l'invasion de 276 dans l'hypocauste d'une villa, dont elle pouvait orner la bibliothèque. Ia comparaison s'impose avec la Minerve du Pnyx et elle ne peut être rapportée à l'époque augustéenne. Pour dater le monument, il faut le replacer dans le milieu moral et politique des Flaviens, en un temps où la dévotion à Athéna se répand dans l'impire. Par contre, ce serait à la propagande augustécnne, vers la fin du troisième quart du $\mathrm{I}^{\text {er }} \mathrm{s}$. av. J.-C., qu'on est conduit à attribuer le buste d'homme trouvé au Viala, près du coude formé par la voie Domitienne entre Béziers et Narbonne avant de s'engager sur la digue de l'étang de Capestang. Jans ce portrait - une image de César 9 - un réalisme de tradition républicaine s'allie à un adoucissement du rendu de certains traits du visage, qui, lui, est augustéen. Ia pièce serait un peu postérieure au Marc-Antoine de Narbonne.

Le sarcophage du musće de Lyon ${ }^{10}$, dans lecuel Fspérandieu retrouvait une représentation du triomphe de Bacchus et d'Ariadne, est plutôt orné d'une scène d'initiation dionysiaque, dont une fresque disparue de la Domus Aurea, à Rome, serait une exacte réplique. C'est ćgalement à tort 11 qu'on interprète comme un jeu de dames, ou tout autre jeu analogue, la tablette posée sur les genoux des deux personnages assis figurés sur un

(8) Du Mêne, Les Amis du musée de Poitiers, nº 6, fév.-avr. 1952, p. 2-7.

(9) F. Braemer, Bull. soc. nat. antiq. Fr., 1948, p. 112-116.

(10) Ch. Perrat, ibid., 1949, p. 225.

(11) Fr. KRETzScmuEn, Trierer Zeitschft., 1951, p. $96-108$. 
bas-relief de Troves (E. 7725). La disposition des baguettes montees sur chevilles et glissant dans des rainures parallèles, portant des indications arithmétiques, caractérise un abaque, et le bas-relief montre deux calculateurs assis maniant la table à calculer; pròs d'eux un personnage debout compte sur ses doigts les quantités enregistrées par l'abaque. In semblable instrument, plus petit et qui devait être tenu ì la main, figure sur un bas-relief de Junkerat.ı (E. 5343).

C'est à une production locale qu'il faut attribuer les petits bronzes, généralement recueillis dans des sépultures, que conserve le musée d'Agen, représentant surlout des divinités gallo-romaines d'une exécution maladroite ${ }^{12}$. Dans la statuette donnée comme un Mars cascqué, J. Carcopino suppose qu'on a voulu représenter un corybante, associé au culte de la Grande Mòre: le porsonnage n'est pas casqué, mais coiffé d'un loonnet phrygien, et figuré dans un mouvement de danse.

Une nouvelle description est donnée d:I buste en argent de Vaison (Vaucluse), portrait d'un personnage de la cité des Voconces 13 , et des compléments sont apportés à rolle de la statue impériale 'uirassée, recueillie dans le «nid» de statues de la rue Segond-Weber à Orange 14. Le thème central montre un Arimaspe en lutte avec deux griffons ailés, héraldiquement dressés de part et d'autre de lui. L'Arimaspe, vôtu à l'orientale d'une robe longue et coiffé du bonnet scytho-phrygien, poignarde dans le ventre le griffon de droite; au-dessus du sujet central, un gorgoneion et une palmette. Le motif de l'Arimaspe et des

(12) M. Durand-Lelibvre, Bull. soc. nat. antiq. Fr., 1951, p. 218.

(13) J. SAUTeL, Mon Piot, 17, 1952, p. 149152.

(14) Ch. PiCard, C.R.A.I., 1952, p. 248-249 griffons est rare : il reparaît sur le torse de Volubilis (Maroc), sur la cuirasse de Turin et sur celle de l'ancienne collection Galimberti; d'autres rapprochements pourraient être encore cherchés à Rhodes et à Rome, et l'examen des motif's portés sur les lambrequins donnerait des dates utiles, la statue étant acéphale.

On peut placer entre les années 11 et 10 avant l'òre la construction du sanctuaire de la Gens Augusta, où prit place, à côté du buste d'Octavie désormais immortelle, le buste de Julie, fille d'Auguste, alors âgée de 28 ou 29 ans, dont les têtes ont été retrouvées à SaintRemy-de-Provence (Bouches-du-Rhòne) ${ }^{\text {15. }}$.

Dans les dragages du goulet de $\mathrm{Ca}$ ront, à Port-de-Bouc (Bouches-du-Rhône!, un sarcophage en marbre de Ciarrare a śté remonté à la surface ${ }^{16}$. Il est décoré de la représentation d'un candélabre accosté de deux panthères, supporté par un autel orné aux angles, en forme de volutes, de têtes de béliers. Sur les côtés, une aiguière ct une patère, un lituus et un aspersoir; sur la panse du candélabre, deux Victoires; sous les flanes du motif supérieur, un bouclier et une lance à gauche, une tête coupée à droite.

L'hermès double, en marbre de Paros, de Bacchus et d'Ariadne, d'inspiration archaique qu'on peut situer entre le $\mathrm{I}^{\text {er }}$ et le $\mathrm{II}^{\mathrm{e}} \mathrm{s}$, est une pièce isolée dans la région des Corbières, entre les montagnes de l'Aude et du Roussillon. Est-ce une auvre d'influence méditerranéenne, ou de tradition indigìne ? Seule la localisation précise de l'emplacement de la découverte pourrait éclairer le problème 17. On peut se demander si la tête de

(15) H. Rolland, Rull. soc. nat. antiq. Fr., 1951, p. 221 ; - J. Carcopino, ibid., p. 223-225.

(16) F. Benolt, Rev. d'él. ligures, XVIII, 1952, p. 249-250.

(17) Gallia, IX, 1951, p. 66-68. 
mort, sur laquelle est posée une main, trouvée à Raray (Oise), est antique 18.

Une statuette d'Isis, brisée à la ceinture, des épis (?) dans les mains a été découverte rue du Général de Gaulle à Coulommiers (Seine-et-Marne)19, et à Melun, une stèle assez grossière montre une figure drapée reproduisant le geste de la Vénus pudique; sur les côtés, deux figures d'animaux 20 .

A la liste des petits bronzes trouvés à Paris on ajoutera celui de deux lutteurs, recueilli rue Lacépède en 1882 , et un disque portant gravée à la pointe l'image des Dioscures, ramassé dans une tombe du $\mathrm{I}^{\text {er }}$ s. au quartier de Port-Royal 21.

Un buste d'homme en argent du Musée de Troyes (Aube) offre une étroite ressemblance avec les deux masques d'argent de Notre-Dame d'Alençon (Maineet-Loire) dont il permet de compléter l'ordonnance des colliers superposés 22. A Brienne-la-Vieille (Aube), des débris de statue appartiennent à un torse d'Hercule 23. Des fragments de sculptures sont signalés dans la Côte-d'Or : à Dijon, rue du Suzon 24 , remployé dans un encadrement de fenêtre, torse d'un personnage, tenant le poculum; dans un mur à Freignet, femme avec un attribut difficile à préciser, épi, palme ou torche ${ }^{25}$; à Rochefort - sur-Brévon, sur l'entablement d'un autel funéraire se rattachant par son style au groupe sénonnais, deux per-

(18) G. Matherat, Bull. soc. nat. antiq. Fr., 1951, p. 187.

(19) Le Figaro, 28 oct. 1952.

(20) A. Piganiol, Gallia, IX, 1951, p. 83.

(21) M. Durand-LeFebvre, Bull. soc. nat. antiq. Fr., 1948, p. 105.

(22) R. Lantier, ibid., p. 104-105.

(23) G. GroLey, Rev, archéol. Est, III, 1952, p. $277-278$.

(24) G. GrÉmaud, Mém. comm. antiq. Cote d'Or, XXII, 3, 1952, p. 460.

(25) $\Lambda$. Colombet, Bull. soc. nat. antiq. Fr., 1949 , p. 62. sonnages drapés 20 ; on ignore le sort de la petite tête de femme, la chevelure ramenée en un chignon sur la nuque, trouvée, vers 1912, aux Morvandiot à Fresnes 27.

I. Armand-Calliat décrit une statuette de Vénus Anadyomène, de Collonges-enCharollais (Saone-et-Loire), et souligne le rapport de ces figurines avec le culte des eaux 28; un ex-voto de malade, buste d'homme barbu aux cheveux longs, trouvé dans une ruine à Sercy ${ }^{29}$, et un chenet de terre-cuite de Cortevaix $\mathbf{3 0}$ terminé par une tête de bélier, les yeux et le pelage stylisés en ornements géométriques, sont l'un et l'autre conservés au Musée de Cormatin.

J'ai signalé 31 la présence, dans le commerce parisien des antiquités, d'un «brasero» de terre-cuite, ayant appartenu aux collections G. Loustau et Hamonic. Ia pièce, en forme de haute boite pentagonale, est surmontée d'un couvercle, dont le bouton est fait d'une statuette de femme ayant pu appartenir à une figurine de terre cuite. A l'extérieur, sont ménagées cinq niches abritant les statuettes d'Apollon, de Vulcain, de Minerve, de Mercure et d'une Abondance. Si l'authenticité des figures est certaine, il en est autrement de leur support dont les colonnettes et le décor ont été obtenus par surmoulage d'éléments empruntés à un meuble, tel un secrétaire du milieu du siècle dernier. On est en présence d'un « arrangement » moderne éta-

(26) R. LANTIER, ibirl., 1950, p. 125-126.

(2i) Countois, Mém. comm antiq. Cote d'Or, XXII, 3, 1952, p. 501.

(28) Rev. periodq. la physiophile, $\mathrm{n}^{\circ \mathrm{s}} 33-34$, 1952, p. 35-36.

(29) Mem. soc. d'hist. et d'archeol. Chalonsur-Saône, XXXIII, I, 1952, p. 30-31.

(30) Ibid., p. 31.

(31) R. LavTiER, Bull. soc. nat. antiq. Fr., 1950, p. 89-90. 
bli pour servir de cadre à des statuettes relevant des productions des ateliers de la Gaule Orientale. Le catalogue de la vente Loustau (p. 6, no 11) donne la description d'un second «brasero» disparu.

J. Perrier 32 apporte des précisions sur la mosaĭque découverte, environ $1740, a ̀$ Condat-sur-Vienne (Haute-Vienne) et publie le dessin du pavement à décor géométrique exécuté en 1769 sur l'ordre de 'Turgot.

Les mosaïcues de Saint-Romain-enGal, de Zliten et de Boscéaz sont des documents importants pour la représentation des mois dans l'iconographie galloromaine 33 , thème en faveur dans un pays essentiellement agricole comme la Gaule. Dans les images que l'on croyait pouvoir interpréter comme des scènes de chasse, il serait plus exact de voir les mois personnifiés par les travaux des champs, rentrée des provisions, chasse aux oiseaux (novembre), rentrée des troupeaux (octobre). Ces figurations doivent être rapprochées des données fournies par la littérature de la fin de la République et du début de l'Empire.

Des documents intéressants sunt apportés à l'histoire des matériaux de construction par l'examen des pierres, briques et mortiers du « Palais des Thermes » à Paris ${ }^{34}$. Les blocs de pierres ont été extraits des carrières du fond d'Arcueil-Cachan, de Bagneux ou de Clamart. La composition des briques est très proche de celles qui sont employées de nos jours. Quant à la valeur du mortier, elle est fonction du soin apporté à sa fabrication, de la qualité des matériaux choisis, peut-être de son aptitude à durcir avec le temps, malgré une teneur en

(32) Bull. soc. archéol. et hist. Limousin, IXXXXIV, 1952, p. 163-168.

(33) H. STEn, Gallia, IX, 1951, p. 21-30.

(34) A. Desguine, ibid., p. 57-64. chaux inférieure à celle des ciments modernes.

Un examen direct de l'œnochos de bronze doré à portrait de reine de SaintRemy-de-Provence 35 permet de préciser que la princesse lagide représentée en buste sous l'anse tenait bien au creux du bras gauche une double corne d'abondance, dont les extrémités étaient réunies et serrées par la main droite. Ce détail confirme, de façon précise, l'attribution, précédemment proposée, pour l'identification du buste avec une image d'Arsinoé II en Agathé Tyché. De l'art alexandrin relève aussi une coupe en argent trouvée aux Fins d'Annecy (Haute-Savoie) au début de ce siècle et décorée du trident de Neptune soutenu par deux griffons affrontés et d'un faisceau de foudre ${ }^{36}$.

Tes patères d'Amiens ${ }^{37}$ et d'Auxerre $\mathbf{3 8}$ ont été l'objet de nouvelles recherches. $\mathrm{Au}$ lieu de la représentation d'un petit édifice sur le second de ces récipients, on pourrait aussi bien y voir celle d'une outre de cuir ou d'une bonbonne d'osier, pourvue d'un double système de suspension.

Poursuivant ses études sur les représentations de navires dans l'iconographie antique, P.-M. Duval 38 donne une description détaillée des barcques en bronze de Blessey (Côte-d'Or) et de Cerveau (Saône-et-Loire), rattachant la première au groupe des grosses embarcations fluviales. La seconde, à fond presque plat, offre des proportions plus exactes et

(35) Ch. PICARD, Rev. archéol., 1952, I, p. 110-111.

(36) Dr. P. BIScH, Rhodania, 24, 1948, p. 2932. 115.

(37) J. HEURGON, Mon. Piot, 46, 1952, p. 93-

(38) J. Ilarmand, Rev. archéol, 1952, 2, p 101-102.

(39) Rev. archéol, Est, III, 1952, p. 233-243. 
pourrait peut-être représenter un modèle en réduction.

$\mathrm{Au}$ dossier des problèmes toujours en suspens, on ajoutera: un essai d'interprétation des dodécaèdres «celto-romains », objets symboliques qui auraient été utilisés pour la divination ${ }^{40}$, et dont l'aire de répartilion s'étend au Nord d'une ligne Poitiers-Lyon-Bâle. Les recherches de L. Armand-Calliat 41 sur la ferrure à clous et ses origines on Charollais, où des fers à chevaux ont été ramassćs associés à des armes et à des poteries des VII $^{\mathfrak{e}}$ et VIII $^{\mathrm{e}}$ s., laissent entrevoir le rôle des Barbares dans la dispersion de la ferrure du cheval. D'autres fers ont été recueillis sous un remblai de grès d'époque gallo-romaine, associés ì des hipposandales, dans un milieu du $11^{\circ}$ s. à Sens (Yonne) ${ }^{42}$. Pour les cylindres en os tournés et percés de trous, l'interprétation en tant que charnières de coffrets ou de petits meubles parait enfin s'imposer : 18 de ces cylindres ont été trouvés, munis de leurs goupilles, dans un puits de Saint-Remy-de-Provence 43; on nous donne le catalogue des 202 cylindres trouvés dans les ruines de Vertault (Còte-d'Or) ${ }^{44}$.

La découverte des ivoires de SaintLoup-de-Comminges (Haute-Garonne) ${ }^{45}$, que l'on peut comparer à ceux de Beauvais, du théâtre de Vienne, de Martres'Tolosane, de Dorflingen (Suisse), et qui par les sujets représentés, Jupiter Sara-

(40) Lisonard SAINT-MICHeL, Lettres d'humanité, 1951, p. 92-116.

(41) Mem. soc. d'hist. et d'archeol. Chalonsur-Saône, XXXIII, 1952, p. 14-15.

(42) 1. Parruzot, Rev. archeol. Est, III, 1952, p. 284-285.

(43) H. Rolland, Bull. soc. nat. antiq. Fr., 1950, p. 33-37.

(44) P. PARIs, Rev. archeol. Est, III, 1952, p. 284.

(45) J. Fouet et M. LABrousse, Mon. Piot, 46,1952, p. $117-129$. pis, Satyre et Ménade, Attis, têtes juvéniles, pugilistes arrêtés par l'arbitre, rajppellent les plarpuettes d'ivoire des cimetières d'Alexandrie, fournit une documentation importante à l'étude des fabrications artisanales de coffrets au

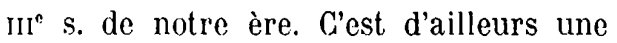
des caractéristiques de l'industrie galloromaine que la multiplicité des ateliers d'artisans à travers le pays : fabricants de patères de bronze, installés à Chalonsur-Saône ${ }^{46}$; bronziers travaillant à Vertault, spécialisés, à ce qu'il semble, dans les bronzes ornementaux pour les meubles ${ }^{47}$; émailleur's de la Meuse, dont les fibules zoomorphes ont été recueillies n Bourgogne à Vertault 48 et au Bolar ${ }^{49}$, en Lorraine à Flvange 50 ; fours de verriers du Namurois, dont les «services » funéraires se retrouvent dans les sépultures de Firzet, d'Avesnes, de Walsbetz à la fin du $1^{\text {er }}$ et au début du I $^{\circ}$ s. ${ }^{51}$; briqueteries et tuileries fournissant les Tongres et les Nerviens 52 au $\mathrm{II}^{\mathrm{e}}$ s.; fabrique de tuyaux de plomb de T'(itus) Atei(us) Ing(cnuus) a Vienne 53; fonderies de fer à SaintChéron (Seine-et-Oise) ${ }^{54}$ et dans la région de Bourguin (Isiren), ou les potiers Catissus, Mareus, Martinus ont apposé leurs

(46) L. Armand-Calliat, Mém. soc. d'hist. et d'archeol. Chalon-sur-Saône, XXXIII, 1952, p. 23.

(47) R. Jorrroy, $\mathrm{XX}^{\mathrm{e}}$ congrès assoc. bourguign. soc. sar., Semur 1949, p. 94-95.

(48) R. PARIs, Bull. soc. hist. et archéol. Chatillonnais, 1951-52, p. 83-86.

(4) A. Coroniset, Bull. archéol. Comité., 1950, p. 177-182.

(50) E. Bengthol, Les cahiers lorrains, 4 , 1952 , p. 5-8.

(51) G. Faider-Feytuans, Études d'hist. et d'archeol. namuroises dédies a Ferdinand Courtoy, Namur, 1952, extrt.

(52) H. BiÉviLet, ibid., p. 83 sqq.

(53) J. RuF, Rhodania, 1943, p. 36-40.

(54) A. Pigantor, Gallia, IX, 1951, p. 83.

(5i)) J. (Haverw, Érocations, 1951, p. 836- 
mar'ques circulaires sur des céramiques à pâte gris ardoise assez sombre, contrastant avec celles de la sigillée claire mćditerranéenne, aux $\mathrm{II}^{n}$ et $\mathrm{III}^{\mathrm{e}}$ siècles ${ }^{50}$; centre important de fabrication de poteries communes en forêt de Lyons (Eure) ${ }^{57}$. Les officines de Vichy ont joué un grand rôle aux origines de l'histoire céramique de la Gaule romaine. Il n'est guère de fabrications qu'elles n'aient tentées et réussies 58 : vases à glaçure plombifère, à pâte claire, au moins dès le $\mathrm{I}^{\mathrm{er}} \mathrm{s}$. de notre ère; poteries rouges sigillées, au cour's de la seconde moitié du II ${ }^{\mathrm{e}}$ s., d'une teinte moins foncée que celles de Lezoux, exécutées dans les ateliers d'Advocisus, Cinnamus, Decmus ou Decmanus, et dont les décors s'inspirent du vieux répertoire gaulois (serpent cornu); vases à reliefs d'applique, procédé déjà utilisé pour l'ornementation des poteries à glaçure plombifère, représentant les dieux de l'olympe, des scènes homériques (combat d'Hector et d'Ajax devant les vaisseaux), des masques de Pan ou de grotesques, des gladiateurs; enfin des céramiques à décor incisé ou guilloché.

Les ateliers de la vallée du Rhòne, en particulier à Lyon et à Vienne, ont repris aux officines de Vichy la tradition des vases à reliefs d'applique ${ }^{50}$. Ces productions se recommandent par leur unité : des médaillons circulaires moulés, modelés à la cire, appliqués à la barbotine sur la panse de certains vases, principalement entre 70 et 170 ap. J.-C., et peut-être plus tard encore. Les prototy-

(50) Du MEMe, ibid., p. 867-870, 920, 934.

(57) H. van Effenterre, Gallia, IX, 1951, p.

(58) Dr. $\Lambda$. MORLET, Tourisme, plages et villes d'eau, février, mars, avril, mai, aout 1952.

(59) P. Wuildeumier et A. Audin, Les medaillons d'applique gallo-romains de la vallee $d u$ Rhône, Annales Univ. Lyon, $3^{e}$ sorr. Lettres, fasc. 42, Lyon, 1952. pes sont à rechercher en Grèce, d'où la mode de ces décors est passée à Tarente, en Campanie, à Calès, à Ostie, en Étrurie. Déjà nxé en Grèce au Iv $v^{c}$ s., le répertoire, qui subira peu de modifications, fait une place importante à la religion, aux thèmes mythologiques, aux scènes historiques, agonistiques avec prédominance, en Gaule, des combats de gladiateurs. Très en faveur auprès des GalloRomains - on les retrouve dans l'ornementation des lampes et des moules à gâteaux - furent les représentations de raractère érotique, et là on se demande par quelle pudibonderie, qui d'ailleurs n'a rien à faire avec l'archéologie, les auteurs ont de leur propre chef supprimé toutes les reproductions graphiques des pudenda. C'est vouloir oublier que tout document doit être intégralement publié. Ces ouvrages ne sont pas, d'autre part, destinés à figurer sur les rayons de la bibliothèque d'un pensionnat pour 《jeunes demoiselles ». Et puis de telles représentations n'avaient pas le caractère que nos contemporains leur appliquent. Objets de cadeaux, mais aussi copies à bon marché d'argenterie, ces vaisselles s'adressaient à une clientèle dont les goûts artistiques ne dépassaient pas la qualité des inscriptions aussi choisies que celles figurant sur nos assiettes et nos cendriers. Si l'on connait les noms de quelques-uns de ces fabricants, Amator, Apollo, Apollinaris, Folir, Latinus, il est bien diflicicile d'attribuer à l'un ou à l'aultre la paternité de tel ou tel vase, tant les procédés ont été souvent démarqués. Aux influences du vieux fonds celtique se rattache directement le médaillon à l'image de Succllus ${ }^{60}$, accompagné de l'inscription Sucellum propitium, bonhomme coiffé du pileus, vêtu du sagum à manches

(60) A. Aunis, Bull. soc. nat. antiq. Fr., 1949 , p. $196-197$. 
courtes et d'un pantalon, tenant l'olla et le maillet, un loup à sa gauche, un arbuste à sa droite.

Très importanle est, au ir s., l'expansion, le long de la frontière septentrionale de l'Empire, des poteries fabriquées dans les officines de Montans, de Banassac et de Iua Graufesenque 61. Parmi ces exportations figuraient des gourdes circulaires à deux anses, ornées de feuillages, de décors en S, d'un lion courant dans un médaillon, exécutées à La Graufesenque, vraisemblablement par Secundus, environ 65-85, qui ont été recueillies en Hollande, à Nimègue et à Vechten, ainsi que sur le Rhin dans une sépulture du cimetière de la Bleichstrasse à Weisenau, près de Mayence ${ }^{62}$. Les fouilles de ce même atelier de La Graufesenque ${ }^{63}$ ont fait apparaitre deux autres poincons, Bellérophon s'emparant de Pégase et le motif déjà connu du cerf les jambes repliées sous le corps, ainsi que deux graffites mentionnant deux potiers travaillant en association, Vedrullus et Secundus. L'examen des autres graffites fait connaître un compte de potier sur fond de plat. des noms de fabricants, sur poinçonsmatrices, Crucuro, Fronii ou Fronici, et une formule qui n'a rien à voir avec un compte, invitation à boire ou autre. Ces potiers de La Graufesenque, à la fin du $\mathrm{I}^{\text {er }}$ ou au début du Il ${ }^{\circ}$ s., ont exporté leurs céramiques en Bourgogne où les marques de Vitalis, d'lrbanus, de Cintusmus ont été relevées aux Bolars (Côte-d'Or). On constate, à peu près dans le même temps,

(61) R. KNonn, Terra sigillata Gefässe des ersten Jahrhunderts mit Töpfernamen. Stuttgart, 1952.

(62) F. Frmensdorf, Mainzer Zeitschrift, 46-47, 1951-1952, p. 13-17.

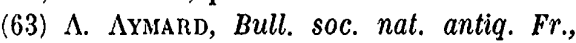
1951, p. 169-170; - R. E. A., LIV, 1952, p. 93101 ; - I. BalsaN, Rev. Rouergue, 6, 1952, p. 384-385. que les officines de Lezoux répandent leurs productions dans l'Aube, à Fontaine-Mâcon ${ }^{64}$, et on a retrouvé à Gienle-Vieux, sur la Loirc, la marque de Doeccus 65 .

La découverte de nouveaux fours à augets sur le littoral morbihannais cot, à Saint-Gildas-de-Rhuys, à Port-Navalo, à Jocmiquel, à Larmor-Baden, à La Trinité-sur-Mer, à l'Ile aux Moines, à I.ogeo, précise l'importance de l'industrie du sel, d'origine gauloise, mais qui se poursuit à l'époque romaine. A l'aire d'expansion de la céramique d'Argonne, décorée à la molette, on doit ajouter les tessons conservés au Musée de Namur (Belgique) ${ }^{67}$.

A propos des découvertes de CastelRoussillon, G. Claustres 08 donne une liste des vases arrétins, trouvés récemment en Gaule : gobelet avec groupe de danseuses, à Clermont-Ferrand; scòne de théâtre sur un vase de Castus à Gergovie; danseuse sur un tesson du Cayla; tête de bouc d'un modiolus et tesson avec animaux à Narbonne.

On se préoccupe toujours de rechercher les moyens de daler rertaines poteries communes, et. $\Lambda$. Blanchet 00 attire l'altention sur les rapports chronologiques à établir entre les monnaies enfermées dans un vase et celui-ci. Il appuie sa démonstration en signalant deux vases, l'un de Tòtes (Seine-Inféricure), l'autre de Beaufort (Isère), qu'on peut ainsi

(64) J. Coudray, Rev. archéol. Est, III, 1952, p. 129-130; - G. Gaudron, ibid., p. 276-277. (65) H. HouzE், Bull. soc. archéol. et hist. Orléanais, XXII, 1944, p. 3-4.

(66) Y. Coppens, Bull. soc. polym. Morbihan, 1951, p. 92-94.

(67) J. MaRTin, Ann. soc. archéol. Namur, XLVI, 1951, p. 73-99; - Cf. Gallia, VIII, 1950, p. $55-56$.

(68) Etudes roussillonnaises, II, 1952, p. 169-171.

(69) Bull. soc. nat. antiq. Fr., 1949, p. 245. 
dater des années 270 ap. J.-C. A leur tour, les céramiques, principalement les restes de cols et de lèves d'amphores, apportent de très utiles critères à la datation des sites gallo-romains $\mathbf{7 0}$.

I a répartition de marchandises aussi fragiles que les verreries s'ordonne en partie le long des grandes artères fluviales; principalement dans les vallées du Rhin et du Danube. Tel est le cas pour la dispersion des gobelets, canthares à pied, amphores, bouteilles et seau de verre, dont le décor, obtenu par tailles profondes dans l'épaisseur de la matière, est emprunté à la mylhologie, à la légende, aux jeux de l'amphithêatre et aux sujets de genre. Exécutés, au milieu du $\mathrm{II}^{\mathrm{c}} \mathrm{s}$., dans un atelier de Cologne, ces verres ont été distribués dans les villes du Rhin, du Danube, de la Save et, vers l'Ouest, on les trouve à Reims et à Étampes. Ils sont arrivés en Angleterre, à Rome et jusqu'en Orient 71.

Les inscriptions laissent entrevoir les intermédiaires de ces transports. C'est ainsi que la corporation des Transalpini et des Cisalpini, qui devait avoir des bureaux à Avenches (Suisse), dans un complexe de locaux semblable au forum des corporations à Ostie, assurait le transport des produits de la Gaule méridionale par le Rhône et à travers la Suisse, ou des marchandises en provenance italique par le lac de Côme, puis par Bregenz 72. Le rôle des traficquants italiens dans l'Occident latin a fait l'objet d'un mémoire de diplôme d'études supérieures d'histoire 73. La proximité de la voie fluviale

(70) E. Thevexot, Rer. archéol. Est., III, 1952 , p. 158.

(i1) F. Freirersdorf, Figürliche geschlifene Gläser. Ein Kölner Werkstatt des Ill. Jahrhunderts, in Röm.-germ. Komm. d. deuts. arch. Instiluls, Röm.-Germ. Forschungen, B. 19. Berlin, 19:5l.

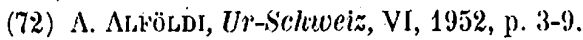

(73) Cl. Pouzol, Fac. Lellres Paris, 1952. n'est pas sans expliquer l'importance, aux II" ct III $^{\mathrm{e}}$ s., des fabriques de céramiques dc Rhcinzabcrn et d'Heiligenberg, qui travaillaient pour l'exportation ver's les pays danubiens 74. Il n'en fut pas autrement des modalités de la répartition des chaudronneries celtiques, romaines et du Haut Moven âge, en Finlande, en Scandinavie, en Irlande et en Europe occidentale $\mathbf{7 5}$ et centrale $\mathbf{7 6}$, depuis leurs .centres de rabrication en Grande-Bretagne et en Gaule. On constate la survivance en Gaule septentrionale et en Belgique, accompagnant des chenets et des trépieds dans les tombes nerviennes du ${ }^{\circ}{ }^{\circ}$ s., de chaudrons à anneau mobile et corps de fer, avec un fond de laiton. Ces transports multiples impliquent l'existence de routiers, dont le reflet peut être conservé par un document, comme la Table de Pcutinger, qui semble se référer à des documents très anciens, sur lesquels étaient portées des voies mixtes de batellerie et de portage $\mathbf{7 7}$, itinéraires de caravanes à l'origine empruntant des tronçons différents pour se rendre aux lieux de foires ou dans les villes. Certains points du territoire étaient alors appelés à jouer un ròle important du fait de leur position sur lia carte, tel le site de Cahors à la limite de la Comata, de l'Aquitaine et de la Province.

Le probleme de l'introduction du vin, puis de la viticulture en Gaule est lié aux questions relatives à la circulation fluviale et maritime. I.es Gaulois qui avaient ignoré la vigne et le vin jusqu'au moment de leurs contacts avec les marchands méditerranéens, ne tardent pas à compler

(74) H. HeInz, Bull. facul. Lettres Strasbourg, 1951, p. 176.

(75) C.F.C. HAWKES, Essays presented to D.G.S. Crawford, p. 172-199. Londres, 1951.

(76) G. Faiden-Feytmays, L'antiq. class., 1952, p. 409-411.

(ii) P. BarRike, R.k.4., LIV, 1952, p. 102108. 
parmi leur's meilleur's clients. De précieux renseignements sont apportés sur les modalités de ce commerce par les découlvertes faites dans les navires naufragés en bordure du littoral de la Méditerranée et dont les cargaisons étaient composées d'amphores vinaires 78. L'épave d'Anthéor' fournit un des premiers jalons datés de l'histoire de ce commerce du vin italien vers la Gaule, au début du $\mathrm{I}^{\mathrm{er}} \mathrm{s}$. avant l'ère. La marque, en caractères osques, portée sur le bouchon de l'un de ces récipients ${ }^{79}$, fait connaitre le nom des Lassii, grands négociants exportateurs de vins, installés à Pompéi ct à Sorrente. au temps de la prospérité du vignoble campanien. La conquête de la Narbonnaise avait eu pour effet d'assurer la diffusion de la vigne en Gaule et d'élargir les rapports commerciaux entre les producteurs italiens et les consommateurs indigènes $\mathbf{8 0}$. Dès les premières décades qui suivirent l'annexion, et probablement avant, les habitants d'Alésia font venir des vins d'Italie et de Sicile ${ }^{81}$, et cette importation se poursuit au $\mathrm{I}^{\mathrm{er}}$ s. ap. J.-C. Il n'est pas exclu qu'à cette époque les vins de Narbonnaise soient arrivés jusqu'en Bourgogne. Vers la fin du même siècle, les essais d'implantation de la vigne semblent avoir donné en Bourgogne des résultats concrets $8 \mathbf{2}$, et au milieu du siecle suivant un grand vignoble est en pleine production, grâce aux aptitudes particulières de la cote bourguignonne. I'archéologie garde le témoignage des changements ainsi ap-

(78) J. Braener, Bull. centre d'et. sousmarines, $\mathrm{n}^{\circ}$ 1, 1952, p. 4-8; - Bull. soc. nat. antiq. Fr., 1951, p. 154-155.

(79) J. Heurgon, La Parola del passato, XXIII, 1952, p. 113-118.

(80) G. Galtier, Bull. anc. élèves école sup. commerce Montpellier, $\mathrm{n}^{\circ}$ 207, 1951.

(81) E. THEVENOT, $X X^{\mathbf{e}}$ congrès assoc. bourg. soc. sav., Semur, 1949, extrt.

(82) Du MEME, Annales Bourgogne, XXIV, 1952, p. 245-257. portés dans l'économie de la contrée. Alors que disparaît l'amphore vinaire, de type allongć, se multiplient dans les sites du $\mathrm{II}^{\circ} \mathrm{s}$. les amphores à panse renflée et quinze estampilles précisent l'origine espagnole du contenu de ces récipients, huile, olives 83. Un graffite avant cuisson sur une amphore des Bolards (Côte-d'Or) précise la quantité, 6 boisseaux, 14 setiers, de la denrée expédiée d'Espagne ${ }^{84}$. L'huile et les olives de Bétique remplacent, en Bourgogne, les vins d'Italie. Une marque sur amphore d'Autun 85 fait connaître le nom de l'un de ces fournisseurs d'huile de Bétique, appartenant à la farnille des Aelii Optati, négociants exportateurs travaillant, environ 160, dans la région d'Astigi (Ecija, Espagne).

Il semble bien que le grand développement atteint par la viticulture bourguignonne 80 soit, pour une large part, le ré-sultat des efforts faits par les grands propriétaires fonciers pour remédier par la vigne au désavantage subi du fait de leur éloignement des grandes voies navigables, en particulier sur les territoires qui, à la fin des temps gallo-romains, relevaient immédiatement d'Autun, la côte de Nuits et la Còte de Beaune. Sous le Haut Empire, bon nombre parmi les personnages pourvus des ressources nécessaires à la création d'un domaine viticole étaient revêtus de fonctions administratives ou honorifiques les obligeant à demeurer dans les chefs-lieux des civitates, et c'est ainsi que s'établit entre l'idée de métropole et celle de vignoble de qualité,

(83) Du Même, Rev, archéol. Esl, III, 1952, p. 224 .

(84) Du MêMe, Bull. soc. nat. antiq., Fr.. 1949 , p. $187-188$.

(85) Du MÊME, Archivo españ. de arqueol., 1952, p. 225-231.

(86) R. Dion, Annalcs, Économies, Sociétés, Civilisations, 7, 1953, p. 1-12; - Bull. assoc. géographes fr., 1951, p. 128-133; - E. THÉVÉNoT, Rev. archéol. Est, II, 1951, p. 151. 
l'étroite association qui retiendra encore l'attention de Grégoire de Tours. L'inégalilé reconnue des crûs de la Cole de Beaune et des crûs de la Côte chalonnaise répond à l'inégal intérêt que les civilisations d'Autun et de Chalon ont porté à la viticulture.

Ia proximité d'une grande voie navigable est à l'origine de la formation du vignoble de Bordeaux ${ }^{87}$, qui marque sur le cours de la Garomne un point singulier ne tenant ni à la nature des sols, ni aux propriétés du climat : en un temps où la Jocomotion mécanique est inconnue, la présence d'une grande artère fluviale menant à la mer incitait les navires à venir chercher un vin qui se vendait si cher dans les pays du Nord. Parmi les vignobles nés en France du commerce maritime, celui de Bordeaux se distingue par sa haute antiquité. Il est le seul mentionné par la littérature gréco-romaine, le seul dont les Anciens aient indiqué l'origine. Si Strabon n'en parle pas encore, c'est qu'au temps de T'ibère la vigne est encore impuissante à dépasser les limites de l'olivier et confinée dans la Narbonnaise. Mais elle ne tardera pas à avancer le long de deux voies naturelles, le couloir rhodanien et le seuil de Naurouze, par lesquelles le vin méditerranéen est exporté vers la Gaule centrale et septentrionale. Mais le transport coute cher, et pour diminuer. les frais, il est indispensable de rapprocher le vignoble du marché. Un fait economique apparait alors, l'association du vigneron et du potier, à Montans, près de Gaillac-sur-Tarn, premier exemple d'une viticulture commerçante dans le bassin aquitain. Et, là encore, ce n'est pas le hasard qui a présidé au choix du site où se fait le contact entre les deux industries: Gaillac marque

(87) R. Dion, La Revue des Deux-Mondes, 15 oct, 1952, p. 672-685. le point à partir duquel la navigation fluviale peut descendre jusqu'à la Garonne, c'est-à-dire à l'Océan. Si la création du vignoble de Bordeaux fait pendant à celle du vignoble bourguignon, les modalités n'en sont pas les mêmes; inventée en Bourgogne, la viticulture a été importóe chez les Bituriges. Mais à son tour le Bordelais ajoutera à la nomenclature des cépages romains un élément nouveau, la Biturica.

7. Religion. - Deux dédicaces et un fragment d'autel a Mercure ont été trouvés à Villars ${ }^{1}$. Quant à la dédicace de Douarnenez (Finistère), elle doit être lue : Neptuno H(espcrio), c'est-à-dire à Neptune occidental, ou mieux à Neptune de la Mer Occidentale 2.

Les documents du culte de Vulcain sont particulièrement abondants en Lyonnaise, en Belgique et dans les deux Germanies, où il succède à un dieu forgeron, celte ou germain, témoignant de l'importance accordée aux industries du métal dans la Gaule indépendante. Aux côtés de Mercure, dieu des arts et du commerce, et de Minerve qui veille aux travaux de fabrication, Vulcain représente le technicien par excellence, dans un pays renommé pour l'habileté de ses forgerons ${ }^{3}$.

Un peu partout, jusqu'en Occident, Hercule est le compagnon de Bacchus. Un nouvel exemple du contact entre ces divinités est apporté par l'interprétation que propose $\mathrm{Ch}$. Picard ${ }^{4}$ du contenu de la cachette de Neuvy-en-Sullias (Loiret) où, comme à La Bussière-Étable (Hte-Vienne) on est en présence du mobilier d'une très riche sépulture, ayant abrité un char fu-

(1) J. SAUTEL, Provence histor., 1952, p. 50.

(2) P. Merlat, Gallia, X, 1952, p. 67-75.

(3) P.-M. DUYAL, ibid., p. 43-57.

(4) Ch. PiCARD, C.R.A.I., 1952, p. 415-416; Bull. liaison prov. soc. hist. et archéol. orléanais, oct. 1952, p. 2-3. 
néraire, auquel appartient la statuette d'applique, en bronze, d'un petit Hercule tenant la massue et les pommes d'or des Hespérides, dans un entourage de feuilles et de branches de lauriers. Isa figurine, de caractère dionysiaque, devait garnir le fronton du char, emprunté par les prévilégiés dionysiaques pour accomplir le voyage d'outre-tombe sous la protection de leur dieu. Les « chars Thraces» relevent de la même coutume, répandue d'une extrémité à l'autre de la Méditerranée, au Nord comme au Midi (Banasa, Volubilis). C'est aussi dans une sépulture, postérieure à l'année 267, que fut recueillie, au Thuit (Eure) la petite statuette de Bacchus à la panthère, œuvre du $\mathrm{II}^{\mathrm{e}} \mathrm{s}$. ayant décoré un trépied, conservée dans les collections de la Walters Art Gallery, à Baltimore 5 .

Il reste difficile d'interpréter le caractère de la divinité représentée sur la stèle de Fraignot (Côte d'Or). Cependant le caractère flottant du vêtement fait penser à l'image d'une victoire plutôt qu'à une figure de Cérès, et l'attribut fusiforme ser'ait alor's une palme el non des épis 0.

Peut-être sera-t-on amené à établir des contacts entre le culte des Matres et celui de Vénus, non seulement en tant que déesse de la fécondité, mais aussi comme divinité funéraire. Pareil rapprochement s'appuie sur une statue de Vénus, trouvée en 1948 à Wessen (Limbourg belge) 7 . Il semble que cette polyvalence s'attache aussi aux dieux orientaux. C'est aussi que dans un pays de vignobles, la Bourgogne, dans les sanctuaires de Mithra, à Entrains, à Nuits, aux Bolards, centre de vieux cultes apolliniens près des eaux salutaires,

(5) Dorothy K. HILL, Gallia, X, 1952, p. 3142 .

(6) $\Lambda$. Colomber, Bull. soc. nat. antiq. Fr., 1948-9; p. 162, 191.

(7) J. Vyrmaseren, Latomus, XI, 1951, p. 6366. on est tenté de mettre le culte du dieu en rapport avec la vigne et le vin ${ }^{8}$. Ce qu'on connaît de l'iconographie mithriaque ne va pas à l'encontre de cette tentative d'interprétation : Mithra naissant du rocher, une grappe de raisins à la main (Rome); Sol offrant à Mithra une grappe de raisins (Heddernheim); dadophore présentant à Sol et à Mithra un rhyton de vin (Fiano Romano); Sol et Mithra représentés avec un rhyton de vin (Troia, Portugal); association du taureau, du figuier, de l'épi de blé et de la vigne sur un autel de Séville. Des textes font aussi état de cette association, signalant, en Italic, les contacts étroits de prêtres mithriaques avec le culte de Liber Pater et, à Doura, dans les comptes du Mithraeum, figure une jarre de vin. L'ensemble de ces documents se présente comme le reflet d'une même mystique mettant Mithra, suivant les latitudes, en relation avec la vigne et le blé, ces deux éléments essentiels de la nourriture corporelle et spirituelle des hommes. Quelques précisions sont apportées sur le mobilier cultuel de l'un de ces sanctuaires, Les Bolards : fibules, rouelles, croix 9 .

Le culte de Cybèle n'a pas connu une moindre fortune. La présence de deux Attis funéraires dans le rempart romain de l'Institut Catholique à Toulouse, rapprochée de la découverte d'autres monuments d'Attis en pays toulousain et dans la muraille de Narbonne, témoigne de l'extension de cette dévotion dans la Gaule méridionale, où elle fut introduite par des Orientaux. Son succès pourrait s'expliquer par les possibilités ofrertes de témoigner ainsi d'un certain civisme local ou d'un loyalisme à l'égard des empereurs 10.

L'action des religions orientales se ma-

(8) E. Thevenot, Rev. archéol. Est, III, 1952, p. 125-127.

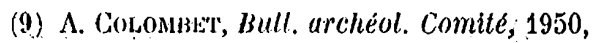
(10) M. Rrakis, Latomus, XI, 1952, p. 59-62. 
nifeste encore par l'importation d'objets, témoignages de la dévotion populaire aux divinités de l'Égypte. La bague découverte à Médis, près de Royan (CharenteMaritime) 11, à l'effigie de Jupiter-Ammon en associant les attributs (calathos et cornes de bélier ammoniques) de l'un et l'autre dieu, illustre l'efiort de syncrétisme unissant les divinités égyptiennes, qui s'imposent aux fidèles dans toutes les provinces de l'Empire. Le sistre en bronze à quatre tringles mobiles dans leurs logettes et surmonté de la figurine d'unè chatte couchée, recueilli dans une sćpulture à Saint-Remy-de-Provence, laisse entrevoir la présence, à Glanum. de sectateurs d'Isis ou de Cybele ${ }^{12}$.

On doit à M. C. Mahaut 13 un essai sur les cultes gallo-romains à Bordeaux, et l'examen de découvertes anciennes ou récentes, faites dans les sanctuaires rustiques bourguignons, apporte d'utiles compléments à l'histoire de la dévotion populaire. A Beaune (Cote d'Or), un ApolIon Bélénus avait son temple à la source de l'Aigue. Dieu guérisseur si l'on en juge d'après les ex-voto recueillis sur cet emplacement, pieds et jambes coupées sous le genou, il avait succédé à une divinité celtique, celle de l'Aqua Belene, fixée sur le tracé d'un très ancien chemin reliant à Chalon la haute vallée de la Seine, très suivi au $\mathrm{II}^{\circ} \mathrm{s}$. avant notre ìre 14. La sainteté du lieu explique sa christianisation au $\mathrm{r}^{\mathrm{s}} \mathrm{s}$. Une chapelle dédiée à Saint Martin ot un cimetière prennent alors la place du temple païen. Dans quelques-uns de ces lieux de culte, à Bouze, à Beire-le-Ghâtel, ̀̀ Nuits-Saint-

(11) M. Labrousse, Rev. archéol., 1952, 2, p. $93-95$; - F. EyGUN, Gallia, IX, 1951, p. 107. (12) H. Rolland, Bull. soc. antiq. Fr., 1948, p. $35-36$.

(13) Annales Midi, 64, 1952, p. 87. Diplome ét. sup. hist. Bordeaux, 1951.

(14) E. Thevenot, Rel'. archéol. Est, 3, 1952, p. 244-249.
Georges, à Courcelles-lès-Monts, tous situés au voisinage d'un point d'eau, l'un des ex-voto caractéristiques est un maillet en pierre tendre. L'un d'eux porte une dédicace à Silvanus ${ }^{15}$. A cette indication apportée à l'identification de l'une des divinités honorées dans ces sanctuaires campagnards, on ajoutera celle donnée par les découvertes faites dans l'une des fosses du fanum d'Hofstade-les-Alost (Belgique) 16, où avaient été enfouies après un incendie, des statuettes se rattachant toutes, comme au temple de Saint-Aubin-sur-Mer (Calvados), au culte de la Déesse Mère. Certains de ces lieux de culte étaient situés aux frontières entre les cités. Il en est ainsi du fanum de la forêt domaniale de Val-Suzon, à $15 \mathrm{~km}$. au N.-0. de Dijon 17, détruit par un incendie à l'époque des Flaviens. L'abondance des monnaies appartenant toutes aux frappes lingonnes semble indiquer que le sanctuaire était placé sur la ligne de dómarcation entre les Lingons et les Séquanes, qui scrait à fixer entre l'Ouche et le vallon de Suzon. Dans les ruines de la cella à plan presque carré, entourée d'un portique et recouverte d'une toiture supportée par des piliers de bois, on recueillit des ossements de bœur, de monton, de sanglier et de cheval, restes de sacrifices, des fibules et une pointe de javelot. Le voisinage d'une fontaine n'est pas moins recherché pour l'installation de l'un de ces fana. Dans le Mâconnais, à Azé ${ }^{18}$, près du captage d'une source, on recueillit les restes du mobilier cultuel d'un fanum, vases, monnaies, statuettes de terre-cuite, femmes et enfants, dées-

(15) DU MENIE, ibid., p. 99-103.

(16) S. J. DE LAET, Latomus, XI, 1952, p. 4546.

(17) E. Guyot, Le Bien public, 7 janv. 1951; - Ann. Bourgogne, XXIV, 1952, p. 186.

(18) L. ARMand-Catliat, Mem. soc. d'hist. et d'archéol. Chalon-sur-Saọne, XXXIII, 1952. p. 22. 
ses-mères, ex-voto de bronze (dont une vulve), prouvant la fréquentation du sanctuaire aux $\mathrm{II}^{\mathrm{e}}$ et $\mathrm{III}^{\mathrm{e}} \mathrm{s}$. de notre ère.

Par la découverte, à Péguilhan (HauteGaronne) de la partie supérieure d'un autel servant de bénitier dans la chapelle de Bétis, le panthéon gaulois s'enrichit d'une nouvelle divinité, Carpentus $^{19}$. On connaissait déjà une dédicace à un dieu Carpantus, provenant de Fayence (Var). Faut-il rapprocher le nom de cette entité divine de carpentum, mot que le latin emprunta au celtique pour désigner un véhicule de parade ? Mais la même racine reparait dans des noms de lieu de Narbonnaise, de Cisalpine et de Bretagne. Est-ce un dieu des charrons et de la circulation, l'emplacement de la découverte étant au voisinage d'une voie antigue ? Il s'agit plutot d'un dieu topique de Peguilhan et des environs. Mais est-ce une raison suffisante pour envisager une celtisation de la vallée de la Save et la pénétration des Celtes en Aquitaine orientale?

Le dieu Baco changera-t-il de nom pour répondre à celui de Bagon et devenir, de dieu porc, un dien guerrier des Éduens ? hypothèse qu'appuierait la qualité du dédicant, un décurion de l'Ala prima Flaviana ${ }^{20}$. Au sujet de l'inscription Deac Sequana, gravée sur un col de vase ramassé dans le temple des sources de la Seine, P. Lebel 21 observe que $S:$ quana est à la fois cas sujet et cas régime traduisant une formule vivante dans une population dont la langue s'achemine vers le roman.

Les monuments de la sculpture religieuse provoquent, eux aussi, de nou-

(19) M. Labrousse et G. Fouet, Annales publiés par la Faculte des Lettres de Toulouse, I, 2, 1951-1952, p. 51-56.

(20) P. Lebel, Mém. comm. antiq. Cote d'Or, XXII, 1952, p. 467.

(21) Du MÊME, ibid., p. 559. veaux essais d'interprétation. $\Lambda$ l'iconographie funéraire se rattache la statue de sphinge d'Avallon (E. 2218), rappelant le thème du fauve ravisseur, image de la mort dévorante, mais aussi symbole de protection de la sépulture, thème que traduit le fauve d'Entrains (E. 2250) et qui reparaîtra dans la sculpture romane de la Bourgogne 22.

Je relief du musée de Beaune (E. 2043) n'offre aucun rapport avec Epona et le dompteur de chevaux. Il se rattache à la série des représentations du couple éduen, dispensateur des biens de ce monde et des félicités éternelles. La présence d'animaux précise une contamination par l'intermédiaire des monuments au Tricéphale. Comme sur le relief de Reims, le cerf est un symbole de richesse, et le dieu assis s'apparente au dieu au maillet, au dieu accroupi et au Tricéphale. La découverte de certaines colonnes au géant anguipède près d'une source témoigne du caractère bénéfique de cettc divinité, dispensatrice des eaux bienfaisantes $\mathbf{2 3}$.

Les r'apports de l'eau avec les dieux du panthéon gallo-romain apparaissent de plus en plus fréquents. Un inventaire analytique des colonnes du dieu cavalier au géant anguipède, découvertes en Sarre ${ }^{\mathbf{2 4}}$, accentue les caractères de ces figurations d'un dieu céleste et d'une puissance infernale, une association étroite avec les eaux, et l'auteur passe en revue les différents essais d'interprétation, critiquant la thèse de $\mathrm{F}$. Benoit qui maintient ses positions quant au caractère funéraire du dieu ${ }^{2: 5}$ et, à propos de la re-

(22) M. ReNard, $X X^{\mathrm{c}}$ Congres assoc. bourguignonne soc. sav., Semur, 1949, p. 93.

(23) E. Thevenot, L'antiq. class., XXI, 1952, p. $98-106$.

(24) J. Moreau, La nouvelle Clio, IV, 1952. p. 219-245, 415.

(25) Ibid., p. 84-90. 
présentation de Mar's combattant l'anguipode sur l'armure de parade de straubing, pense y trouver un argument nouveau à l'appui de l'origine méditerranéenne de ces représentations 20. Celles-ci d'ailleurs ne sont pas exactement les mêmes: dans la Moselle, si les figures du dieu cavalier à l'anguipède sont nonbreuses, rares sont les colonnes et les autels aux (juatre divinités. Il semble (ju'on se trouve en présence de modèles réduits du monument 27. Faut-il considérer comme l'incarnation féminine de cette même divinité l'Evona du marais des Bordes, à Saulon-la-Chapelle (Côte-d'Or)28? I a nouvelle Epona icaunaise 29 , conservée chez un collectionncur dijonnais présente une particularité qui reparaît sur un fragment sculpté des sources de la Seine : la jument sur laquelle la déesse est assise en amazone et qu'accompagne un poulain. pose le pied droit antéricur sur un socle en forme de lyre. De même que d'autres images d'Epona, la statuette d'Entraigues (Loiret) a été recueillie près d'une fontaine 30 .

8. Numismalique. - Des découvertes de monnaies ont été faites : à la sortie méridionale de Graulhet, (Tarn), au lieu dit «Briançon », sur une butte dominant la route de Castres, site occupé depuis l'âge du Bronze 1 ; - à Locronan (Finistère), un denier de M. Tullius (Decula ?), portant à l'avers la tête de Rome,

(26) F. BexolT, Latomus, XI, 1952, p. 467476.

(27) A. Colomist, Rev. archeol. Est, III, 1952, p. 52 .

(28) E. Thevevot, Bull. soc nat. antiq. Fr., 1949, p. 221-223.

(29) A. Colonibet, Rev. archeol. Est, III, 1952, p. 284 ; - Bull. trimestr. assoc. bourguignonne soc. sav., $\mathrm{n}^{\circ} 10-11$, juillet-aout 1952, p. 5 .

(30) Abbé MouffuET, Bull. soc. nat. antiq. Fr., 1951, p. 241.

(1) M. Labrousse, Gallia, IX, 1951, p. 136. au revers une Victoire ailée, appartient à un ensemble disparu, contemporain de la première moitić du ${ }^{\text {er }}$ s. av. J.-C. 2 ; à Port-Haliguen en Quiberon (Morbihan), un vase en terre renfermait une monnaie d'Auguste, émise à Lyon avant 10 av. J.-C.. et des pieces frappées entre 70 et 103 ; - sur le territoire de Coudert (cne de Saint-Bonnet-l'Enfantier, Corrèze), aureus de Vespasien frappé à Lyon en il 4; - à Bazoches-les-Hauts (Eure-etJoir), monnaies de Vespasien et de Clau(le II 5 ; - dans les champs entre Cléry ct la Loire, monnaies carnutes de bronze, frappes de Domitien et de Constantin ${ }^{6}$; - à Champagnac-la-Noaille (Corrèze), au lieu dit "Les lontenelles " ?, sesterces de Trajan et de Sabine, dupondius ou as de Marc-Aurèle, frappé sous Antonin en 159-160, sesterce de Tucilla, fille de MarcAurèle; - à Verdes (Loir-et-Gher), près de la voie romaine de Châteaudun, plus d'un millier de grands bronzes de Trajan à Maximin 8; - à Cépoy (Loiret), lors de la reconstruction du pont sur le canal, monnaies de la fin du $\mathrm{II}^{\mathrm{e}}$ s. ou du début du $\mathrm{III}^{\mathrm{C}} \boldsymbol{\theta} ;$ - sur le territoire de la commune de Germignonville (Eure - et - Loir), au N.-E. de la ferme de Morasson, trésor enfoui vers le commencement du II $^{n}$ s., monnaies de Trajan à Septime-Sévère 10; - à Saint-Jean-de-I,auras (cne d'Artigue,

(2) P. Merlat, ibid., p. 89-90.

(3) DU ME.re, ibid., p. 85; - Bull. soc. d'hist. et d'archéol. Bretagne, 1952, p. 27.

(4) P.-F. Fournier, Gallia, IX, 1951, p. 110.

(5) Bull. liaison provis. soc. archéol. et hist. Orléanais, $\mathrm{n}^{\circ} 16$, janv.-févr. 1952, p. 1.

(6) Abbé Noues, Bull. soc. archéol. et hist. Orléanais, 1944, p. 8.

(7) M. Labrousse, Bull. soc. scientif., hist. et archéol. Corrèze, 74, 1952, p. 57-68.

(8) Abbé Nouel, Bull. liaison prov. soc. archéol. et hist. Orléanais, no 17 , mars-avril 1952, p. 1.

(9) Ibid., n 16, janv.-févr. 1952, p. 1-2.

(10) Abbé Noubis, ibid., n" 19, juill.-oct. 1952, p. 5 . 
Hte-Garonne), un trésor d'antoniniani, enfoui entre 258 et 260 , marque le passage, dans le Midi de la Gaule, de la première invasion franque 11 ; - à Ingrandes (Toiret), sur le bord de la voie romaine, dans un vase, monnaies, depuis dispersées, de Probus à Dioclétien 12 ; à Auvilliers, 990 petits bronzes de Valérien à Aurćlien 13; - à Beauvais (Oise), rue Jean-de-Lignière, trósor de 251 pièces de IDomitien à Gordien III, enfouies vers le milieu du III" s.14; - à Sens (Yomne), le trésor de la rue Alex ${ }^{15}$, datée de 274, se composail d'un denier de Gallien, frappé à Rome, de 405 antoniniani de Volusien à Aurélien, frappés surtout à Rome, puis à Milan et à Siscia, de 807 antoniniani des empereurs gaulois émis par les officines de Cologne et de Trèves, et de 67 autres issus d'ateliers locaux, imitant le numéraire de Claude II et des empereurs gaulois. A l'exception de quatre antoniniani, toutes ces monnaies appartiennent à la période d'inflation des années 260-274; - la cachette trouvée à Crain (Yonne), lor's du forage d'un puits, entre dans la série des enfouissements des monnaies de Tétricus associées à celles de Probus, cernant une aire de la Belgique et du Luxembourg à la Isoire, couvrant à l'Ouest le Cotentin et la Bretagne, à l'Est la Saone-et-Loire, l'Isère et la Haute-Savoie, correspondant à la marche des troupes de Probus, parties du Rhin pour libérer la Gaule des envahisseurs de 271-276 16; - à Rue (Somme), au lieu-dit «Flandre», trois vases contenaient des

(11) M. Labrousse, Gallia, IX, 1951, p. 135. (12) Bull. liaison provis. soc. archéol. et hist. Orléanais, $\mathrm{n}^{\circ} 17$, mars-avril 1952, p. 4.

(13) Ibid., p. 1.

(14) A. PIganiol, Gallia, IX, 1951, p. 82.

(15) G. FABRe, Rev, archeol. Est, III, 1952, p. $65-89$.

(16) P. Lebei, ibil, p. 61; - - Ann. Bourgogne, XXIV, 1952, p. 193; - J. LAFAURlk, Bull. soc. nat. antiq. Fr., 1954, p. 219-220. monnaies de Gallien à Tétricus ${ }^{17}$; - à Babiot (Dordogne), découverte d'un bronze de Maximin II Gaza 18; - à Ghécy, dans la Loire, avec les débris d'un coffret ou d'un petit seau, douze sous d'or furent recueillis, 2 d'Arcadius et 10 d'Honorius 18.

Le trósor trouvé à Seltz (Bas-Rhin) en 193020 fut en partie dispersé. Enfouies dans les premiers mois de 308 , les pièces sont originaires d'ateliers différents, mais $84 \%$ ont été frappées à Trèves. Pour une période de l'histoire où les textes sont avares de renseignements, les monnaies du trésor de Seltz apportent des précisions sur la prise du titre d'Auguste par Constantin, sur son alliance et sa brouille avec Maximien Hercule. I'examen de la dispersion des cachettes monétaires du temps des empereurs gaulois n'est pas moins riche en enseignements 21 . Il permet de déceler une période d'invasion entre les années 159 et 262 et, environ 268, une poussée nouvelle des envahisseurs.

Ia contribution apportée à l'histoire de l'art par les revers monétaires n'est pas moindre. Sur une monnaie de Claude, trouvée à Alésia ${ }^{22}$, portant l'image romaine de la Liberté sous les traits d'une femme nue, on peut reconnaitre une reproduction de la statue de la Liberté, dressée dans le sanctuaire de la déesse, en 52 av. J.-C., par le tribun P. Claudius, au Palatin sur l'emplacement de la maison

(17) Fr. Vasselle, Bull. trim. soc. antiq. Picardie, 1952, p. 170.

(18) Bull. soc. hist. et archéol. Périgord, XXXIX, 195\%, p. 19.

(19) Bull. liaison prov. soc. archeol. et hist. Orléanais, $\mathrm{n}^{\circ} 19$, juill.-2oût 1952, p. 2.

(20) H. Herzfelder, Rev. numism., 5e ser., XIII, 1952, p. 31-68.

(21) P. VAN GansBeKe, Rev. belge de numism., 98, p. 5-30.

(22) J. 'Toutain, Bull. archéol, Comilé, 1950), p. 183-187. 
de Cicéron, et qui avait ou pour modele une courtisane de Tanagra.

\section{VI}

\section{Temps Chrótiens ap Mŕnovingiens}

Les recherches sur les rapports entre Gallo-Romains et Barbares retiennent, spécialement l'attention. Un mémoire présenté à la Faculté des Lettres de Lyon 1 traite de la société gallo-romaine en face des invasions barbares. En un saisissant raccourci, A. Piganiol 2 brosse le tableau offert par la Gaule au temps d'Attila. Aver l'invasion du 31 décembre 406, «des nations innombrables et très féroces ont occupé l'ensemble des Gaules ». Is speclacle qu'offre alor's le pays est, par nous, incohérent. Les employés des finances ot des postes continuent leur métier, les Barbares se hattent contre les paysans brigands, les prêtres luttent contre les diables, les empereur's lointains rayonnent encore comme une lumière de salut. L'armée est un gouffre pour les finances; la jeunesse fuit les carrières militaires et la bureaucratie financière les attire. Les taxes sur la propriété achèvent sa ruine et les marchands succombent sous le poids de la fiscalité. Presque tous les métiers sont devenus héréditaires et le grand effort de l'administration a été d'attacher les paysans libres à la terre pour assurer la constance des récoltes. Cependant la noblesse des Gaules demeure singulièrement riche et puissante, bien qu'elle ait été décimée au cours des catastrophes du II $^{\circ}$ s. La Gaule, qui prend lentement le visage de la France, reste un pays riche, même si des régions, com-

(1) R. Pelletien, Mém. dipl. et. sup. hist., Lyon, 1952.

(2) Saint-Germain d'Auxerre et son temps, p. 119-133. me la plaine languedocienne, sont alors dépeuplées. L'entrée en scène des archerscavaliers des steppes apporte des arts nouveaux, qui ont déjà séduit Chinois el Germains, et le vieux fonds celtique est là pour les recevoir.

I.e $v^{r}$ s. est aussi une période marquante pour la christianisation de la Gaule 3 , malgré la persistance du paganisme, romme en témoignent les campagnes de Saint-Martin et l'atmosphere de crise qui s'ouvre avec le priscillianisme. Une autre affaire est celle du fonctionnement de l'institution du métropolitain, enfin à toutes ces difficultés s'ajoutent les invasions barbares. Le rôle de l'évêque dépasse fréquemment le cadre ecclésiastique, il est aussi le defonsor civitatis. Un courant monastique puissant se dessina dans le même temps, en Gaule méridionale, à l'intéricur des grands monastères de Lérins et de Marseille, foyers intellectuels et artistiques. Cependant, si en dépit de l'influence exercée par les Barbares sur l'F́glise, celle-ci conserve toute son organisation intérieure, le rôle joué par les monastères dans la sauvegarde de la culture antique ne doit pas être exagéré et la décadence est manifeste dans le domaine artistique 4.

Le $\mathrm{XV}^{\mathrm{r}}$ centenaire de Saint-Germaind'Auxerre a donné l'occasion à la Société des sciences naturelles et historiques de l'Yonne de réunir, en 1948, à Auxerre un congrès de l'Association bourguignonne des Sociétés savantes, entièrement consacró à la vie et à l'œuvre de l'un de ces grands hommes d'église qui exercent une action si profonde sur la politique et les maurs des temps mérovingiens 5 . Germain est l'un de ces personnages qui dé-

(3) J. ZeIller, ibid., p. 1-13.

(4) J.-R. Palanque et Et. Delaruelue, Rev. hist. Eglise Fr., XXXVIII, 1952, p. 52-72.

(5) Saint Germain d'Auxerre et son temps, Auxerre, 1950. 
butèrent dans la carrière d'avocat, après avoir commencé leurs études en Gaule et fait leur droit à Rome. Tout semblait le destiner à devenir l'un de ces grands administrateurs, comme cet Eventius de Vienne ${ }^{6}$, gouverneur de la province de Viennoise, appelé par la faveur impériale au Sénat de Rome, s'il n'avait été terrassé par une grâce soudaine qui le conduisit. à la plénitude du sacerdoce. Il était dans la destinée de Germain d'être directement mêlé, pour le combattre, au dernier grand mouvement de pensée théologique qui se manifeste en Occident, le Pélagianisme, dont l'épitaphe de ce même Eventius, retrouvée à Rome autour de la Confesssion de Saint-Pierre, porte la marque. Légat apostolique en Grande-Bretagne, il a lutté politiquement et militairement contre l'hérésie. La grandeur et la valeur de l'ceuvre de Germain est d'avoir accrédité l'idéal humain qu'eurent sous les yeux tous les hommes du Moyen âge. Il nous a révélé la conception du monde et de la vie que répandait le clergé gallo-romain.

Saint Germain participa également au développement de la vie monastique. On peut se demander, toutefois, si les missionnaires anglais ou bretons, qui ont diffusé en Gaule le culte de certains saints (celui du martyr Genès) ont séjourné dans le monastère fondé par saint Germain dans une île de l'Yonne. Il se pourrait que cette insula Aralancnsis ne soit que la déformation de l'insula Lerensis, à moins encore qu'on ne lise Arelatensis, ce qui rendrait possible l'existence du monastère arlésien, fondé par Saint-Hilairc dans l'insula suburbana Arelatensis, sur la rive droite du Rhône, au quartier Gallègue 7. On sait qu'alors Arles conserve sa double fonction de métropole politi331 .

(6) H.-I. Mannou, R.É.A., LIV, 1952, p. 326-

(7) F. BenolT, Saint Germain d'Auxerre et son temps, p. 181-189. que et religieuse, inaugurée dès le règne de Constantin. Arles est encore un relais entre Rome et l'Angleterre, sur la route conduisant par les vallées de la Loire et de la Seine aux ports d'embarquement vers l'Irlande et la Bretagne.

Plusieurs travaux traitent des origines diocésaines. Un auteur anonyme consacre une étude à l'évêque Diopeton (ou Diopetus) et aux origines chrétiennes d'Orléans ${ }^{8}$. Le regretté chanoine G. Drioux 9 avait laissé le schéma d'un article sur l'église de Langres au $v^{\bullet}$ s., ses évêques, ses sanctuaires, les modalités du culte et l'apport des reliques. Dans ce diocdsc, les monnaies recueillies dans les sanctuaires païens s'arrêtent avec le IV s., plus rarement au $\mathrm{v}^{\mathrm{c}}$. On peut en conclure que la christianisation des campagnes était un fait accompli. Aux origines du diocese de Jimoges ${ }^{10}$, il n'y a rien à retenir d'une prétendue apostolicité de saint Martial, qui ne repose que sur une fiction forgée de toutes piòces, aux $\mathrm{x}^{\mathrm{c}}$ et $\mathrm{XI}^{\prime \prime} \mathrm{s}$, par les moines de Saint-Victor et Adhémar de Chabanne. Martial est venu seulement au $\mathrm{III}^{\circ} \mathrm{s}$. et sa prédication n'a partiellement touché que Limoges et quelques bourgades routieres. Une svangélisation des campagnes au $\mathrm{III}^{\circ}$ s. n'a laissé aucune trace; celles-ci sont restées païennes et seront évangélisées seulement aux vII $^{\circ}$ ou virr ${ }^{\mathfrak{e}}$ s. par des prédicateurs pratiquement inconnus, à la suite des

(8) Annales religieuses du diocese d'0rléans, 30 déc. 1944; cf. contra: chanoine Chenesseau, ibid., XXV, 1945, p. 26-27. Le vrai nom serait, selon Duchesve: Dislopater. Le vicus extra muros, berceau de la chrétienté, ne peut être recherché à Saint-Lignan. La fondalion de Saint-Pierre-le-Puellier, pas plus que celle de Saint-Pierre-Emport, ne peut ĉlre alluiluce a Dislopater.

(9) Saint Germain d'Auxerre et son temps, p. 194.

(10) R. Lmouzin-LanotTe, Le diocèse de Limoges des origines au Moyen age, Strasbourg-Paris, 1951. 
progrès de l'érémitisme et du monachisme. La multiplication des paroisses rurales est un phénomène tardif en Limousin, qui se place aux vII et au virI ${ }^{\circ}$ s., et on constate de sérieuses différences entre les régions forestières et les pays de plaine. Les premiers monastères s'installent au $\mathrm{vi}^{\circ} \mathrm{s}$. (Saint-Yriex) et au $\mathrm{VII}^{\mathrm{e}} \mathrm{s}$. (Saint-Eloi). Mais la floraison monastique n'éclatera qu'avec les guerres du vill $^{\circ}$ s. qui livrent l' $\Lambda$ quitaine aux Carolingiens. A l'intérieur de l'église de Bourges ${ }^{11}$, le développement de la vie monastique appartient au $\mathrm{VII}^{\mathrm{e}}$ s., alors que l'évangélisation commence environ 300 . Sainte-Croix et la callédrale sont les églises les plus anciennes. Dans l'ancien diocèse de Paris, la région de Deuil 12 avait été évangélisée par les prêtres syriens, confondus plus tard avec l'évêque de Tolède, Saint Eugène, dont le corps inhumé près d'un ancien lieu de culte païen gallo-romain, fut transporté, au viIr" s., à Deuil qui, au siècle suivant, devint un prieuré de Saint-Denis.

Dans la discussion toujours ouverte sur la civitas Coriosolilum, P. Merlat 13 apporte un élément important. Il remarque que l'adjectif corisopitcnsis ne figure pas dans la Gesta sanctorum Rotonensium rédigcée entre 870 et $8 \% 5$, que le texte porte sculement corisopiti, interpolé en interligne. Il en conclut que la prétendue civitas Corisopitum, distincte de la civitas Coriosolitum et s'appliquant au futur diocèse de Cornouaille, semble bien n'être qu'un mythe propagés par la Chronique de Nantes et les textes narratifs qui en découlent. Ise même auteur propose de fixer la scission du diocese de Carhaix entre

(11) M. de Laugardière, L'Église de Bourges acant Charlemagne, Paris, 1951.

(12) M. Roblis, Mem. fédér. hist. et archéol. Paris el lle-de-France, II, 1952, p. 7-19.

(13) P. Merlat, Bull. soc. d'hist. el d'archeol. Bretagne, 1952, p. 9-13; - cf. H. WAQUET, ibid., p. 6-9. les années 467 et 489. Aquilonia et le Gaudet se seraient alors partagé son territoire sur l'initiative des évêques 14.

$\Lambda$ l'appui des nombreuses constatations faites sur la persistance de l'ćlément gallo-romain dans la population aux temps mérovingiens ${ }^{15}$, de nouveaux arguments sont apportés pour l'Alsace, où malgré la conquête alamane, la culture de la vigne ne disparait pas, fait qui ne peut s'expliquer que par la permanence des vignerons gallo-romains ${ }^{16}$. La toponymie conduit aux mêmes conclusions. La rareté, dans le département de la Haute-Marne, des toponymes en -angc, démontre le peu d'influence exercce par le parler' frunc au temps du bilinguisme. Les Gallo-Romains ont remplacé les noms franciques par des noms en -court, très nombreux dans la Haute-Marne 17. De même Mortaix, Morgne et les toponymes apparentés ne traduisent pas la présence de garnisons de Maures ou la colonisation des campagnes gauloises par des Maures. Ces noms s'appliquent à des morts-bois, à des terrains couverts de ronciers ou de broussailles, a des bois, dont les qualités sont insuffisantes pour une exploitation, et très longtemps laissés en friche 18

Toponymie, topographie ct archéologie s'accordent pour localiser le théâtre de la bataille de Vouillé à $15 \mathrm{~km}$. de Poitiers. Mais le site du combat doit-il être placé à Dissay, sur la rive droite du Clain, ou à Parigny, sur la rive gauche ? Le second emplacement serait plutot à retenir, les conditions topographiques paraissant favorables à l'établissement

(14) Annales Brelagne, 1952, p. 105-109.

(15) R. LaNtier, Ampurias, XIV, 1952, p. 218-224.

(16) Dollinger, Bull. soc. academique BasRhin, 1947, p. 40-57.

(17) P. L LEBLL, Mém. comm. antiq. Cole d'Or, XXII, 1952, p. 579.

(18) M. Robis, Rull, soc. nat. antiq. Fr., 1949, p. 171-182. 
d'une ligne de défense sur les bords de la Pallu, et vers Parigny; près du gué du Moulin de Train, un immense ossuaire d'hommes et de chevaux est peut-être le témoin du carnage de 50719.

Le roble des colonies de Germains installées dans les Gaules à la fin du III $^{\circ}$ s. a été fortement exagéré, et il n'est pas possible de rechercher, comme l'avait tenté J. Werner, les origines de la civilisation mérovingienne dans la culture des Lètes 20. Ceux-ci ne sont pas tous des Germains. D'autre part, on ne connaît pas de forme de passage entre les sépultures antérieures aux Grandes Invasions et celles qui leur sont postérieures, et un siècle sépare les dernières trouvailles gallo-romaines des premiers établissements mérovingiens. Les sépultures de Vert-la-Gravelle, de Vermand, d'Abbeville-Homblières, de Monceau-le-Neuf, de Furfooz, attribuées aux Lètes, sont sans rapports étroits et leur caractère germanique est loin d'être prouvé. Flles sont, comme les tombes de la Germanie libre - et celles-ci peut-ĉtre plus fortement encore - tributaires des modes d'ensevelissement et des mobiliers funéraires gallo-romains.

L'attention a déjà été attirée sur la disposition des villes contemporaines des Grandes Invasions. Il est impossible que l'enceinte ait pu représenter à elle seule, à Paris, comme à Autun par exemple, la totalité de la cité 21 . Le castrum, conçu comme une acropole, dont les murs dominent les pentes les plus raides, barrant un angle aigu de l'enceinte du $\mathrm{I}^{\mathrm{er}} \mathrm{s}$. (Autun), est une forteresse, un lieu de re-

(19) Descrorx, Bull. soc. antiq. Ouest, $4^{\mathrm{e}}$ sér., III, 1952, p. 22-23.

(20) S.-J. de LaET, J. Dhondt, J. Neuquin, Etudes d'hist. et d'archéol. namuroise dédiées a F. Courtoy, I, p. 149-172; - voir : J. WERNER, Archaeologia geographica, I, 2, p. 23-32.

(21) E. Thevenot, Rev. archéol. Est, III, 1952, p. 121-122. fuge. Hors les murs l'agglomération continue son existence dans des faubourgs, malgré des destructions épisodiques plus ou moins étendues. Dans ces quartiers suburbains, sur la Seine comme sur le Rhin 22 , s'élèvent les premiers sanctuaires chrétiens, près des cimetières ou des villes. A Cologne l'église Saint-Pantaléon est issue, avec son fundus, d'une villa gallo-romaine. Il en aurait été de même à Tours et à Auxerre, où de vastes atriums, dans les demeures de grands personnages, auraient été transformés en basiliques 23 . Pour des questions de prestige, autant que pour des raisons de sécurité, ces premières églises, élevées hors les murs, à Auxerre, à Tours, à ClermontFerrand, sont ramenées au $v^{e} s$. à l'abri de l'enceinte 24 . L'ecclesia publica devient un martyrium et cette transformation s'explique par le caractère de protection qu'on attache au martyr en ces périodes troublées. Elle a pour conséquence le développement en Occident d'un culte et de pratiques, dont les répercussions s'appliquent aussi bien à l'architecture qu'à l'art des églises. On connaît les dispositions de quelques édifices et des complexes : à Arles, l'ecclcsia se dresse à l'angle S.-E. de l'enceinte, dans une région plus élevée, accompagnée d'un baptistère et précédée d'un atrium. L'appartement de l'évêque était situé au premier étage, le logis des clercs au rez-de-chaussée. On a peu de précisions sur l'architecture des cathédrales : à Metz l'église du monastère de Saint-Pierre de la Citadelle repose sur les restes d'une basilique civile ou d'une

(22) F. Frankrsmonk, Niederhein. Jahrb. $d$. Vereins... Niederrhein, III, 1951, p. 24-26.

(23) R. Louis, Bull. soc. nat. antiq. Fr., 1950, p. 26; - Les églises d'Auxerre, Autessiodurum christianum, des origines au XI siccle. Auxerre, 1954.

(24) J. IIUbent, Saint Germain d'Auxerre et son temps, p. 15-23. 
église de la fin du $\mathrm{II}^{\mathrm{e}}$ ou du $\mathrm{IV}^{\mathrm{e}}$ s. ${ }^{25}$, avec une abside circulaire à l'intérieur, polygonale à l'extérieur, d'un intérêt exceptionnel pour l'histoire du plan basilical, qu'il n'est plus nécessaire de faire venir d'Orient, comme un emprunt tardif de l'Occident à l'architecture chrétienne de l'Orient méditerranéen. A Vienne (Isère), la basilique de Saint-Pierre, lieu de sépulture des évêques depuis le $\mathrm{v}^{\mathrm{e}} \mathrm{s}$, a gardé de sa première construction une partie de sa façade occidentale : fronton orné à l'antique d'une forte moulure, dessinant un triangle et rappelant l'ordonnance d'un monument contemporain, le mausolée de Galla Placidia à Ravenne. La cólchbre inscription de Narbonne relatant les conditions dans lesquelles, en 14.̇, l'évêque Rusticus reconstruisit son église, en montrant l'ambition des évêques du ve s. d'assurer dignement le culte chrétien, précise la persistance des pratiques du Bas-Empire en matiere de construction: les travaux, surveillés par le clergé, sont exécutés pour le plan et la décoration avec les mêmes communautés de pratique unissant les divers artisans des provinces de l'Ancien Empire romain. Ia même impression se dégage de quelques-uns des baptistères contemporains, tel celui de Marseille, le plus grand édifice de ce genre connu dans le monde chrétien, après celui du Latran. Cependant les églises n'étaient pas grandes, et les quelques basiliques imposantes de Constantin et de ses émules sont d'heureux accidents dans l'histoire de l'architecture chrétienne, mais elles étaient nombreuses et se multiplièrent au $\mathrm{v}^{\mathrm{e}} \mathrm{s}$., conséquence de l'extension de la dévotion pour les martyrs et pour les saints, nés en d'autres pays auxquels on demande la plupart des reli-

(25) A. Grenier, R.E.A., LIV, 1952, p. 116 . 118. ques. En Gaule, la basilique est dédiée au martyr, et souvent élevće sur le lieu même de son supplice.

Un précieux répertoire 26 nous est donné de ces monuments, reproduisant au $1 \mathrm{~m} / \mathrm{m}$, les plans de 179 édifices, églises épiscopales et baptismales; édifices antiques et églises oratoires funéraires; églises monastiques et collégiales; oratoires monastiques; ćglises à plan central; églises rurales et de types divers. Ia carte de répartition fait connaître une dispersion assez homogène, avec des blancs s'étendant sur la Bretagne et dans l'extrême Sud du pays. Un fait capital se dégage du tableau chronologique: la rupture profonde entre la civilisation du $\mathrm{IX}^{\mathrm{e}} \mathrm{s}$. et les débuts du Moyen âge, qui se traduit dans l'art de hâtir et la pauvreté du décor des églises que l'on construit alors, coupure qu'on ne peut expliquer que par un profond bouleversement social et économique. Or, si l'on se reporte à la carte consacrée à l'extension des invasions normandes en France, on constate que la totalité du territoire, à l'exception des I andes, du Languedoc et des provinces orientales, a subi les ravages des invasions normandes. C'est aussi le temps où la forêt recouvre, aux emplacements où on la rencontre encore aujourd'hui, de vastes espaces cultivés aux époques gallo-romaine et mérovingienne. La réalité des faits vient à l'encontre de la théorie de Viollet-le-Duc d'un progrès continu de l'art depuis le règne de Charlemagne jusqu'au $\mathrm{xII}^{\mathrm{e}}$ s. La disposition même des plans des édifices, chronologiquement classés, facilite une étude de leur évolution: l'extrême exiguité des églises épiscopales primitives offre un contraste saisissant avec les dimensions,

(26) J. Hubert, L'architecture religieuse du Haut Moyen age en France. Plans, nolices et bibliographie. 2e part., Éc. Htes Et., sc. relig. coll, chrétienne et byzantine, Paris, 1952. 
déjà notables, données dès la fin du $\mathrm{v}^{0} \mathrm{~s}$. aux basiliques funćraires.

Les fouilles exécutées à Poitiers, autour du Temple Saint-Jean ${ }^{27}$, à 100 mètres au sud de la cathédrale, ont révélé un dispositif insolite, conséquence de remaniements très complexes d'édifices antérieurs, comportant deux salles rectangulaires accolées, précédées d'un portique et flanquées d'une sorte d'annexe à plan carré. Ces constructions représenteraient les restes du premier groupe épiscopal au $\mathrm{IV}^{\mathrm{e}} \mathrm{s}$. : cathédrale double ayant l'exiguïté des sanctuaires primitifs, comme la cathédrale double de Parenzo (Italie), et baptistère. Au VI ${ }^{\mathrm{e}}$ s., on construit le baptistère de la nouvelle cathédrale, et l'une des églises jumelées, flanquée alors de trois absides, aurait donné le monument actuel, dont certaines anomalies s'expliquent dès lors parfaitement. Ce sonl aussi les vestiges d'une première église qui ont été retrouvés à MartresTolosane (Haute-Garonne) ${ }^{28}$, sous l'église actuelle. Placée sous le vocable de Santa Maria de Martyribus, peut-être élevée sur l'emplacement d'un édifice civil incendić, la basilique, de caractère funćraire, était entourée d'un cimetière, qui se prolonge vers le Nord et a donné des fragments de sarcophages de type arlćsien. Il est vraisemblable que les mosaïques, trouvées autrefois au Nord de l'église paroissiale de Montcarret (Dordogne)29, soient contemporaines de la première occupation chrétienne. Il en est de même de quelques chapiteaux remplacés dans l'édifice actuel. A Saint-Martin d'Angers ${ }^{30}$ les fouilles ont fait connaître un tronçon, longtemps fréquenté, de route antique et

(27) DU MENE, Cahiers archéol., VI, 1952, p. $135-143$.

(28) M. Labrousse, Gallia, IX, 1954, p. 128129.

(29) Du Meime, ibid., p. 120-124.

(30) Bull, monum., CX, 1952, p. 204-214. trois périodes du développement archi. tectural du site : $1^{\circ}$ ) près du chemin, un bâtiment peu important; $2^{\circ}$ ) dans le troisième quart du III $^{\circ} \mathrm{s}$. exhaussement de la voie et construction d'un grand bâtiment en bordure; $3^{\circ}$ ) remaniements apportés aux installations précédentes, transformation du site en lieu d'inhumation et retour à l'état rural. $\mathrm{Au} \mathrm{vI}^{\circ}$ ou au début du $V_{I I}{ }^{\circ}$ s., une ferme s'installe sur cet emplacement, peu après une grande salle est transformée en église, flanquée à l'Est et au Nord d'une pièce en saillie ct, sur le côté oriental, d'une abside en fer à cheval. Un mur percé d'arcades correspond à la cloture du chœur.

Une description précise nous est donnée de l'église funéraire de l'abbaye de Jouarre et de ses cryptes 31 pratiquées à l'extrémité orientale du monument, situé dans le cimetière. La crypte, dite de SaintPaul est célèbre par le bel appareil décoratif du mur occidental, ses colonnes à chapiteaux de marbre, ses tombeaux; au Sud, la crypte de sainte Ébrégésile n'a conservé de l'état primitif que les fûts de colonnes el, trois chapiteaux de marbre. L'église, à plan rectangulaire, abrite trois étages de sépultures : au fond, au même niveau que la crypte de saint Paul, des sarcophages de pierre à couvercles arrondis ou à double versant, ornés de stries longitudinales et d'une feuille de fougère au pied; à l'étage supérieur, des tombes en plâtre coulé à couvercle bomhé; au-dessus, des cercueils en bois.

Des précisions sont apportées à la description des baptistères d'Aix-en-Provence ${ }^{32}$ et de la cathédrale de Nevers ${ }^{33}$.

Sur les côtes de la Manche, les îles de l'embouchure du Trieux (Côtes-du-Nord)

(31) J. Hubert, IV Congrìs hist. art. Ilaut moy. age, 1952, extrait.

(32) J. Formirá, Bull. soce nat. antiq. Fr., 1951, p. 167,

(33) R. Louis, ibid., p. 46-59. 
furent des centres de vie monastique dont quelques témoins ont été signalés 34 : à l'île Saint-Mandez, une chapelle s'élève sur l'emplacement d'une cclla memoriac; à l'Ile Verte, une construction du $\mathrm{Xv}^{e} \mathrm{~s}$., repose sur une épaisse couche d'ardoises, de tuiles, de briques et de tessons des $\mathrm{v}^{\circ}$ et $\mathrm{VI}^{\circ} \mathrm{s}$.

Les débris de sculptures du vir s. signalés dans de précédentes chroniques, recueillis lors de la reconstruction de Cheminot (Moselle), appartiennent au decor de l'église du domaine royal mérovingien, dont Cheminot était le centre ${ }^{35}$. Dans la région de Sens (Yonne), la découverte de tessons gallo-romains ct barbares, près de Maslay-le-Grand 36, permet de localiser le site de la villa mérovingienne de Massolacum et, à vienne-en-Val, des monnaies mérovingiennes marquent l'emplacement d'un village ${ }^{37}$.

Dans la construction de ces églises, on constate le remploi de monuments galloromains : deux autels dédićs, l'un Vassianibus, l'autre à Silvanus, avec maillet sur l'un des côtés, à Saint-Saturnin-d'Apt 38; hénitier dans un cippe anépigraphe, fragment d'autel aux Déesses Mères, dans la chapelle de Sainte-Marguerite à Baumontde-Malaucène ${ }^{39}$. A Die ${ }^{40}$, dans l'enceinte du Bas Empire sont encore encastrées des pierres tombales qui devraient être mises à l'abri et leurs inscriptions correclentenl publiées.

La source la plus abondante et la plus riche en renseignements pour la connaissance de la civilisation mérovingienne

(34) Bull. soc. emul. Cotes-du-Nord, LXXV, 1950-54, p. 1-38.

(35) Annales Est, 5e sér., 3, 1952, p. 93.

(36) J. Coudray, Rev. archéol. Est, III, 1952.

(37) Bull. liaison prov. soc. archéol. et hist. Orléanais, n० 16, janv.-fév., 1952, p. 1.

(38) J. SAutel, Provence hist., 1952, p. 50.

(39) Ibid., p. 52.

(40) M. Roblin, Bull. soc. nat. antiq. Fr., 1949, p. 201. est apportée par l'étude des sépultures auxquelles Éd. Salin 41 consacre le deuxième volume de son grand ouvrage. La répartition dans lc temps et dans l'espace des cimetières pose un ensemble complexe de problèmes relatifs aux origines des populations, aux influences qu'elles subirent, aux coutumes, aux croyances, à l'organisation sociale. Trois facteurs principaux, la tradition romaine et gallo-romaine, la tradition germanique et l'action de l'Eglise ont contribué à la formation du rituel funćraire. On retrouvera méthodiquement groupées dans ces pages les solutions proposćes par l'auteur à ces divers problemes et dont il a été fait état maintes fois dans ces chroniques. Cet excellent ouvrage sera, dans l'état actuel de nos connaissances, le meilleur des guides pour l'archéologue, autant que pour l'historien.

Martyrium ou cella memoriae, élevée sur une construction plus ancienne, telle est l'interprétation proposće pour la crypte triconque de Théopole (Basses-Alpes), près de Saint-Genez du Dromon ${ }^{42}$, siège du village et de la villa de Dardanus. Iaa présence d'une chapelle haule fail penser aux mausolés antiques à deux étages de Iyon, de Fontenelle, d'Auxerre et de Ghalon-sur-Saône. Dardanus, préfet du prétoire des Gaules entre 409 et 414, et. son épouse Galla, se seraient retirés dans ce lieu solitaire, auquel ils donnèrent le nom de Theopolis, et leur sépulture aurait été en relation avec la fondation de la crypte. Le caveau funéraire paléo-chrétien du cimetière d'Agaune (Suisse) est apparenté aux hypogées à-demi enterrés

(41) Ed. Salin, La civilisation mérovingienne d'après les sépultures, les textes et le laboratoire, $2^{\mathrm{e}}$ part. Les sépultures, Paris, 1952. Cf. R. LaNTiER, Journal des savants, 1952. p.

(42) F. BENoIT, Rivista di archeolog. christian., XXVII, 1952, p. 69-89. 
qui, en Gaule, entouraient les basiliques primitives ${ }^{43}$.

Les sépultures de la place du Champde-Mars et de l'avenue Fmile-Zola, à Nyons (Dròme), faites de tuiles avec couvercle en bâtière, ou de débris de marbre, sans mobiliers funćraires, relèvent du $v^{\circ}$ s. ${ }^{44}$, de même que les tombes sous tuiles, à dallages de lauzes, également sans mobilicrs funéraires, du domaine de Dogne, voisines de celles trouvées à Marsanne (Dròme) ${ }^{45}$. Le tumulus hallstattien de l'Arbre Rond, à Saint-Remèze (Ardèche) abritait une sépulture, dans laquelle une plaque-boucle wisigothique à représentations humaines voisinait avec une boucle à double crochet hallstattienne remployée dans le mobilier funéraire $\mathbf{4 6}^{4}$ $\Lambda$ Pompogne (Lot-et-Garonne) des tombes barbares ont été mises au jour près des ruines d'une villa gallo-romaine ${ }^{47}$. Dans un cimetiere de la Gironde, audessus d'un sarcophage, des couches de cendres, dans laquelle des vases avaient été déposés renversés, marquent l'emplacement de foyers rituels. On a aussi reconnu la présence d'une fosse commune contenant huit squelettes ${ }^{48}$. A Condes (Puy-de-Dóme), devant la façade occidentale de Saint-Genès, quatre sarcophages ne renfermaient aucun mobilier funéraire ${ }^{49}$. Les travaux de la place du Château, près du donjon et de la facade Ouest des halles, à Roanne (Loire), ont révélé qu'à cet emplacement un cimetière chrótien avait remplacé un lieu de sépulture païen. G'est alors, au ve s., que l'on construit la chapelle Saint-Jean

(43) L. BLoNDEL, Vallesia, 1951, extr.

(44) Bull. soc. d'hist. et de statis. Drôme. I.XXII, 1952, p. 60.

(45) Ibid., p. 63.

(46) M. Louts, Gallia, X, 1952, p. 100.

(47) P. Grinat, ibid., IX, 1951, p. 126.

(48) A. PEZaT, B.S.P.F., XLIX, 1952, p. 486.

(49) P.-F. Fournier, Bull. histor. et scientif. Aurergne, LXXIV, 1952, p. 63-64. of le baptistion Saint-Pierre. I.es remblais provenant du fossé creusé lors de l'invasion des Sarrasins, en 725 , recouvrent les tombes, exlraussent le sol d'une hauteur de 3 à 4 mètres. Les inhumations sont alor's déplacées en direction du Nord, dans le quartier de Fontenelle 50. Une boucle rectangulaire décorée de lions et de dragons à tête léonine, une plaque pentagonale avec deux lions accroupis de part et d'autre d'un arbre, l'une et l'autre en argent niellé, un crochet en argent gravé, 6 sous d'or d'Arcadius, frappés à Rome et à Milan, 18 sous d'or d'Honorius des ateliers de Rome, Milan et Ravenne, proviennent d'un cimetic̀re mérovingien du début du v $v^{\mathrm{e}}$ s., au voisinage d'Orléans ${ }^{51}$. Les huit sarcophages à cuves trapézoïdales, groupés deux à deux et alignés sur la déclivité du terrain à Ia Roche-Clermault (Indre-et-Loire), occupent, aux $\mathrm{vi}^{\mathrm{e}}$ et viI" s., l'emplacement d'un cimetier'e précédemment utilisé, au voisinage d'un lieu dit «La Ville noire» 52 . A Poitiers, un sarcophage de l'ancien cimetière de Saint-Jean-l'Hospitalier a été découvert rue du Général-Desmarçay 53. Jne communication au CIX' Congrès archeologique de France ${ }^{54}$ rósume ce qu'on sait du grand cimetière de sarcophages, parfois superposés sur sept niveaux, au voisinage de l'église de Civaux (Vienne). La présence d'un corps saint particulièrement vénéré pourrait expliquer cette accumulation de sépultures. L'hypothèse demande à ôtre vérifiée par des fouilles à conduire sous l'autel de l'église, afin de vórifier si,

(50) Fr. DÉCHELETTE, Rev, archéol. Est, III, 1952. p. 201-205.

(51) J. Lafaurie, Bull. soc. fr. numismat., 8 , 1952. p. 180-181.

(52) P. Condonvier-DÉtrie, Gallia, IX, 1951, p. $93-94$.

(53) F. EYGuv, Bull. soc. antiq. Ouest, $4^{e}$ sér., II, 1952 , p. 241

(54) DU MEve, Congrès archéol. Fr., CIXe sess., Poitiers 1951, p. 179-183. 
pour des r'aisons de piété, par respect pour un sarcophage vénéré déposé sous l'autel, ou par la présence d'une crypte contenant des reliques, on s'est cru obligé de prendre des dispositions aussi anormales que celles remarquées dans le sanctuaire. Sur le territoire de la commune d'Availles-Thouarsais (Vienne), on a reconnu l'emplacement de deux cimetières, l'un près de la ferme de Ia Brianderie, tombeau à hypogée et sarcophages; l'autre à Availles, sarcophages de calcaire ou de briques ${ }^{55}$. A Rézé (Loire-Inférieure), un sarcophage en calcaire coquillier peut être mérovingien ou carolingien 56 . Dans la Sarthe, au Nord-Ouest du château de Chéronne, à Tuffé 57 , des sépultures des $I V^{\mathrm{e}}$, $\mathrm{v}^{\mathrm{e}}$ et $\mathrm{VI}^{\mathrm{e}}$ s., orientées O. N. O.-E.S. E., abritent des corps reposant directement dans le sable, accompagnés d'un fer de lance et de tessons de poterie grise godronnée. Le souterrain-refuge du GrandRuge, à Paizay-le-Sec, a été occupé au Haut Moyen âge 58. Une plaque-boucle à décor d'entrelacs a été recueillic dans un sarcophage au lieu dit «Les Petites-Iandes », à Château-l'Ilermitage 50. De nouvelles tombes des vil ${ }^{\mathrm{C}}-\mathrm{vill}^{\mathrm{e}} \mathrm{s}$. ont été trouvées dans la carriòre du Fourneau à Cheméré-le-Grand 60 . Une douzaine de sarcophages en plâtre, contenant des vases et une plaque-boucle niellée d'argent à décor d'entrelacs, avaient été fouillés par Glairambault, en 1728-1729 dans le cimetière mérovingien de Châtenay-Malabry, près de Sceaux (Seine) 61. On signale des

(55) D.-M. MAHIÉ, Bull. soc. antiq. Ouest, $4^{\mathrm{e}}$ sér., II, 1952, p. 82-108.

(56) L. Bouchaud, Bull. soc. hist. et archéol. Nantes, XC, 1952, p. 42-43.

(57) P. Conmoxwín-DÉthle, Gallia, IX, 1951, p. 101.

(58) F. EYGun, ibid., p. 105-106.

(59) P. CORdonviler-DÉTRIE, ibid., p. 100.

(60) DU MEME, ibid., p. 101.

(61) R. Dauvergave, Bull. soc. nat. antiq. Fr., 1951, p. 177-178. découvertes de sarcophages à Blamécourt 62, a Boutigny (Seine-et-Oise) ${ }^{63}$, et à Audeuil aux environs de Beauvais (Oise) 64. Des ossements, aperçus dans une carrière, situce à flanc de côteau à la sortie du village de Fresquienne (SeineInférieure), marquent peut-être l'emplacement d'un cimetière franc ${ }^{65}$. Dans le Pas-de-Calais 66, si les mobiliers funéraires trouvés dans les cimetières de Dury et de Nœux-les-Mines sont pauvres, les 17 sépultures fouillées à Mazinghem ${ }^{67}$, contemporaines de la fin du vi et du vile s., sont caractérisées par l'abondance des armes, francisques, framées, umbos, des scramasaxes, des objets d'équipement et de parure, dont une boucle en fer damasquinće et une fibule ronde à décor d'orfèvrerie sur plaque de bronze. Dans le cimetière, déjà connu, de Dollot (Yonne), sur les pentes d'une colline orientée au S.-0., 15 nouvelles tombes ont donné des plaques-boucles, une petite hachette en jadéite, mais aucune poterie. Dans deux sépultures un clou de fer était plaré près du crâne $\mathbf{6 8}$. Une certaine hiêrarchie se dessine dans l'ordre des cimetières chrétiens de Dijon, situés aussi bien à l'Est qu'à l'Ouest du castrum. Le plus fréquenté fut celui de l'Est pròs de SaintWútienne. Celui de l'Ouest, d'abord païen, dut au voisinage des basiliques de SaintJean et de Sainte-Paschasie de devenir un lieu saint et le mouvement qui y porta les fidèles s'accentua par la fondation du monastère de Saint-Bénigne. Cependant,

(62) Rev. d'hist. ecclésiast., XLVIII, 1952, p. 414; - Le Monde, 19 janv. 1952.

(63) A. Piganiol, Gallia, IX, 1951, p. 83.

(64) Du MÊre, ibid., p. 82.

(65) H. van EFenterRe, ibid., p. 84.

(66) J. ILeurgos, ibid., p. 80 ; - L'Anliq. class., 1952, p. 423.

(67) Bull. soc. antiquaires Morinie, 1952, p. 5) $45-567$.

(68) J. Coumay el P. Parruzot, Ret. archéol. Est, III, 1952, p. 130-134. 
par son éloignement de Saint-Étienne il semble qu'il ait été réservé à la sépulture des grands personnages 60 . Des inhumations des $v^{\mathbf{e}}$ et $v l^{\mathbf{e}} \mathrm{s}$, dans des coffres de pierres sèches, ont été trouvées à Dijon, face au $n^{\circ} 4$ de la rue Monge, sur l'emplacement de l'un de ces cimetières, au Sud de l'église Saint-Jean qui, dès le $\mathrm{IV}^{\mathrm{e}} \mathrm{s}$. est la première église cimétériale de la cité 70. Des tombes dans des coffrages de pierre et des sarcophages ont été découverts à Hauteville-les-Dijon, à quelques mètres du shemin du fort. Le cimetière, qui s'étendait sur deux niveaux, avait été probablement installé sur l'emplacement d'un site gaulois 71. Faut-il ćgalement rechercher une certaine hiérarchie des tombes dans le cimetière de Curtil-sousBurnand (Saône-et-Loire) ? De part et d'autre d'une allcée dallée auraient été disposćes, d'un côté les sépultures de l'« aristocratie», de l'autre celles des artisans. Cette distinction, un peu trop subtile, ne semble reposer que sur la découverte, dans un mobilier funéraire, d'un fer à friser et, d'autre part, tout ce que nous savons des dispositions des grands cimetières par rangées de l'Allemagne occidentale infirme cette hypothèse, princes et manants étant confondus dans une même rangée d'inhumations. Dans cette partie orientale du cimetière, un certain nombre de tombes présentent un entourage de maçonnerie, nécessité par le peu de consistance du terrain dans lequel elles sont pratiquées. Parmi les objets recucillis en 1951 figure le baudrier placé sur l'épaule gauche du squelette de la tombe 33 et les grandes plaques-boucles qui en font partie. Comme à Estagel (Pyrénées-Orientales), des tombes d'enfants avaient été disposées dans l'allée empier-

(69) Chaune, Mém. comm. antiq. Côte d'Or, XXII, 1952: p. 524-525.

(70) G. Grémaud, ibid., p. 524.

(71) P. MOREAU, ibid., p. 542-544. rće 72. Fn Lorraine, une sépulture est signalée à Rimling 73 et, à Choloy (Meurtheet-Moselle), dans une gravière au SudOuest du village de Menillot, le cimetière d'une petite agglomération rurale, pauvre en mobiliers funéraires, avait été occupé jusqu'à la fin du vid s. puis transporté prìs de la chapelle Saint-Pierre, où cinq tombes ne contenaient que les squelettes 74. En Alsace, des découvertes fortuites ont été faites dans les cimetières de Kolbsheim, de Dangolsheim et de Westhoffen, situés près des grandes villas royales de Kirchheim et de Marlenheim, sur des terres cultivées par des colons au service des princes. Les mobiliers sont caractérisés par leur uniformité et la rareté des boucles damasquinées. Dangolslieim est un cimetière alaman où une sépulture du vir ou du viII ${ }^{\mathrm{e}} \mathrm{s}$. a livré une ćpée au pommeau sommé d'un bouton de bronze ouvragé et un fourreau orné d'un décor serpentiforme terminé par deux têtes de monstres. Sept fosses dans le loess, disposées en rangées, ont été fouillíes à Uttenheim ${ }^{76}$. Elles contenaient des poteries à décor en fer à cheval comme à Quatzenheim et à Griesheim et un fragment de javelot à douille fixće sur une hampe de chêne $\mathbf{7 7}$.

Les premiers éléments d'une chronologie qui reste à préciser sont apportés par un mémoire sur les sarcophages des écoles d'Arles et de Marseille 77; un pre-

(72) M. LaFond, Mém. soc. d'hist. et d'archéol.. Chalon-sur-Saône, XXXIII, 1952, p. 2021, 34-36.

(73) Jes caliers lorrains, 1952, p. 19, 52 .

(i4) $\Lambda$. Liegler et G. Steinibach, Rev, archéol. Fst, III, 1952, p. 278-283.

(75) C. Sauer, Cahiers d'archeol. et d'hist. Alsace, no 132,1952, p. $90-113$

(i6) A. STleber, ibid., p. $110-118$.

(7i) F. BENoIT, Sarcophages chrétiens d'Arle's et de Marseille, dans Beitrüge zur Kunstgeschichle des I Jahrtausends. I, Spätantike und Byzanz, 1952. 
mier groupe fut importé d'Italie ou de Grèce au cours de la première moitié du IV $^{\ominus}$ s.; les cuves à décor's de strigiles et d'arcatures apparaissent au cours de la seconde moitié de ce même siecle; les œuvres du début du v ve annoncent déjà l'art de Byzance et du Moyen âge. Tout ce qui subsistait encore au $\mathrm{IV}^{\bullet} \mathrm{s}$. des traditions de l'humanisme dans ces ateliers disparaît au cours du $v^{e}$ et du $v^{\circ} s$. devant l'absence du modele et l'aplanissement du décor. Ne recevant plus les marbres de Carrare, les ateliers marseillais, gravitant autour du foyer d'art que fut l'abbaye de Saint-Victor, doivent utiliser la pierre du pays. L'interdépendance de ces diverses expressions est l'un des caractères de cet art nouveau. Qu'il s'agisse de la toreutique, de la plastique, de la céramique ou de la verrerie, la tendance est à la suppression des saillies, à l'aplanissement du relief. Dans les écoles de sculpture, au dessin architectural se substituent de frêles colonnades, sans épaisseur ni profondeur, évoquant la fresque ou les panneaux historiés des vaisselles de métal. Le répertoire du sculpteur se confond avec celui du mosaïste dans l'utilisation des mêmes thèmes chrétiens, où domine un zoomorphisme abstrait. Le modelé expressionniste des figures que peut rehausser une cernure est un procédé plus pictural que sculptural. La simplification de la composition, le cloisonnement du décor en niches, parfois avec représentations de rideaux, rappelle les mosaïques de San Vitale à Ravenne, Déjà s'annonce le renoncement à la figure humaine au profit du géométrisme abstrait qui, au vII ${ }^{\mathrm{e}}$ s., s'applique au décor de la cuve.

Le compartimentage du décor se retrouve aussi sur les sarcophages de plâtre parisiens, trouvés dans les églises, le long des voies menant à la cité. Un premier groupe est représenté par un pan- neau rectangulaire à motif circulaire et ornements dans les quatre écoinçons; sur un second groupe, la composition n'est plus limitée que par les dimensions du panneau. Le décor géométrique, rosaces, croix, chrismes, cercles oculés, domine. I'animal et l'homme sont moins souvent représentés : oiseaux, quadrupèdes, pois-sons; Jonas, Daniel. L'homme est toujours figuré de face. Est-il nécessaire de rechercher jusque dans l'âge du Bronze, les origines de ces motifs de caractère bénéfique ? Les sarcophages étaient moulés sur place: deux creux ont été recueillis à Sainte-Croix-Saint-Vincent, 78 .

On relève l'apparition, encore timide, du géométrisme dans l'application du cordon souple doublant la bordure du cadre, sur le sarcophage de Saint-Agnan (c $c^{\text {ne }}$ de Ségur, Aveyron), orné de scènes empruntées à la vie familière, atelier de forgeron, paysan piochant avec une houe, survivance de l'école paléochrétienne à l'époque wisigothique 79 . Taillé dans une pierre de la région d'Autun, illustré de la figure de Daniel dans la fosse aux lions et de deux griffons affrontés de part et d'autre d'un canthare godronné, le sarcophage de Charenton-sur-Cher (Cher), plutôt que wisigothique ${ }^{80}$, est originaire d'un atelier bourguignon ou rhénan travaillant au vir ${ }^{\mathrm{e}} \mathrm{s}$. Le thème des griffons, qui reparait sur un sarcophage en plomb de la forêt de Citeaux (Côte-d'Or), du Iv ${ }^{\mathrm{e}} \mathrm{s}$. plutôt que du $\operatorname{III}^{\circ}$ s., a été légué par l'art du Bas-Empire à celui du Haut Moyen âge ${ }^{81}$. D'un symbolisme baptismal et funéraire relèvent les scènes de chasse au cerf gravées sur lcs sarcophagcs dc Bailleul-le-Soc (Oise), de Toulouse, de

(78) M. Durand-Lerebvre, Cahiers archéol, VI, 1952, p. 168-175.

(79) F. BENorT, Bull. soc. nat. antiq. Fr., 1948, p. 100-105.

(80) G. Gaudron, ivid., 1949, p. 214.

(81) J. HURERT, ibid., p. 76-77. 
Tréclun (Còte-d'Or'), d'Andrésy (Seine-etOise), de Chelles (Seine-et-Marne) ${ }^{82}$.

Un centre de fabrication de sarcophages a été signalé à Rézé (Loire-Inf.) et un autre dans un bois, en face d'Arcy-sur Cure (Yonne), non loin de la voie d'Agrippa. Dans une carrière de calcaire tendre, cing ou six sarcophages, à demi dégrossis et à demi dégagés, sont encore en place dans le banc de pierre. Le creusement de la cuve et unc première taille ćtaient faits à la carrière. Une discussion est ouverte sur l'origine des sarcophages accumulés à Quarré-les-Tombes, entre les $\mathrm{vI}^{\mathrm{e}}$ et $\mathrm{X}^{\mathrm{v}} \mathrm{s}$. : entrepôt, ou cuves retirées d'un ancien cimetière, Quarré et ses abords ayant attiré aux temps galloromains les « riches estivants », avant de devenir un domaine de chasse des rois franes 83 ? Cette deuxiòme interprétation nécessite un effort d'imagination.

Pour l'étude des ivoires de la basse époque romaine et du Haut Moyen âge, on dispose d'un excellent recueil 84.

De nouvelles trouvailles, faites à Macquenoise (Belgique) attirent l'attention sur l'industrie du verre en Thicrache au temps des Grandes Invasions 85 . Ces fabrications semblent s'y atre maintenues depuis le $\mathrm{II}^{\prime} \mathrm{s}$. jusqu'ì nos jour's. L'importance ancienne du massif forestier, la présence d'une grande voie de communication, la chaussée de Lyon à Boulogne par Reims et Bavai expliquent le déve-

(82) G. GaUdRON, ibid., 1948, p. 64-65.

(83) R. Louis, Rev. archéol. list, III, 1952, p. 25-32; - Bull. liaison prov. soc. hist. et archéol. Orléanais, suppl. au no 19, déc. 1952, p. 7 ; - L. Bouchaud, Bull. soc. hist. et archéol., Nantes, 1952, p. 41.

(84) W.-F. Voldaci, Nlfenbeinarbeilen $d$. Spätantike und d. frühen Mittelatters, $2^{\mathrm{e}}$ éd., Mayence, 1952.

(85) R. Ghambon et Holger Arbaray, Bull. soc. roy. lettres Lund, 1951-2, extr.; - Anna Rosss, Berichten ran de Rijksdienst roor het oudthidliundia Bodemonelersock in Nederland, IV, $195 \%$, p. 14-18. loppement des officines de verriers. Les deux ateliers du village de Formathot, installés sur des buttes artificielles pour Eviter les inondations, ont disparu dans un incendie. Un fragment de four en arkose, quelques morceaux de creusets accompagnaient des débris de verres avec ou sans pied, parfois ornés de filets d'émail, de bols, de gobelets, de vases en forme de clochette. Il n'est pas impossible que les deux fours distants l'un de l'autre d'environ quarante mòtres, aient été spćcialisés dans des fabrications diffórentes. Dans l'une on recueilit des pièces en forme de cornet ornces de filets rapportés, forme rare sur le continent mais destincéc à l'exportation dans les pays scandinaves où on les trouve dans les sites et les cimetières du $v^{c} s$. et de la première moitié du vie. Ces formes faisant défaut en Angleterre, on est amené à envisager des relations commerciales directes entre les pays franes et la Norvège occidentale au cours de cette période. La route suivie ne passait pas par le Danemark. Des verreries franques sont cependant arrivées en Grande-Bretagne où on les rencontre dans les cimetières saxons du Sussex, et il y a licu de supposer qu'elles étaient originaires de la Gaule septentrionale 86 . Ces découvertes, la tradition verrière de ces régions, incitent à conduire de nouvelles recherches sur ces territoires et à les étendre sur l'Artois et la Picardie pour tenter de retrouver quelques-uns des centres industriels qui ont alimentés les marchés anglais et nordiques.

Il n'y a pas que les verreries qui aient alors voyagé. Ia méthode des cartes de répartition des objets permet de reconstituer le tracé des grands courants de la circulation dans la Gaule intéricure du

(86) D. B. IInRDEN, Sussex Country Magasine, 25, 1951, p. 260-268. 
viIr s. 87. Les influences orientales ont été transmises par la route venant de l'Adriatique à la Gaule et à l'Angleterre à travers la Lombardie et les routes passant à l'Est du Rhin, au long du chemin de ta Tène. Le motif des animaux affrontés de part et d'autre de l'Arbre de Vie a suivi la vallée du Rhòne où l'on connaît de nombreux péages. Le tracé est, jalonné par les découvertes faites dans les tombes et par l'imitation des mon. naies de Marseille à Soissons et à Troyes, impliquant l'existence d'un prolongement au Nord vers l'estuaire du Rhin et les Iles Brilanniques. La dispersion des marbres sculptés des carrières d'Aquitaine dans les localites ou les monastères voisins des voies navigables, témoigne de la persistance du trafic fluvial gallo-romain. De même la répartition des trésors monétaires bordelais prouve, environ 675 . l'importance des ports maritimes et fluviaux 88 . La carte des plaques-boucles damasquinées aquitaines indique que l'existence d'une voic ancienne du commerce depuis la vallée du Rhin jusqu'en Espagne, par Bâle, Geneve et Lyon, et des rapports économiques entre l'Aquitaine et la région parisienne, par l'Océan, la Loire et les routes de terre; cette région était aussi en communication avec les pays de l'Est et du Sud-Est. L'existence d'ateliers monétaires locaux est loin d'impliquer une économie fermée. L'importance du trafic fluvial et routier est la conséquence de la survivance de l'économie antique.

Des précisions sonl apportées à la répartition et aux caracteres de ces ateliers

(87) J. HUBERT, Acles Vle Congrès internat. 6il. b!zantines, Paris, 1951, p. 189-190.

(88) A. Lewiss a communiqué aux Journées internat. d'et. meroving. (Poitiers, 1952), une élude sur commerce et navires sur les côtes atlantiques de la Gaule du $V^{\mathrm{c}}$ au VIII $s$. Annales Midi, 64, 1952, p. 278. monćtaires: liste des ateliers armoricains, dans lesquels à partir du $\mathrm{vI}^{\mathrm{e}} \mathrm{s}$. apparaissent les deniers d'argent, pour la plupart sortis des ateliers ecclésiastiques et qui finiront par remplacer l'or comme étalon monétaire au cours du viII ${ }^{\mathrm{e}}$ s. 89 . C'est peut-ctre d'un de ces ateliers bretons qu'est originaire celui de Tremblay (Ille-et-Vilaine), l'une des cing monnaies trouvées à Dijon, les quatre autres étant sorties d'un atelier de la ville même ${ }^{90}$. Une monnaie lombarde d'Honorius. de l'atelier de Milan, a été recueillie près de Strasbourg, à Flessenheim 01 . Par sa technique, le demi-silique de Théodebort, à Saint-Remy-de-l'Provence, est plutôt issu des ateliers romains d'Arles que de celui de Strasbourg ${ }^{92}$. Il est impossible de considérer le trésor de Bordeaux comme le document économique le plus important de la période mérovingienne : il ne peut être reconstitué dans son intégralité et montre seulement que, vers la fin du vir s., la circulation, dont il est le reflet, était composée pour deux tiers de pièces d'or au titre de 750 millièmes et pour un tiers de pieces d'or au titre de 55 0 millièmes ${ }^{04}$.

Du $\mathrm{v}^{\mathrm{o}}$ au $\mathrm{x}^{\mathrm{e}}$ s., l'épée damasquinée ${ }^{95}$ est l'arme caractéristique des Germains et des Scandinaves, mélange de fer pur et d'acier soudés ensemble et dont la disposition rógulière détermine en surface des dessins, chevrons, bouclettes. Les pieces les plus anciennes, de la fin du $\mathrm{IV}^{\mathbf{e}} \mathrm{s}$.,

(89) MocudÉ, Nour, rex. Bretagne, 1952, p. 184-187.

(90) P. Leisel, Mém. comm. antiq. Côte d'Or, XXII, 1952, p. 503.

(91) Dr H. Loxguer, Cahiers d'archeol. et d'hist. Alsace, no 132, 1952, p. 114.

(92) H. Rolland, Bull. soc. Pr. numism., 8, 1952, p. 170-171.

(93) J. Lafaulie, Rev. numism., 14, 1952, p. 229-235.

(94) A. France-Lanond, Bull. archéol. Comité, 1950. p. 193-202. 
ont été trouvées dans les tourbières danoises et portent, en latin, la marque de fabricants d'origine celtique, Rome ayant annexé le Norique, dont les forgerons étaient les principaux fournisseurs de l'Empire, artisans d'origine celtique, héritiers des procédés métallurgiques des Celtes. Leur industrie, devenue très florissante, persiste jusqu'd l'invasion du Norique par les Vandales. Il n'est pas impossible que ces forgerons aient alors émigré vers l'o., remontant la vallée du Danube en direction du Rhin moyen. De caractère artisanal à ses débuts, la fabrication des lames damasquinées reste longtemps secrète et ce n'est qu'à partir $\mathrm{du} \mathrm{vI}^{\mathrm{e}} \mathrm{s}$. qu'on constate leur dispersion dans le monde barbare, à la suite de la création de centres industriels. Le commerce de ces armes restera très actif jusqu'au $\mathrm{x}^{\mathrm{e}} \mathrm{s}$. et les Vikings contribueront à les répandre.

Introduite en Gaule par des artisans d'origine syrienne, la technique de la damasquinure 95 y connut un longue fortune. Elle consiste en un placage à feuille conservée, exécuté le plus souvent sur fond de quadrillage, plus rarement sur un fond pseudo-champlevé. Les incrustations sont parfois profondes, tantôt réelles, tantôt simulées. On utilise aussi le placage en dentelle sur décor incisé. En matière d'incrustation, on distingue : l'incrustation directe sur fer, sur placage d'argent, en réserve.

On doit désormais reconnaître l'armature d'un goryte, dans les fragments de plaques en argent doré trouvés dans la sépulture d'un cavalier des steppes, lors de la construction, en 1881, du fort de Mundolsheim, semblable aux carquois découverts en Hongrie et dans les kourganes de la Russie méridionale ${ }^{96}$.

(95) E. SALIN, Gallia, IX, 1951, p. 31-52.

(96) J.-J. HatT, Cahiers d'archéol. et d'hist. Alsace, no 132, 1952, p. 119-120.
Devant le peu de renseignements précis qu'on possète sur les techniques. on attachera quelque importance aux renseignements apportés par la Vita Domitiani sur un procédé de panification, utilisé à Torcieu (Ain), environ le $\mathrm{IV}^{\circ}$ s. ${ }^{\mathbf{9 7}}$. L'appareil à cuisson lente, le clibanus, était chauffé par-dessus et par-dessous au moyen de braises rouges. Il semble qu'en Gaule, au ves., les paysans consommaient du pain bis, puisque les noms du pain ont été empruntés au germanique, simila, meca, bolling, etc.

Des descriptions sont données de quelques objets de parure trouvés en Chalonnais 98 : plaque-boule à décor guilloché du viI ${ }^{\circ}$ s. à Chassey et pièce semblable au griffon à Sennecy-le-Grand; plaque damasquinée, bague et bracelet dans un nouveau cimetière à Teux-Blancs, près de Saint-Denis-de-Vaux. Les bracelets ouverts, en or, argent ou bronze, provenant de sépultures mérovingiennes, auraient pour prototypes des orfèvreries originaires de la Mer Noire ${ }^{99}$. Il semble bien que le bracelet d'or de Bourg-enBresse, se rattachant à une série partant de la Russie móridionale pour gagner la Hongrie et les Alpes autrichiennes, soit avec les exemplaires de Senlis (Oise) et de Bar-sur-Seine (Aube), un des exemplaires les plus occidentaux de ces parures 100.

Ja présence, dans les collections du Musée des Antiquités de la Seine-Maritime, d'un fond de coupe à couverte noire, décoré d'un cerf entre deux croix devant un arbre a grande palme, pose la question des rapports entre l'embouchure

(97) P. Lebel, Mém. comm. antiq. Cóte d'Or, XXII, 1952, p. 571.

(98) L. Armand-Caldiat, Bull. archeol. Comité, 1950, p. 189-192.

(99) 0. Kleamann, Jahreshafte f. Mitteldeutschland Vorgeschichte, 35, 1951, p. 180.

(100) G. Gaudnon, B.S.P.F., XLIX, 1952, p. 197-198. 
de la Gironde et la Basse Seine 101. Si l'on s'en réfère aux céramiques du Musée Carnavalet, à décor géométrique, rarement animalier, on constate la pauvreté d'invention des potiers mérovingiens de Paris 102. Un essai de classification dans le temps, du $\mathrm{II}^{\mathrm{c}}$ au XIV $\mathrm{x}^{\mathrm{c}}$ s., a été tenté pour les tessons recueillis à Bourgoin (Isère) ${ }^{103}$.

Au dossier de la ferrure à clous du cheval, on ajoutera les découvertes de fers faites dans des milieux des vir ${ }^{\circ}$ et VIII ${ }^{\mathrm{c}}$ S., en Saône-et-toire 104 à Ta GrangeFrangy, à Sennecy-le-Grand et à Givry. Avec le concours des Musées de Iunnd et de Copenhague, trois coupes ont été pratiquées dans le Hague-Dike 105, barrant la presqu'île du Cotentin à l'Ouest de Cherbourg (Manche); assez large, atteignant parfois encore une hauteur de $6^{\mathrm{m}}, 50$, il est actuellement difficile de suivre son tracé qui s'adapte aux formes du lerrain. Le rempart élait destiné à fermer la brèche, ouverte par deux vallées orientées, l'une N.-S., l'autre E.-O. Deux périodes de construction ont été reconnues, la deuxième consistant en un simple exhaussement et dans la construction d'un chemin longeant la totalité du rempart. L'une et l'autre sont séparées par une mince couche de terres brûlées, de charbons et de graines, traces d'un tapis végétal ancien. Il ne s'agit pas de constructions, mais d'arbres et de branchages incendiés. Les matériaux utilisés, argile et sable, ont été pris sur place. Leur stabilisation est assurée par des mottes de

(101) A. BLANGHET, Bull. soc. nat. antiq. Fr., 1948, p. 34-35.

(102) M. Durand-Lerebyne, ibid., p. 59-60.

(103) J. Ghauffier, Elocations, 1951, p. 776777.

(104) L. ARMand-Cabjiat, Rev, archeol. Est, III, 1952 , p. $32-36$.

(105) llolger Arman, Bull. soc. ro!y. lelleres Lund., 1951-52, p. 191-222; - II. vaN EFFexTEKRL, Gallia, IX, 1952, p. 84. gazon. Pour des raisons de défense, le front méridional est le plus solidement construit, consolidé par des assises de pierres disposées obliquement. A la base et sur 1 mètre de hauteur se dresse un mur de pierres, surmonté de lits d'argile et de sable, puis de mottes de gazon. En avant, un fossé est entaillé dans le sol et séparé du rempart par une plateforme large de 1 mètre. Aucune date précise ne pent encore être proposée. Ce qui apparait le plus nettement ce sont les ressemblances du Hague-Dike avec les fortifications danoises d'époque viking, de Hedeby et de Trelleborg. Des fouilles de contrôle dans deux tumulus des Landes, à $4 \mathrm{~km}$. à l:0. de la fortification, n'ont donné aucun résultat. L'hypothèse la plus vraisemblable est celle d'un rempart protégeant un établissement des Vikings, escale à proximité du Raz Blanchard, lors de leurs courses incessantes de la Manche à l'Atlantique pendant le $\mathrm{IX}^{\mathrm{e}} \mathrm{s}$.

On commence seulement à s'intéresser aux vestiges de la civilisation musulmane dans la Gaule mérovingienne. Des fouilles dans la cour de Ia Madeleine ont déjà donné d'heureux résultats et des sondages avaient été entrepris, dans l'étang de Bages (Aude) afin de retrouver les restes d'une flotte musulmane coulée par les vaisseaux de CharlesMartel. Les recherches ont dû être abandonnées, car si les navires ont été effectivement coulés au large de l'antique port des galeres, ils gisent sous une couche de vase si épaisse qu'il est à peu près impossible de les atteindre.

Raymond LANTIER.

Musée des Antiquilés Nationales. Novembre 1954.

(106) Le Monde, 10 oclobre 1952. 